\title{
Optimizing the Production and Injection Wells Flow Rates in Geothermal Field Using Artificial Intelligence
}

\author{
MUHAMMET SALIH ARITURK \\ muhammet.ariturk@gmail.com
}

Follow this and additional works at: https://researchrepository.wvu.edu/etd

Part of the Other Engineering Commons

\section{Recommended Citation}

ARITURK, MUHAMMET SALIH, "Optimizing the Production and Injection Wells Flow Rates in Geothermal Field Using Artificial Intelligence" (2019). Graduate Theses, Dissertations, and Problem Reports. 3772. https://researchrepository.wvu.edu/etd/3772

This Thesis is protected by copyright and/or related rights. It has been brought to you by the The Research Repository @ WVU with permission from the rights-holder(s). You are free to use this Thesis in any way that is permitted by the copyright and related rights legislation that applies to your use. For other uses you must obtain permission from the rights-holder(s) directly, unless additional rights are indicated by a Creative Commons license in the record and/ or on the work itself. This Thesis has been accepted for inclusion in WVU Graduate Theses, Dissertations, and Problem Reports collection by an authorized administrator of The Research Repository @ WVU. For more information, please contact researchrepository@mail.wvu.edu. 


\title{
Optimizing the Production and Injection Wells Flow Rates in Geothermal Field Using Artificial Intelligence
}

\author{
Muhammet Salih Ariturk
}

\author{
Thesis submitted to the \\ Benjamin M. Statler College of Engineering and Mineral Resources at \\ West Virginia University \\ In partial fulfilment of the requirements for the degree of \\ Master of Sciences \\ In \\ Petroleum and Natural Gas Engineering
}

Ali Takbiri Borujeni, PhD., Chair

Ebrahim Fathi, PhD.

Ming Gu, PhD.

Samuel Ameri, Prof.

Department of Petroleum and Natural Gas Engineering

Morgantown, West Virginia

October 2018

Keywords: Artificial Intelligence, Machine Learning, Geothermal Energy, Future Flow Prediction

Copyright 2018 Muhammet Salih Ariturk 


\begin{abstract}
Optimizing the Production and Injection Wells Flow Rates in Geothermal Field Using Artificial Intelligence
\end{abstract}

Muhammet Salih Ariturk

In a geothermal field, power plants are designed for long-term electricity generation. Therefore, it is crucial to predict the future production and injection flow rates of the wells to determine the capacity of a power plant. In the designing of such power plants, calculations and estimations are based on the current future production, and injection flow rates and pressures in the geothermal field. Prediction of future production and injection flow rates also assist in building surface facilities with cost-efficient power plants. The most common problem in a power plant in geothermal fields is the inability to accurately estimate future expected production and planned injection flow rates. Due to this, power plants in the geothermal fields may not perform efficiently. The electricity generation cannot be continuous due to intermittent cycles of low and high energy generation from an inefficient geothermal power plant.

When it comes to power generation from geothermal reservoirs, the knowledge of the porous medium and heterogeneity quantification is vital but challenging. There are many reasons for inaccurate future forecasts, e.g., non-isothermal fluid flow, interference of condensable and noncondensable gases, high temperature and pressure zones, and imprecise reservoir borders, which add to the complexity of the problem. Mostly available and reliable measured data in the field are flow rates for producers and injectors, well-head pressure, wellhead temperature, valve position, off-set wells' production, and injection data. In this thesis, Artificial Intelligence (AI) and machine learning (ML) technology, which is a relatively a new technology with high potentials for providing predictive solutions for the geothermal energy sector, is used to predict future production/ injection prediction using the reliable field data. AI might provide trustworthy resolutions for geothermal reservoirs modeling for forecasting since the model is based on the field measurements instead of making assumptions. AI is an alternative approach to conventional methods to eliminate dealing with uncertainties in the geothermal reservoirs. 


\section{Nomenclature}

$\begin{array}{ll}\text { AI } & \text { Artificial Intelligence } \\ \text { BP } & \text { Back Propagation } \\ \text { BHP } & \text { Bottom-hole Pressure } \\ \text { BHT } & \text { Bottom-hole Temperature } \\ \text { CRM } & \text { Capacitance/resistance modeling } \\ \text { FFNN } & \text { Feed-Forward Neural Networks } \\ \text { ML } & \text { Machine Learning } \\ \text { MLP } & \text { Multi-layer Perceptron } \\ \text { MW } & \text { Megawatt } \\ \text { VP } & \text { Valve Position } \\ \text { WHP } & \text { Well Head Pressure } \\ \text { WHT } & \text { Well Head }\end{array}$




\section{Acknowledgements}

This work that I am presenting in this thesis has been made possible with the help of many individuals and I would like to take this liberty to express my gratitude toward all of them.

First and foremost, the Almighty Allah who is the most merciful and the most beneficent of all and whose blessings I have always sought during the entire process of my thesis.

I would like to express my deepest appreciation to my thesis committee chair, Professor Dr. Ali Takbiri Borujeni, who has been very consistent and patient in guiding me through every step of the way toward my thesis and without the help of whom this work would not have been possible. I have gained a great deal of experience from Dr. Takbiri while working with him. He is a disciplined and hardworking Professor who has absolute commitment with not only his profession but also with his students.

I would like to extend my appreciation to my thesis committee members, Professors Ming Gu and Ebrahim Fathi, for their support and suggestions to improve my work.

I would like to express my deepest gratitude toward my elder brothers and sisters who helped me stay calm and composed in the most tragic events of my life while I was studying for my thesis. I lost three members of my family during my studies, including both of my parents (Memet Sefik Ariturk, Rukiye Ariturk) and the eldest sister (Filiz Ariturk).

While some tragic events happened during my thesis studies, some pleasant things also happened which kept me motivated and determined. I found a loving and supporting life partner Sarah Khalid Ariturk and to whom I would like to extend my deepest appreciation for being an understanding and caring wife.

My thesis acknowledgments would not be complete without mentioning the support of my friends and fellows who supported and guided every time I called upon them. My very good friend Shane-Zehra Lashari deserves the best of my appreciation for her guidance and support. 


\section{Table of Contents}

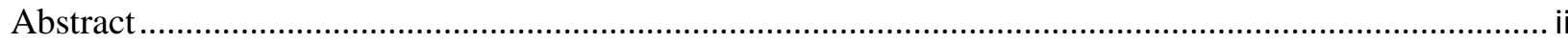

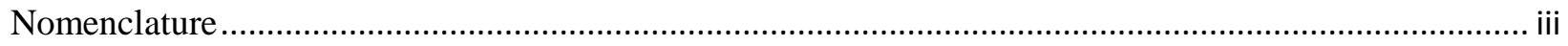

Acknowledgements................................................................................................................. iv

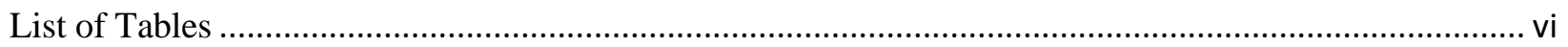

List of Figures .................................................................................................................... vi

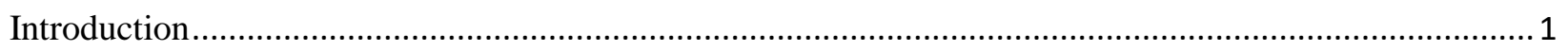

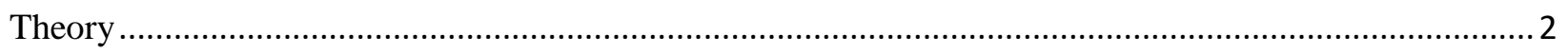

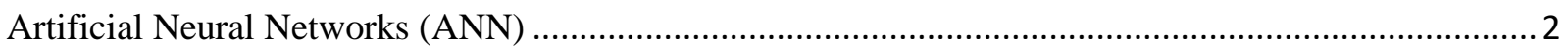

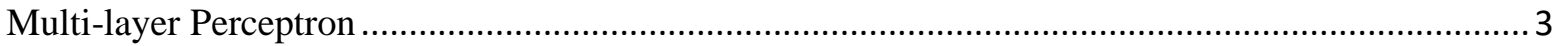

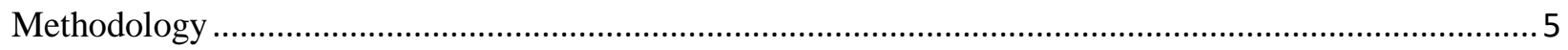

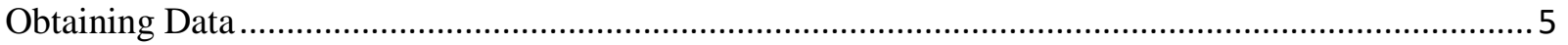

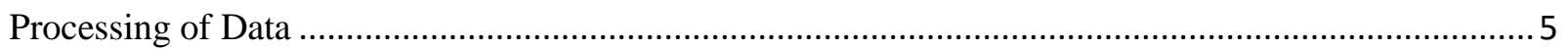

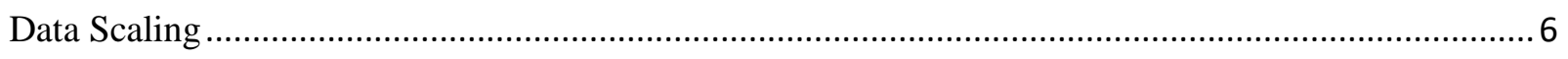

Training of Predictive Model .............................................................................................

Application of Predictive Model for Geothermal Wells ................................................................. 8

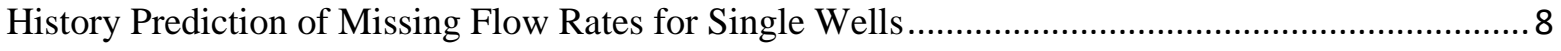

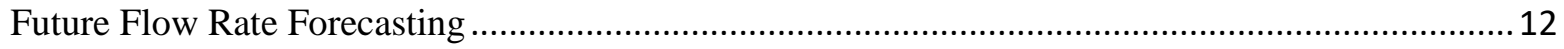

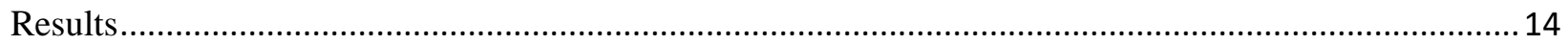

Future Forecasting Scenarios Based on Flow Rates ……………………………………………......14

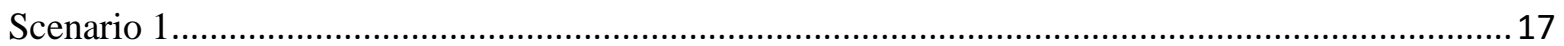

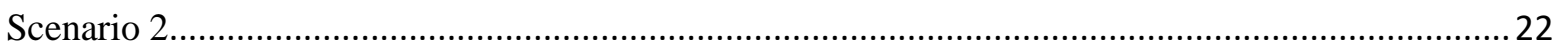

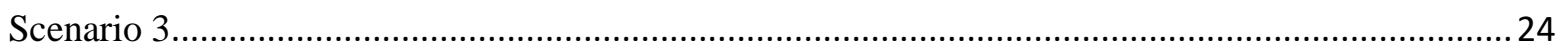

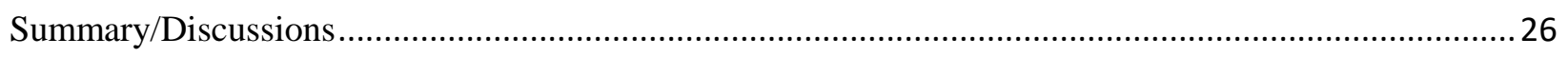

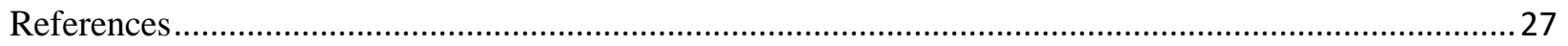

Appendix

Scenario 2

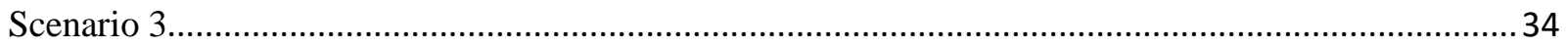

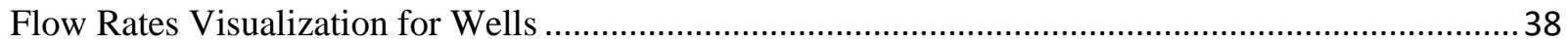

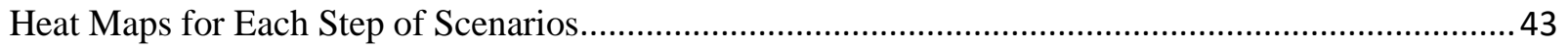




\section{List of Tables}

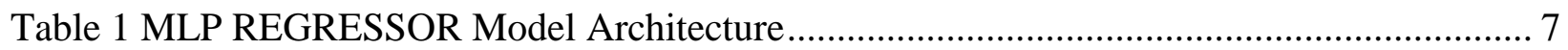

Table 2. Training and Future Prediction Test Accuracy........................................................... 12

Table 3. Total Production and Injection Flow Rates, (these rates were taken as an average last 50

days of flow rates for each wells) ......................................................................................... 15

Table 4. The Injector Pumps Catalogue Capacity ....................................................................... 16

Table 5. Future Injection Scenarios ...................................................................................... 16

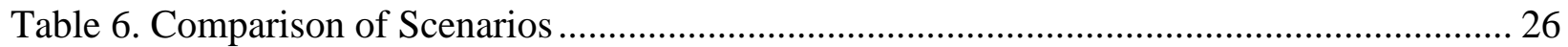

\section{List of Figures}

Figure 1: As long as there is no interconnected cluster of fractures between two sites A and B in a fractured reservoir (upper left) the permeability is very low. As soon as there exists such a fracture system (upper right), the reservoir permeability increases rapidly (below): the percolation threshold is reached (modified from Stauffer and Aharony 1994).................................................................................... 1 Figure 2 Layered feed-forward neural network, (b) non-layered recurrent neural network (Haykin, 1994).

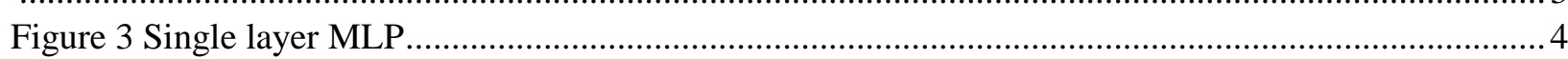

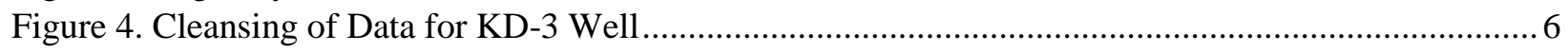

Figure 5. The Cross Plot Diagram for each parameters of KD-3 well ............................................ 8

Figure 6 KD-3 well field measurements; Flow Rates (ton/hr.), Well-head Temperature $\left({ }^{\circ} \mathrm{C}\right)$, Bottom-hole

Pressure (psi), Well-head Pressure (bar) vs. Date (Time) .................................................................... 9

Figure 7. KD-3 Well Field Measurements (Flow Rates Removed) ........................................................... 10

Figure 8. Kd-3 Well Flow Rate History (last $40 \%$ of the production rates removed) - flow rate (ton/hr.) vs.

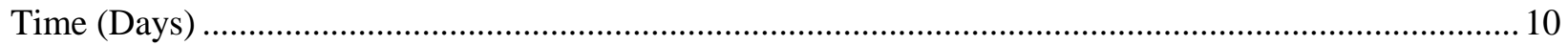

Figure 9. KD-3 Well Future Flow Rates Prediction with Verification (flow rates (ton/hr.) vs Date (Days))

Figure 10 Comparison of Predicted Flow Rates with Real Flow Rates ................................................ 11

Figure 11 Flow Rates (ton/hr.) vs. Time (days) (All Wells) ............................................................. 12

Figure 12 the Heat Map: Correlation Matrix between Producers and Injectors ...................................... 13

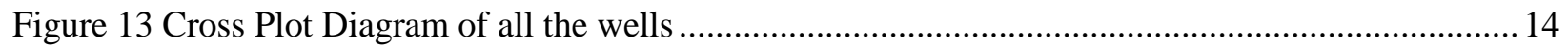

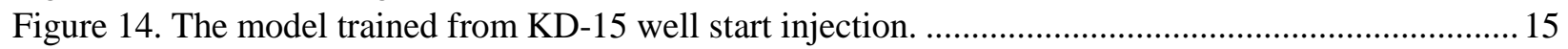

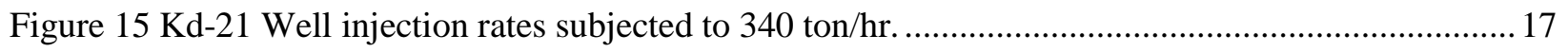

Figure 16. Flow Rates of All Wells KD-21 and Kd-24 Injection Wells Assumed Constant Flow Rate .... 17

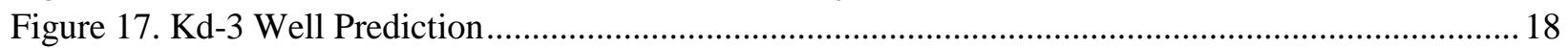

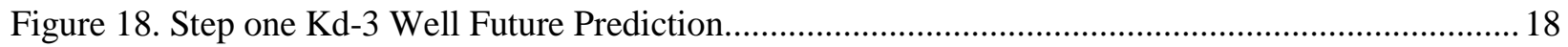

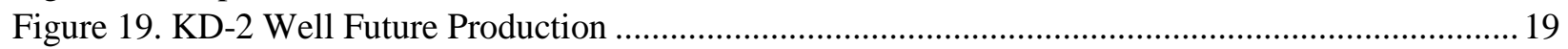

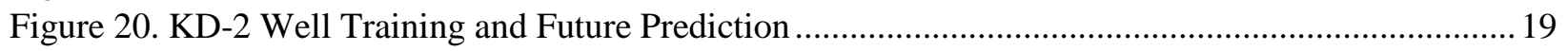

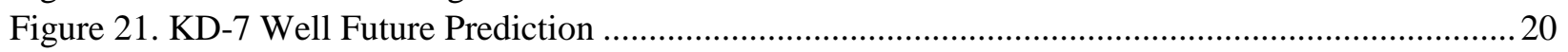

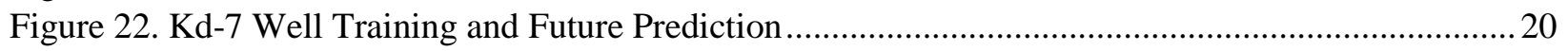

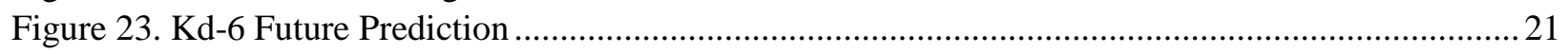

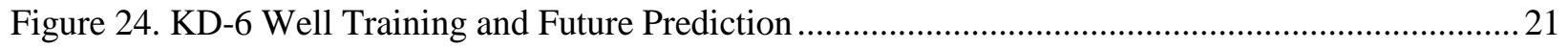

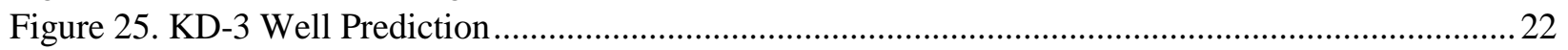

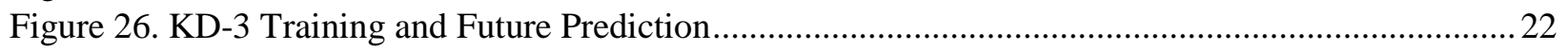

Figure 27. Flow rates vs. Time including All Wells. KD-21 and KD-24 Adjusted Flow Rates................. 23

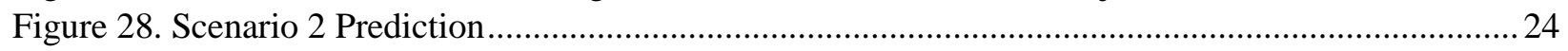


Figure 29. Scenario 3 Injectors Assumed Flow Rates ...................................................................25

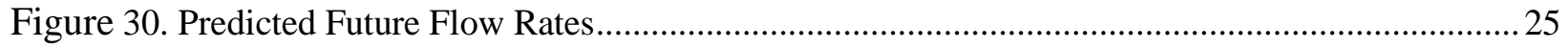

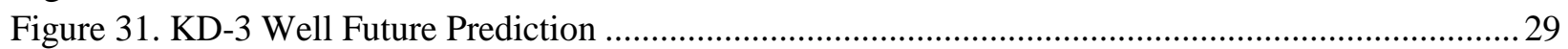

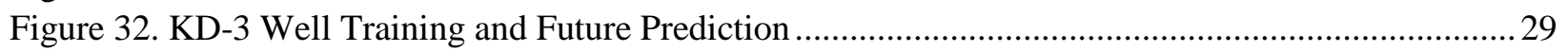

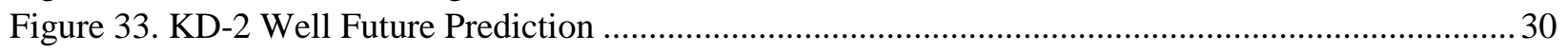

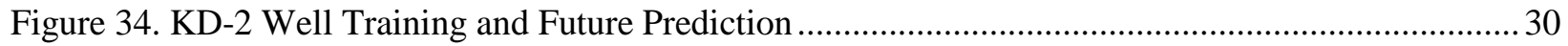

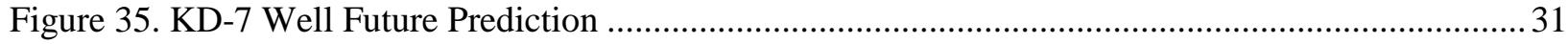

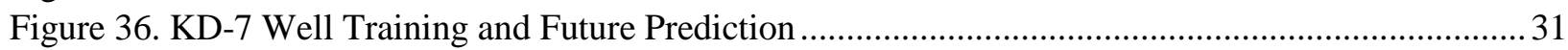

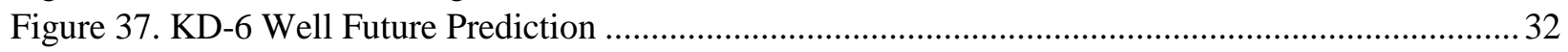

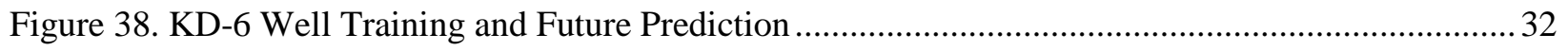

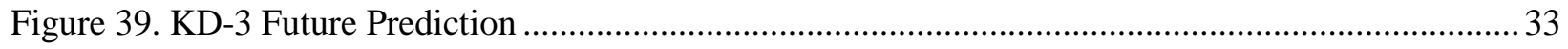

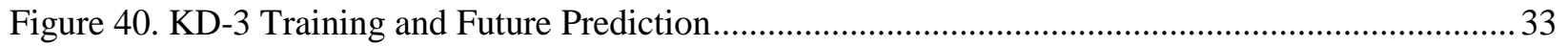

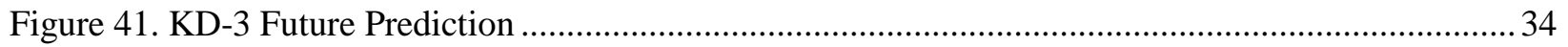

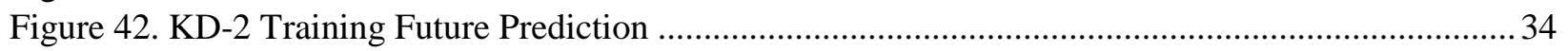

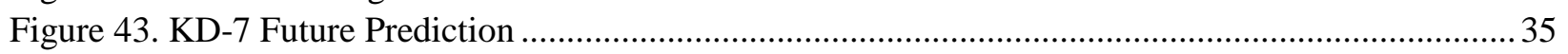

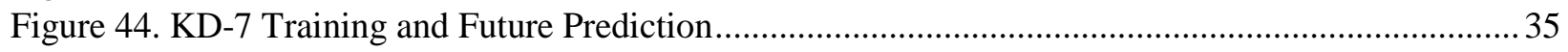

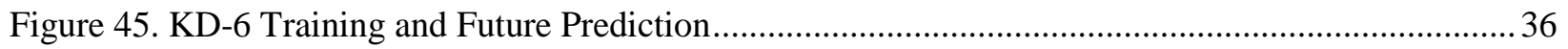

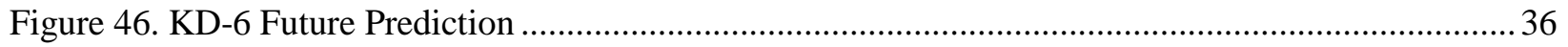

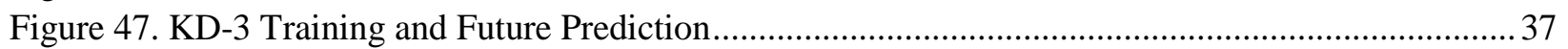

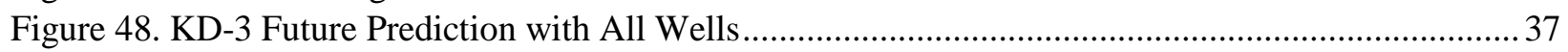

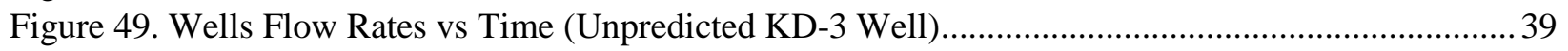

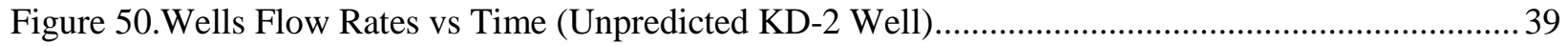

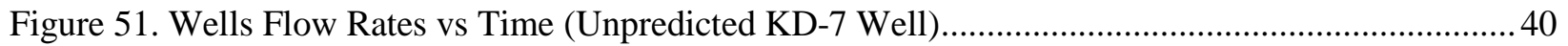

Figure 52. Wells Flow Rates vs Time (Unpredicted KD-6 Well) .......................................................... 41

Figure 53. Wells Flow Rates vs Time (Unpredicted KD-3 Well)......................................................... 42

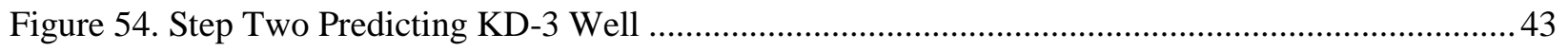

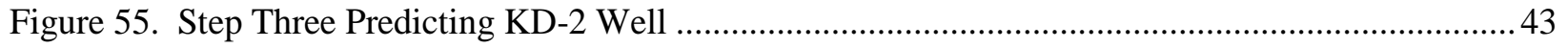

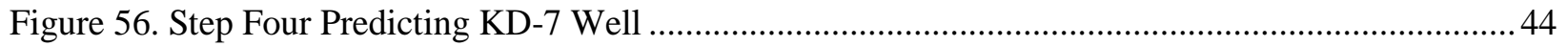

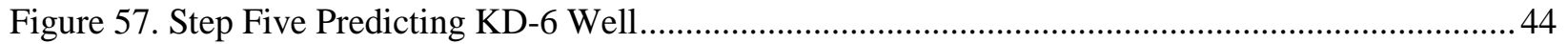

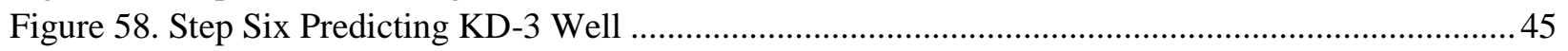




\section{Introduction}

Geothermal energy is a renewable energy source that it has been using in order to generate electricity since beginning of the $20^{\text {th }}$ century. For last decades, many geothermal resources have been explored, and on the scale of thousands of megawatt (MW) electricity generated to directly use. As of 2000, 21 countries are operating power plants using geothermal steam over 5 continents [1]. Geothermal systems mostly can be encountered volcanic, magmatic, or metamorphic areas. Geothermal reservoirs generally consist of massive rocks and mostly have high temperature and pressure zones. These zones usually are under metamorphism effect. Due to high heat and pressure, minerals or geological structure of rocks re-form without melting into liquid phase. The process typically occurs around 200C and the rock starts melting around 850C in which solid phase emerges to liquid phase. During the process, between the chemical components of the minerals and chemically active fluid, which embedded into the rock, reacts together may cause rock changes, however the rock will remain in solid phase. The Metamorphism process also indicates how geothermal sources have fluids contain a high amount of gas, mostly nitrogen, carbon dioxide, hydrogen sulfide and small proportions of mercury, ammonia, radon and baron. Mostly these gases and chemicals are concentrated in the geothermal brine that they are not detrimental since they are pumped to injection wells. Furthermore, these gases can be removable from the brine. These proportion may chance depend on metamorphism degree and geological conditions of the field, and geothermal reservoir conditions. Since geothermal reservoir rocks are massive and conductance of fluid flow is low, fluid transferring will occur through in which fractures and fissures that created by faults. Fluid transport is through rock fractures, that is, the host-rock permeability is fracture-controlled ("fractured reservoirs") [2]. According to the metamorphism degree, the geothermal reservoir rocks permeability and porosity may be very low. Production and Injection may occur near fault zones and fissures. The key is the permeability and its network that rule the fluid flow in a fractured geothermal reservoir. For fluid flow to occur from one site A to another site B in a reservoir there must be at least one interconnected cluster of fractures that links these sites. The condition that such a cluster exists is commonly referred to as the percolation threshold (Figure 1.) [3].

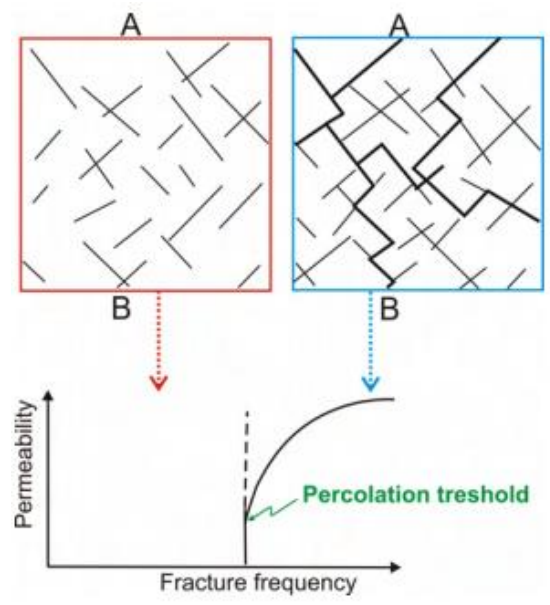

Figure 1: As long as there is no interconnected cluster of fractures between two sites $A$ and $B$ in a fractured reservoir (upper left) the permeability is very low. As soon as there exists such a fracture system (upper right), the reservoir permeability increases rapidly (below): the percolation threshold is reached (modified from Stauffer and Aharony 1994). 
As referred above, the key factor is permeability for the fluid to flow in the porous media; which can be provided along fault, fractures and fissures. Forming of the fracture structure is also depends on tectonic movements. The geothermal areas generally are located rift zones where lithospheric plates are thinned by tectonic settings. The tectonic zones are exposed to extension and convection at zones of upwelling hot material. While the rift zones stretch and frack the outer brittle crust, horst and graben structures occur associate with normal faults. This process happens under huge stress and cause many faults, fractures, and fissures that can provide fluid flow in the geothermal reservoirs. Thus, the geothermal field consists of many faults, fractures by occurring horst and graben structure. Sometimes in the reservoir multiple horst and graben structure are nested in each other that might be a challenge to identify reservoir borders. Horst and graben structure can separate reservoirs each other or can locate in a different place. This situation might also make imprecise of boundary of reservoir. Furthermore, in this complicated case temperature at reservoir zones might be different that can play very important role for transportation of the fluid along porous media. Future flow forecasting is a part of reservoir model and it is very important issue to determine the power plant capacity and efficiency. Conventional reservoir models to predict future prediction might be challenge due to various gases in the field, sometimes unknown reservoir boundary, non-isothermal fluid, and considering computational time, reliability and costs of reservoir modelling for future forecasting might be challenge. In the fields, there are many uncertainties that can affect the results directly. To solve these problems would cost of money, time or both. Nevertheless, there might be many uncertainness, the fact that only certain data would be from field measurements. The field measurement is the outcome with all certain and uncertain parameters. Instead of using conventional methods for prediction, Artificial Intelligence might be a good solution using based on field measurements of the geothermal wells with huge dataset. For conventional technologies that forecast production, decline curve analysis and capacitance/resistance modeling CRM are used, but main problem with these technologies is that they do not make use of a large data. However, Machine Learning ML integrates all available field measurements, such as production and injection history to have comprehensive full-field reservoir modeling using machine learning and pattern recognition Methodology [4]. Artificial Intelligence and Machine Learning can be sub grouped into supervised learning, transfer learning, reinforced learning and unsupervised learning. The supervised learning requires a large of data. Therefore, performing the supervised learning will be convenient for geothermal fields since measurements from the fields have large of data. To aim of this study has two concepts. First, missing data prediction: the data provided from geothermal field has missing flow rates for some wells, however well-head pressure, well-head temperature, flow rates, valve positions, bottom-hole pressures are provided. By using these parameters, missing flow rates will be forecasted by ML supervised learning method. Second, the field has both production and injection wells, upon completing missing flow rates, future prediction of the flow rates of the production wells will be forecasted. Reinjection surplus geothermal brine' amount can be operated manually with an injection pumps, various injections rates effect will be discussed for future prediction.

\section{Theory}

\section{Artificial Neural Networks (ANN)}

An Artificial Neural Network (ANN) is made up of several artificial neurons and a number of interconnections between them. According to the structure of the connections, different classes of network architectures can be identified. In feed-forward neural networks (FFNN), the neurons are organized in the form of layers (CITE). The neurons in a layer receive input from the previous 
layer and feed their output to the next layer. In this kind of network, connections to the neurons in the same or previous layers are not permitted. The last layer of neurons is called the output layer (right column) and the layers between the input and output layers are called the hidden layers. The input layer (left column) is made up of special input neurons, transmitting only the applied external input to their outputs. In a network if there is only the layer of input nodes and a single layer of neurons constituting the output layer then they are called single-layer network. If there are one or more hidden layers (middle column), such networks are called multi-layer networks. The structures, in which connections to the neurons of the same layer or to the previous layers are allowed, are called recurrent networks (CITE). The lines represent weighted connections (i.e., a scaling factor) between processing elements Figure2. The performance of a network as shown in Figure 2 is measured in terms of a desired signal and an error criterion. The output of the network is compared with a desired response to produce an error [CITE]. An algorithm called backpropagation [5] is used to adjust the weights a small amount at a time in a way that reduces the error. The network is trained by repeating this process many times. The goal of the training is to reach an optimal solution based on a performance measurement [6].

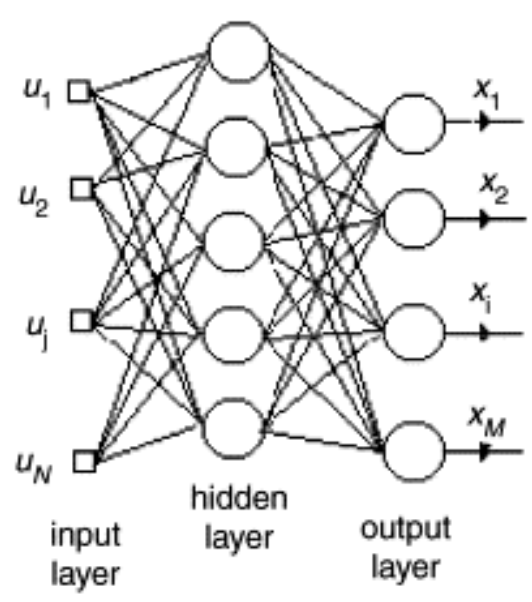

(a)

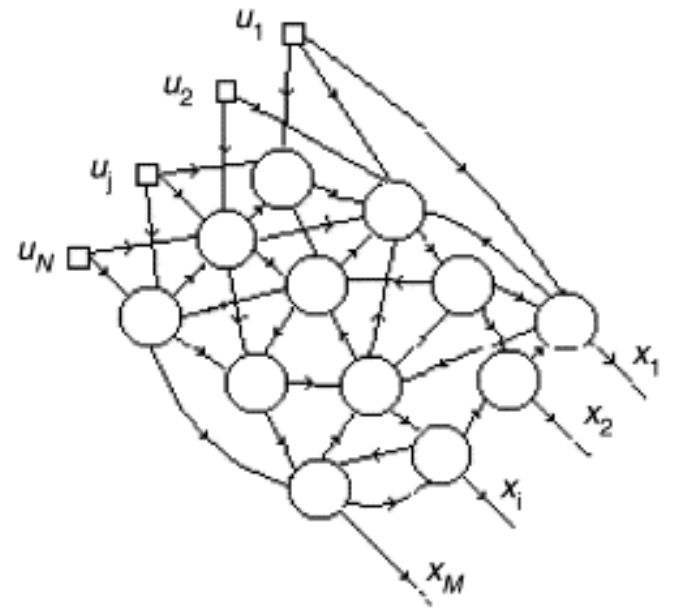

(b)

Figure 2 Layered feed-forward neural network, (b) non-layered recurrent neural network (Haykin, 1994).

Multi-layer Perceptron

Multi-layer Perceptron (MLP) is a supervised learning algorithm that learns a function

$f():. R^{m} \rightarrow R^{o}$ By training on a dataset, where $m$ is the number of dimensions for input and $o$ is the number of dimensions for output. Given a set of features $X=x_{1}, x_{2}, x_{3, \ldots \ldots . . . .} x_{m}$, and a target $y$ it can learn a non-linear function approximator for either classification or regression. It is different from logistic regression, in that between the input and the output layer, there can be one or more non-linear layers, called hidden layers (Figure 3). 


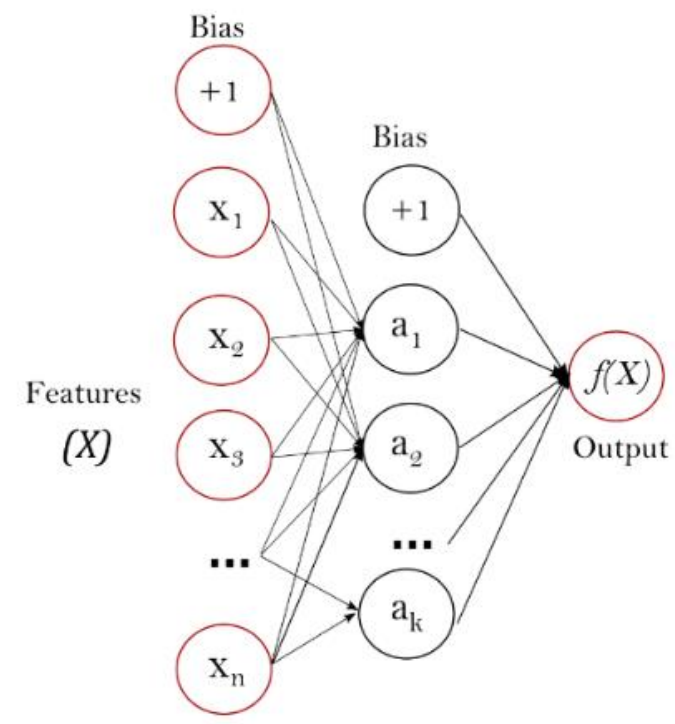

Figure 3 Single layer MLP

The leftmost layer, known as the input layer, consists of a set of neurons $\left\{x_{i}\right.$ I $\left.x_{1}, x_{2, \ldots . .} x_{m}\right\}$ representing the input features. Each neuron in the hidden layer transforms the values from the previous layer with a weighted linear summation, $w_{1} x_{1}+w_{2} x_{2} \ldots \ldots+w_{3} x_{3}$ followed by a nonlinear activation function $g():. R \rightarrow R$. The output layer receives the values from the last hidden layer and transforms them into output values.

The advantages of Multi-layer Perceptron are the capability to learn non-linear models and capability to learn models in real-time [CITE]. The disadvantages of Multi-layer Perceptron (MLP) include [CITE],

- MLP with hidden layers have a non-convex loss function where there exists more than one local minimum. Therefore, different random weight initializations can lead to different validation accuracy.

- MLP requires tuning several hyper parameters such as the number of hidden neurons, layers, and iterations.

- $\quad$ MLP is sensitive to feature scaling.

Class MLP regression implements a multi-layer perceptron (MLP) that trains using backpropagation with no activation function in the output layer. Therefore, it uses the square error as the loss function, and the output is a set of continuous values. MLP regression also supports multi-output regression, in which a sample can have more than one target. Class MLPClassifier implements a multi-layer perceptron (MLP) algorithm that trains using Backpropagation.

MLP trains on two arrays: array X of size (n-samples, $n$-features), which holds the training samples represented as floating point feature vectors; and array y of size (n samples), which holds the target values (class labels) for the training samples:

After fitting (training), the model can predict labels for new samples:

MLP can fit a non-linear model to the training data CLF coefficients contains the weight matrices that constitute the model parameters: 
MLP trains using Backpropagation. More precisely, it trains using some form of gradient descent and the gradients are calculated using Backpropagation. For classification, it minimizes the CrossEntropy loss function, giving a vector of probability estimates $P(y \mid x)$ per sample $x$.

Currently, MLP-Classifier supports only the Cross-Entropy loss function, which allows probability estimates by running the predict-probe method.

MLP-Classifier supports multi-class classification by applying Soft-Max as the output function. Further, the model supports multi-label classification in which a sample can belong to more than one class. For each class, the raw output passes through the logistic function. Values larger or equal to 0.5 are rounded to 1 , otherwise to 0 [CITE].

\section{Methodology}

\section{Obtaining Data}

The data is contributed from the KIZILDERE geothermal field. The field explored in 1963 and the first exploration well opened in 1987. Totally, the field has 4 exploration wells, 5 observer wells, 9 production wells, 5 injection wells. 3 production wells were shut in due to insufficient production or well completion problems. 2 injection wells were abandoned due to injection operational issues. The field measurements were provided between 2000 and 2013. Unfortunately, the data before 1987 and after 2013 are not available. In addition, the field data were recorded as a hard copy before 1987, thus many hard copies were missed, and the existence data quality is poor and recorded intermittently. The exploration wells, the observation wells, and the abandoned production wells data were not included in this study due to referred reasons above. Furthermore, the field was endorsed to private sector from government in 2013, so that the data are restricted for any usage after that time.

\section{Processing of Data}

The field data were gathered from the field data file and discriminated according to well numbers. A standard dataset format has been created, and this format was utilized for the rest of the wells for a model. The data taken the field have many fluctuations such as flow rates. During the welltests or due to any operational cases such as injector pumps power failure, (some of the reasons mentioned in the field report, some of them not) wells were subject to shut-in or were performed limited production etc. These reasons caused measuring fluctuated flow rates either the first 400500 days of production, or in different part of the production history. In the dataset, some sudden changes as it was referred above were cut-off Figure 4. The cleansing of data provides better resolutions while interpreting data on charts, and also it removed many ambiguous points. Moreover, it contributes better test results during the training and future prediction process. 

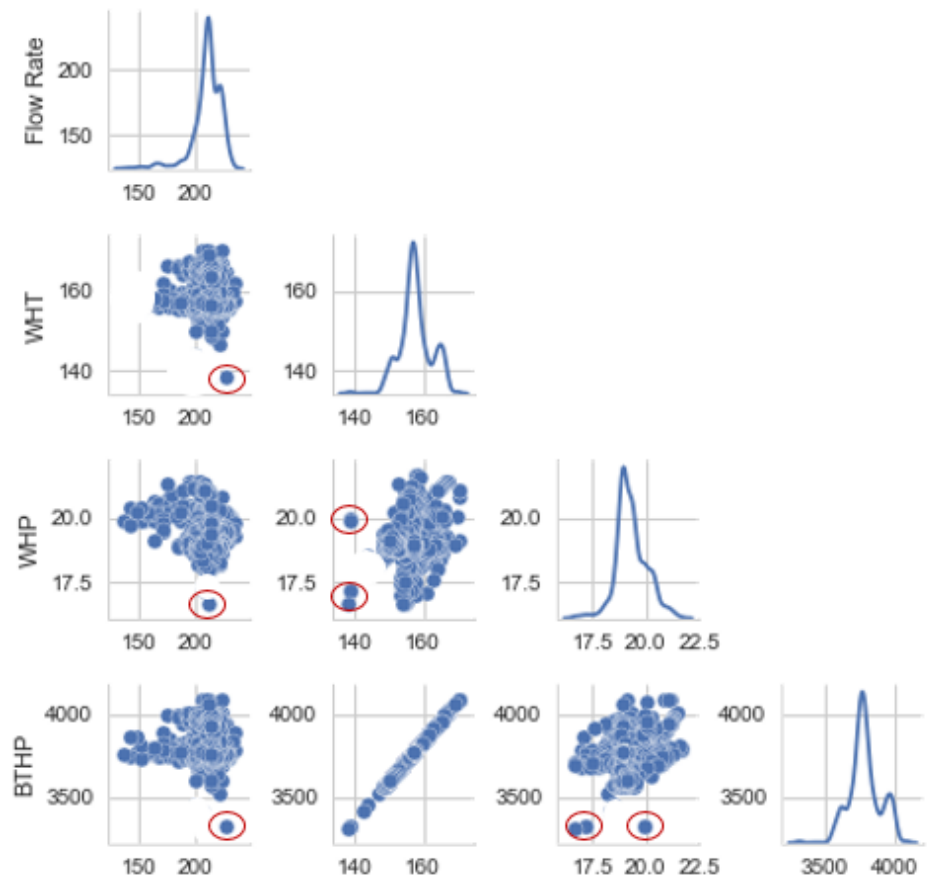

Figure 4. Cleansing of Data for KD-3 Well

\section{Data Scaling}

The dataset consists of different input parameters and mostly they have different unit such as flow rate as ton/hr., temperature as Celsius degree, pressure as psi, etc. The algorithm allows entering the parameters without any standard units. For instance, pressure can be taken bar or psi, or Pascal. The MLP regression algorithm has been selected to predict values. The MLP will perform scaling process. The Min-Max-Scaler is a tool that it can be conducted for pre-processing to create a model, and it is embedded into SCIKIT learn algorithm. The Min-Max-Scaler algorithm performs relative scaling of the whole range of data with respect to its minimum and maximum value, mostly inform of zero to unity, or in some cases from -1 to 1 [7].

\section{Training of Predictive Model}

In this study, for training process almost $80 \%$ of data were used, $20 \%$ data were used as prediction set to stay on safe side. This implementation was used for both predicting the missing flow rates and for future forecasting production flow rates. The Multi-Layer Perceptron Regression (MLP) model were conducted with following architecture.

\begin{tabular}{|l|l|l|}
\hline Feature & Value/Model & Explanations \\
\hline
\end{tabular}




\begin{tabular}{|c|c|c|}
\hline Solver & $L B F G S$ & Solver is an optimizer in the family of quasi-Newton methods \\
\hline $\begin{array}{l}\text { Hidden Layer } \\
\text { Sizes }\end{array}$ & 50 & $\begin{array}{l}\text { The } I T H \text { element represents the number of neurons in the } I T H \\
\text { hidden layer }\end{array}$ \\
\hline Tolerance & 0.0000001 & Tolerance for the optimization \\
\hline $\begin{array}{l}\text { Maximum } \\
\text { iteration }\end{array}$ & 1000 & Maximum number of iterations. \\
\hline variation stop & 15 & $\begin{array}{l}\text { Count of iterations to attempt before stopping if score is not } \\
\text { improving on the train set }\end{array}$ \\
\hline alpha & 0.0000001 & \\
\hline Neutron & 50 & \\
\hline Activation & RELU & the rectified linear unit function returns $\mathrm{f}(\mathrm{x})=\max (0, \mathrm{x})$ \\
\hline learning rate & constant & $\begin{array}{l}\text { 'Constant' is a constant learning rate given by 'learning rate } \\
\text { initiation'. }\end{array}$ \\
\hline
\end{tabular}

Table 1 MLP REGRESSOR Model Architecture

The rest of MLP features were accepted at default settings. The model was first fit to the training then iterated. The mean of each run was taken as a predicted value.

Hidden Layer Sizes: length = n layers

- The $I T H$ element represents the number of neurons in the $I T H$ hidden layer.

Activation:

- Activation function for the hidden layer.

Solver: The solver for weight optimization $\left\{' L B F G S^{\prime}\right.$, 'ADAM'\}.

- The solver has been selected as default ' $A D A M$ ' which refers to stochastic gradient descent.

- However, ' $L B F G S$ ' refers an optimizer in the family of quasi-Newton methods can be used for small dataset

Alpha: float, optional, default 0.0001

Learning rate:

- Learning rate schedule for weight updates. $\{$ 'CONSTANT' $\}$,

- 'CONSTANT' is a constant learning rate given by 'LEARNING RATE INIT'.

Max iteration: 1000

- Maximum number of iterations. The solver iterates until convergence

- (Determined by 'TOLERANCE') or this number of iterations.

LEARNING RATE INIT

- The initial learning rate used. It controls the step-size in updating the weights. Only used when solver='SGD' or 'ADAM'.

Variation stop:

- Count of iterations to attempt before stopping if score is not improving on the train set or on the validation fraction

MLP regression trains iteratively since at each time step the partial derivatives of the loss function with respect to the model parameters are computed to update the parameters. It can also have a regularization term added to the loss function that shrinks model parameters to prevent overfitting. This implementation works with data represented as dense and sparse NUMPY arrays of floatingpoint values. 


\section{Application of Predictive Model for Geothermal Wells}

History Prediction of Missing Flow Rates for Single Wells

The data includes 6 production wells and 3 injection wells. All wells are vertical well. The data taken from field measurements taken has missing flow rates. Some years flow rates could not measure, or they were lost for some wells. Each well mostly have following parameters;

- Production Flow Rates (ton/hr.) - production wells

- Injection Flow Rates (ton/hr.) - injection wells

- Well-head Pressures (WHP) (psi)

- Bottom-hole Pressure (BTHP) (psi)

- Well-head Temperature (WHT) $\left({ }^{\circ} \mathrm{C}\right)$

- Bottom-hole Temperature (BTHT) $\left({ }^{\circ} \mathrm{C}\right)$

- Valve Position (\%)

For some wells some data are missing such as valve position is not recorded, or BTHP is not measured due to operational problems. BTHP was measured by running hole with a tool. Since bottom-hole temperature was considerably high, the tool pulled out of the hole after a while. Therefore, BTHP is not available for all wells. The flow rate is highly correlated with the parameters such pressures, temperatures and valve positions that it can be seen on the Figure 5.
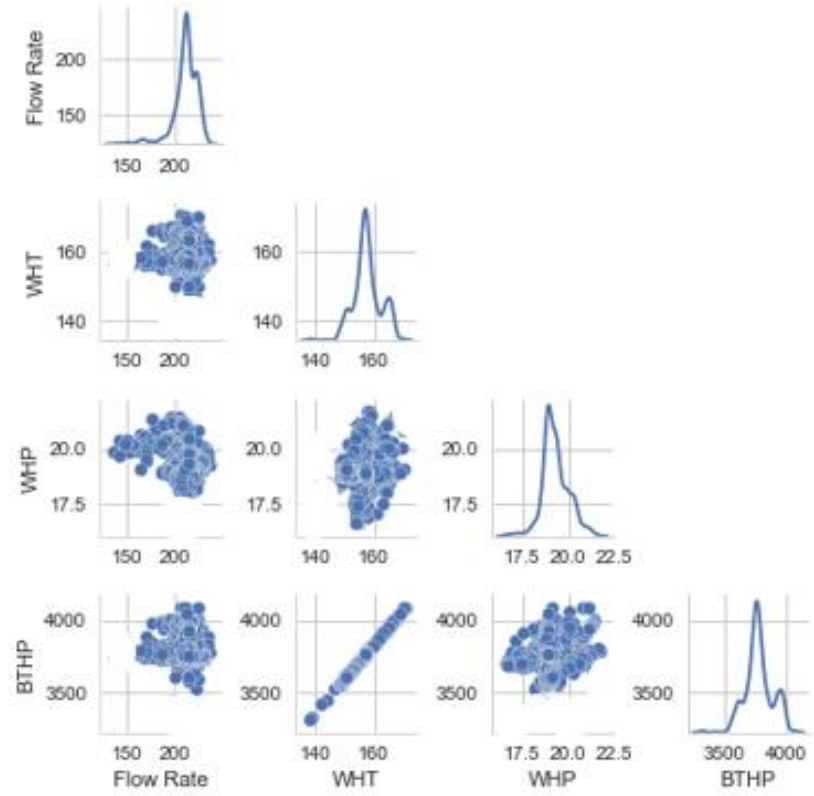

Figure 5. The Cross Plot Diagram for each parameters of KD-3 well

During the history of flow rates for single wells, some part of flow rates were lost or were not recorded. For predicted missing history data based on each single well, input parameters are trained using WHP, BTHP, Valve position, WHT, etc. Figure 6. Then, flow rates predicted as an output. In order to scrutinize the preciseness of the process, one part of the known flow rates cut out from one of the wells. Figure 7. By using of the field measurements such as WHP, BTHP, WHT etc., referred above, were trained and missing part was predicted. 

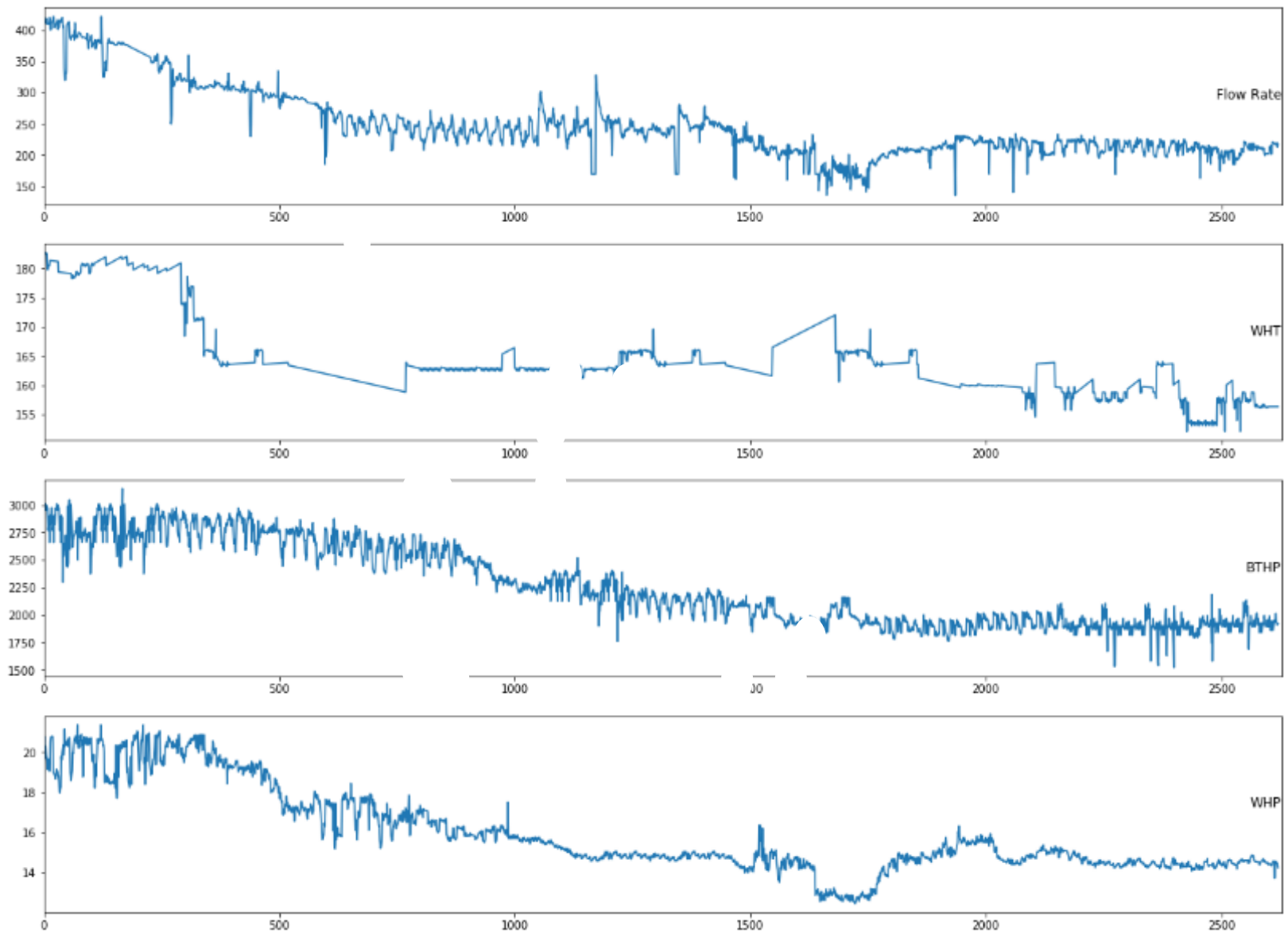

Figure 6 KD-3 well field measurements; Flow Rates (ton/hr.), Well-head Temperature $\left({ }^{\circ} \mathrm{C}\right)$, Bottom-hole Pressure (psi), Wellhead Pressure (bar) vs. Date (Time)

Before running the predictive model algorithm, some of the known data manually cut-off from the dataset for training and predicting cut-off flow rates to determine performance of the predictive model Figure 7. In that case, anticipating how much data should have been removed as maximum is a crucial thing to know to stay on the safe side. Firstly, $10 \%$ of the known data were removed and rest of the procedure were performed as referred above. Then, same procedure was conducted for $20 \%, 30 \%$, and go on. All runs were compared with the original data. The test results indicate that removed data should be maximum $40 \%$ to obtain promising results Figure 8 . Therefore, the missing production or injection flow rates history can be predicted accurately up to $40 \%$ of the original data. 

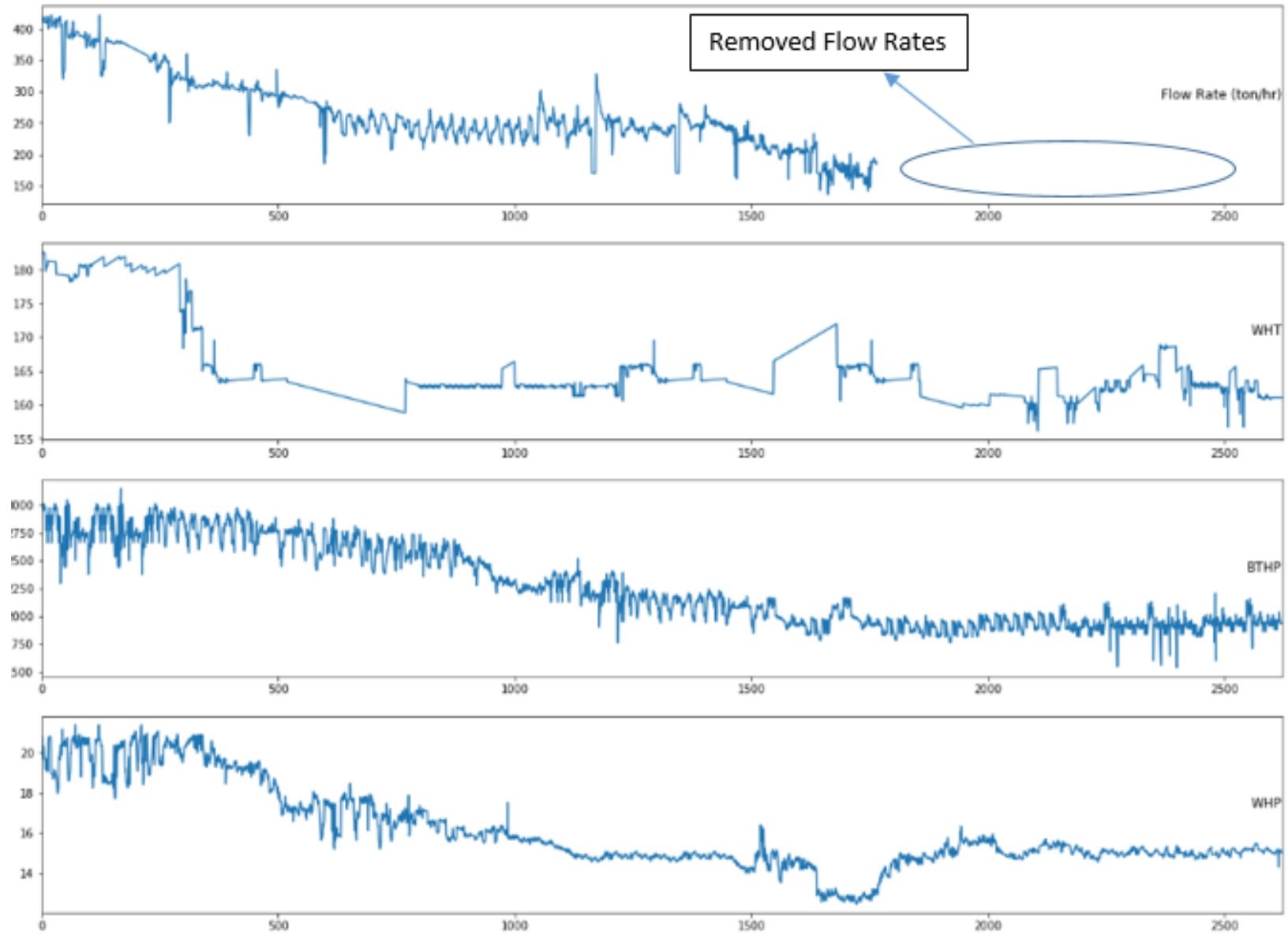

Figure 7. KD-3 Well Field Measurements (Flow Rates Removed)

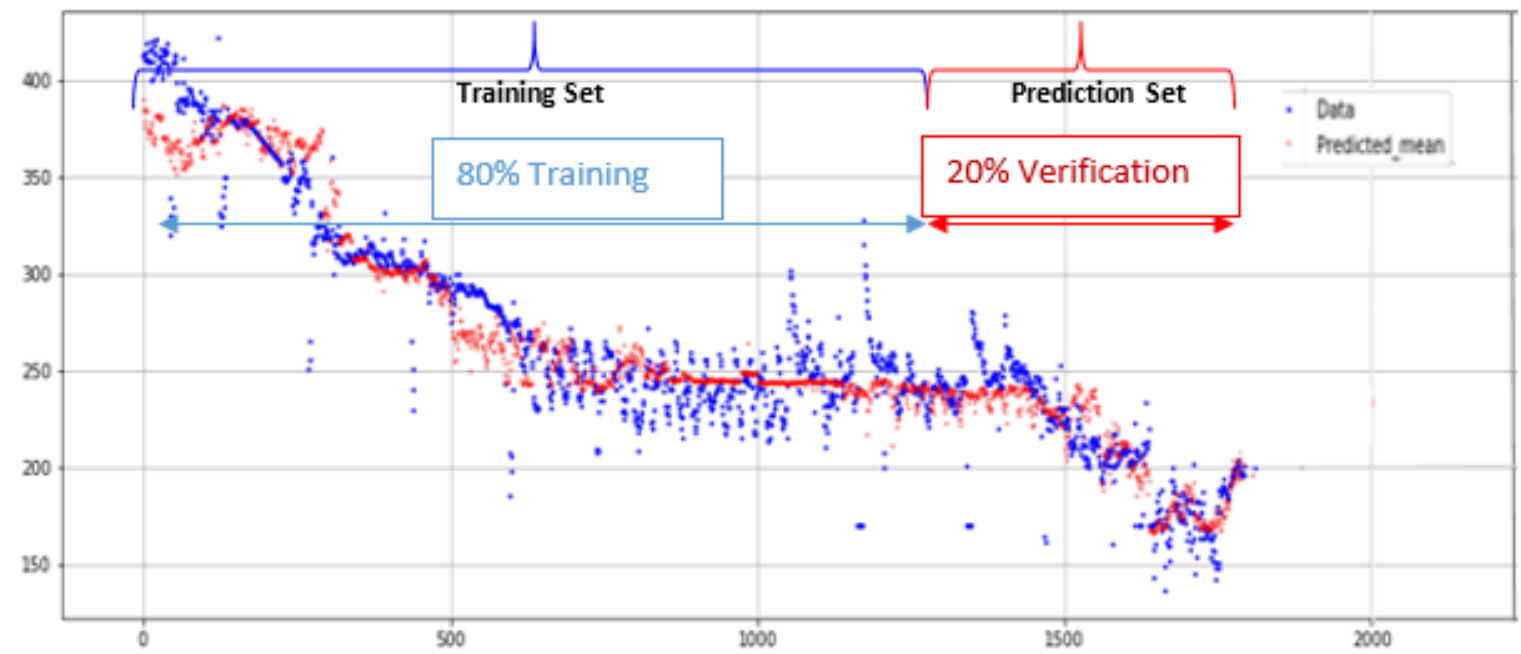

Figure 8. Kd-3 Well Flow Rate History (last $40 \%$ of the production rates removed) - flow rate (ton/hr.) vs. Time (Days) 
For future flow rates forecasting; before prediction performed for blind data $80 \%$ of the original data trained and rest of the data predicted as a verification set. The blind set also match with the original data Figure 8 , 9.

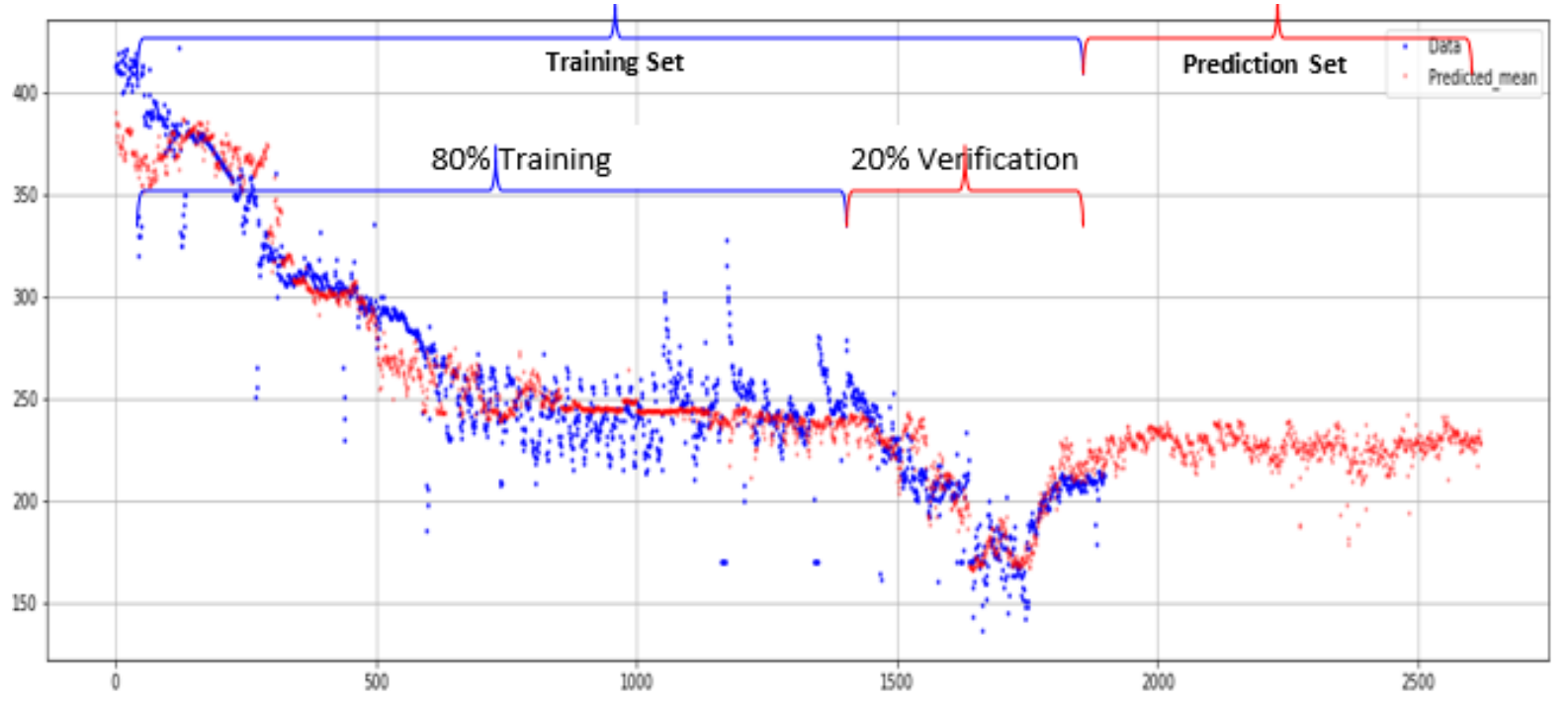

Figure 9. KD-3 Well Future Flow Rates Prediction with Verification (flow rates (ton/hr.) vs Date (Days))

Once the values of Flow Rates were predicted, we imported the removed values of Flow Rates to compare our predicted Flow Rates. The results for this case were promising.

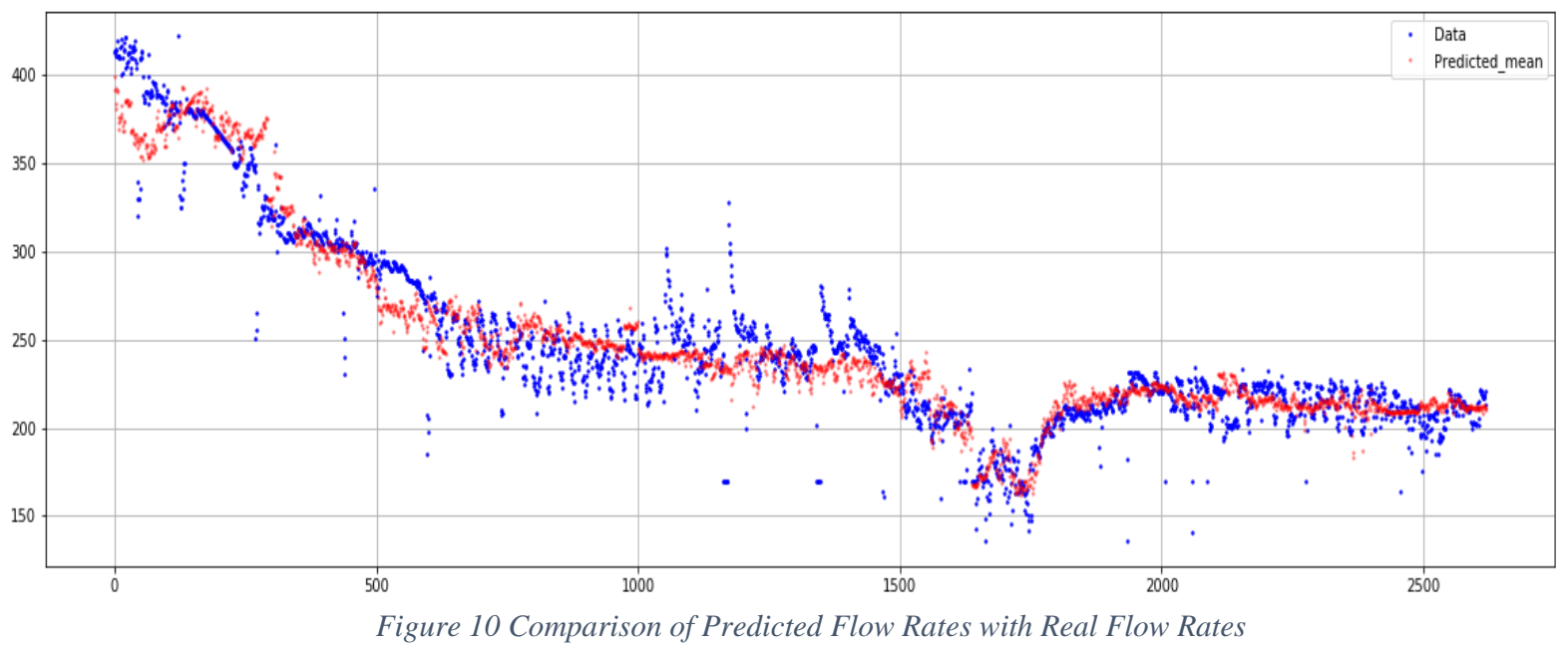

We applied the same procedure for remaining missing data to see the applicability of our developed model. The algorithm provides test scores to display accuracy of prediction based on the input and output values. The score considerably high, and the predicted production flow rates and removed production flow rates were very close each other Table 2. 


\begin{tabular}{|c|c|r|r|}
\hline Prediction Veracity & Removed Data \% & Trained Data \% & Predicted Data \% \\
\hline High & 10 & 90 & 10 \\
\hline High & 20 & 80 & 20 \\
\hline High & 30 & 70 & 30 \\
\hline High & 40 & 60 & 40 \\
\hline Medium & 50 & 50 & 50 \\
\hline
\end{tabular}

Table 2. Training and Future Prediction Test Accuracy

Future Flow Rate Forecasting

When we predicted missing flow rates, we used some parameters such flow rates, pressure, temperature etc. Since we don't know those parameters that we referred above for future productions, we based our model on injection and production flow rates data. The chart below demonstrates the flow rates versus time. Figure 11. Production and Injection data were measured daily between 2000 and 2013 years. Production wells are KD-1, KD-2, KD-3, KD-4, KD-7, and KD-6. Injection wells are KD-15, KD-21 and KD-24. The production wells were opened in different years without injections, therefore, declining of production flow rates are considerably high. Furthermore, wells' productions almost first 400-600 days are much fluctuated foe some wells. This situation might happen due to some reasons. This part will be discussed in the discussion part. Upon adding the injection wells, declining flow rates for each producer started to decrease, and wells flow rates are were balanced.

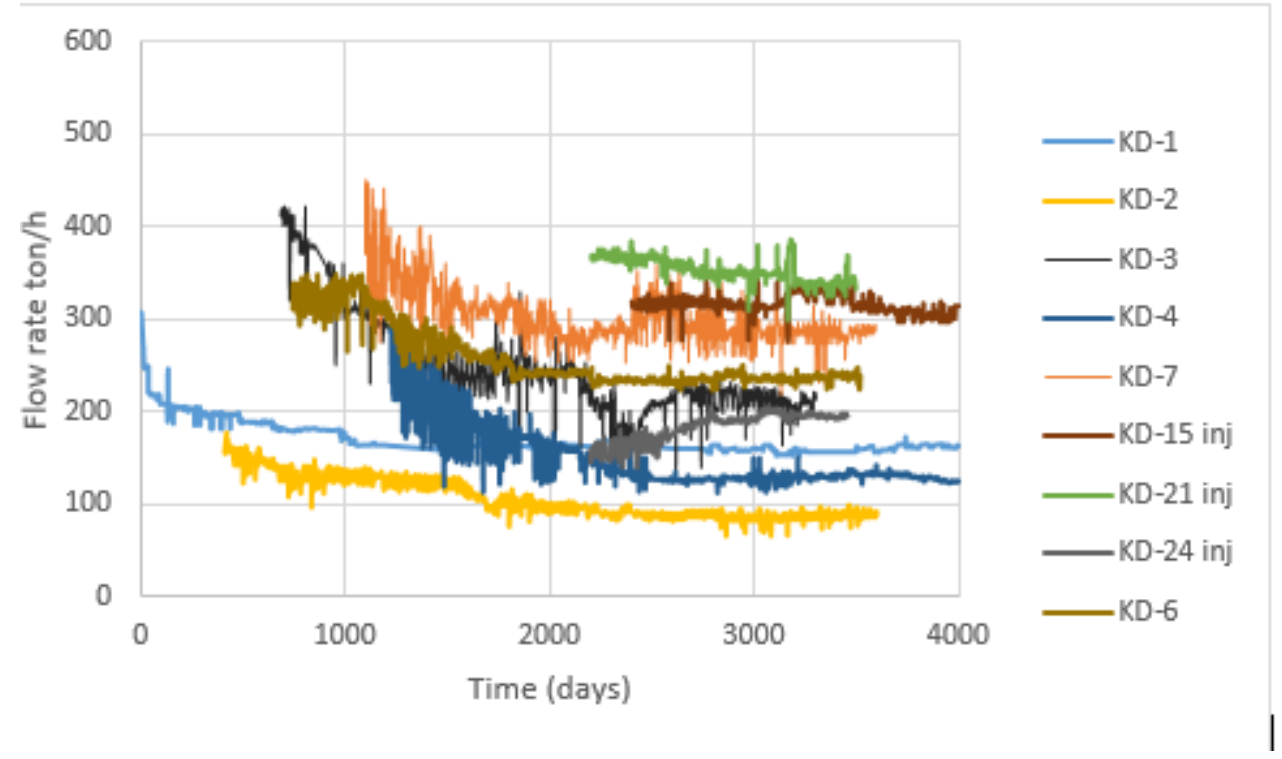

Figure 11 Flow Rates (ton/hr.) vs. Time (days) (All Wells)

The heat map between the producers and the injectors indicate that each producer has interaction another producers and injectors Figure 12. Same condition also exists for injection wells; injectorsto-injectors interactions and injection-to-producer interactions. 


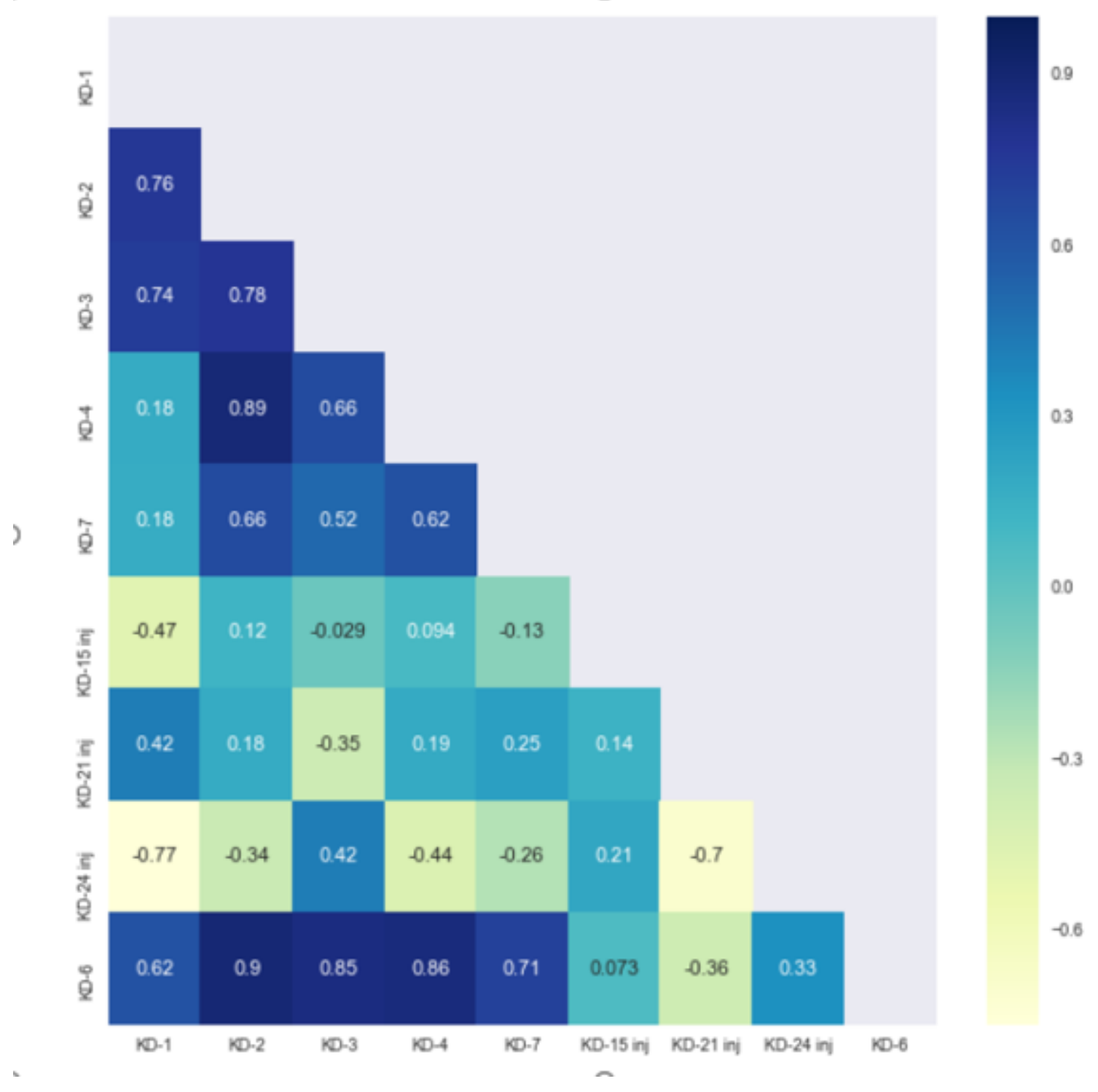

Figure 12 the Heat Map: Correlation Matrix between Producers and Injectors

The heat map points out that each wells interaction with another one. For our understanding, we developed a pair plot between these 9 wells Figure 13. There is visible relationship between wells, some wells are highly correlated. The correlation between all injectors and producers will provide better solutions in terms of allocating injection ratios between the wells. For example, increasing injection ratio for well number KD-24 will provide increment production flow rates for KD-6, and KD-3 wells. KD-21 Injection well can also increase flow rates for KD-1, KD-2, KD-4, KD-7 wells. Since the injectors have interconnection each other, these wells support more fluid each other. For instance, the amount of fluid injected from KD-15 injector well mostly are allocated by two other injectors (KD-21 and KD-24 wells). The KD-15 injection well can cancel, and the amount of fluid injected to KD-15 can be shared between KD-21 and KD-24 injectors. The possibilities can be increased. It will be discussed on discussion part. 

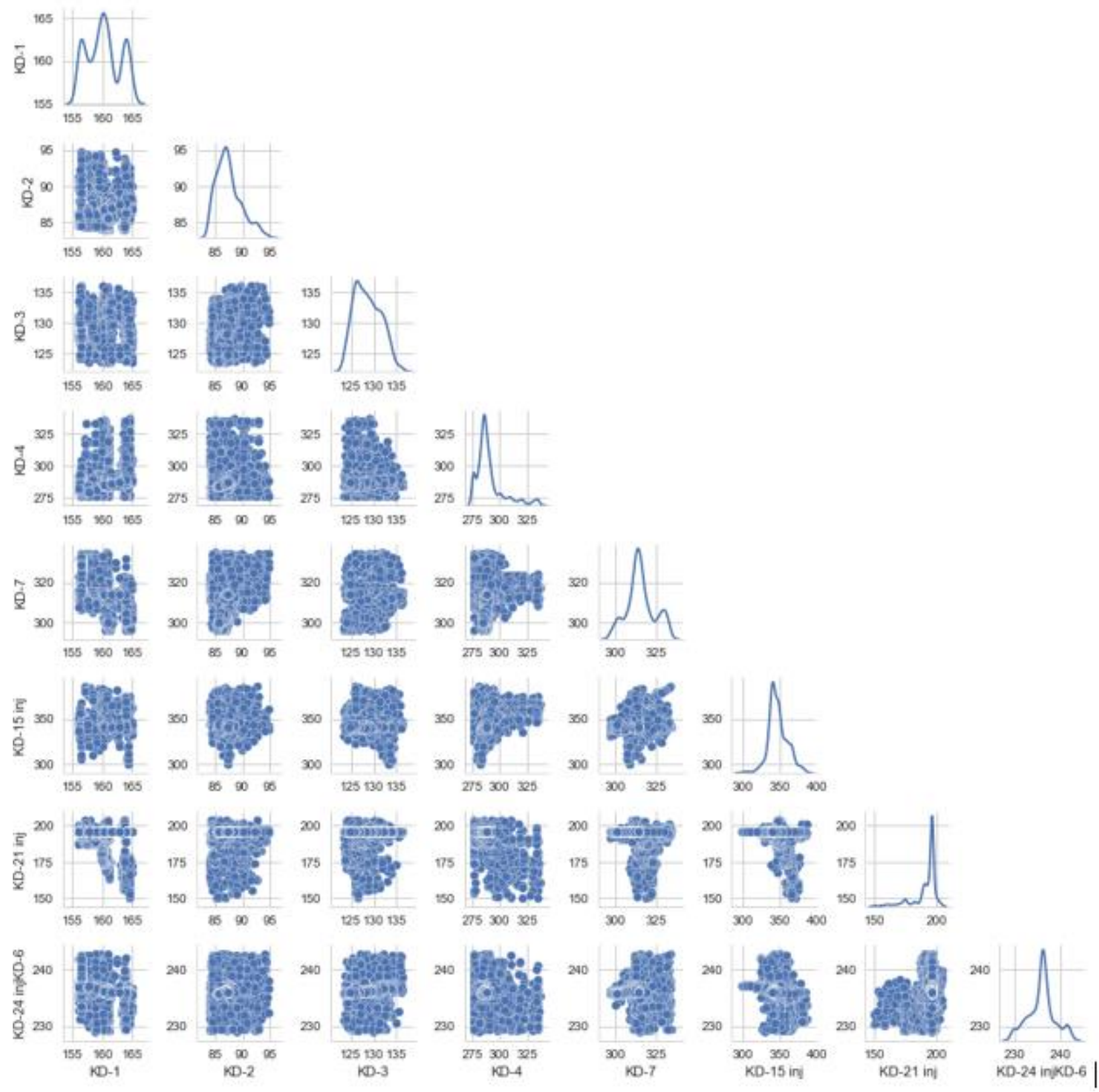

Figure 13 Cross Plot Diagram of all the wells

\section{Results}

Future Forecasting Scenarios Based on Flow Rates

In this part of study, as we discussed above, we used only productions and injection wells' flow rates. There are 9 wells and they started producing or injecting in different times. The producers' flow rates are supported and balanced by adding injectors to the field. Taking into consideration this information, the model has been decided to train when the all wells were active (flow rates data are available for all wells between 2400-3520 (days) except KD-3 well which has available 
production data between 2400-3304). Figure 14. The model has been trained between 2400-3304 then, KD-3 well future production predicted between 3304-3520.

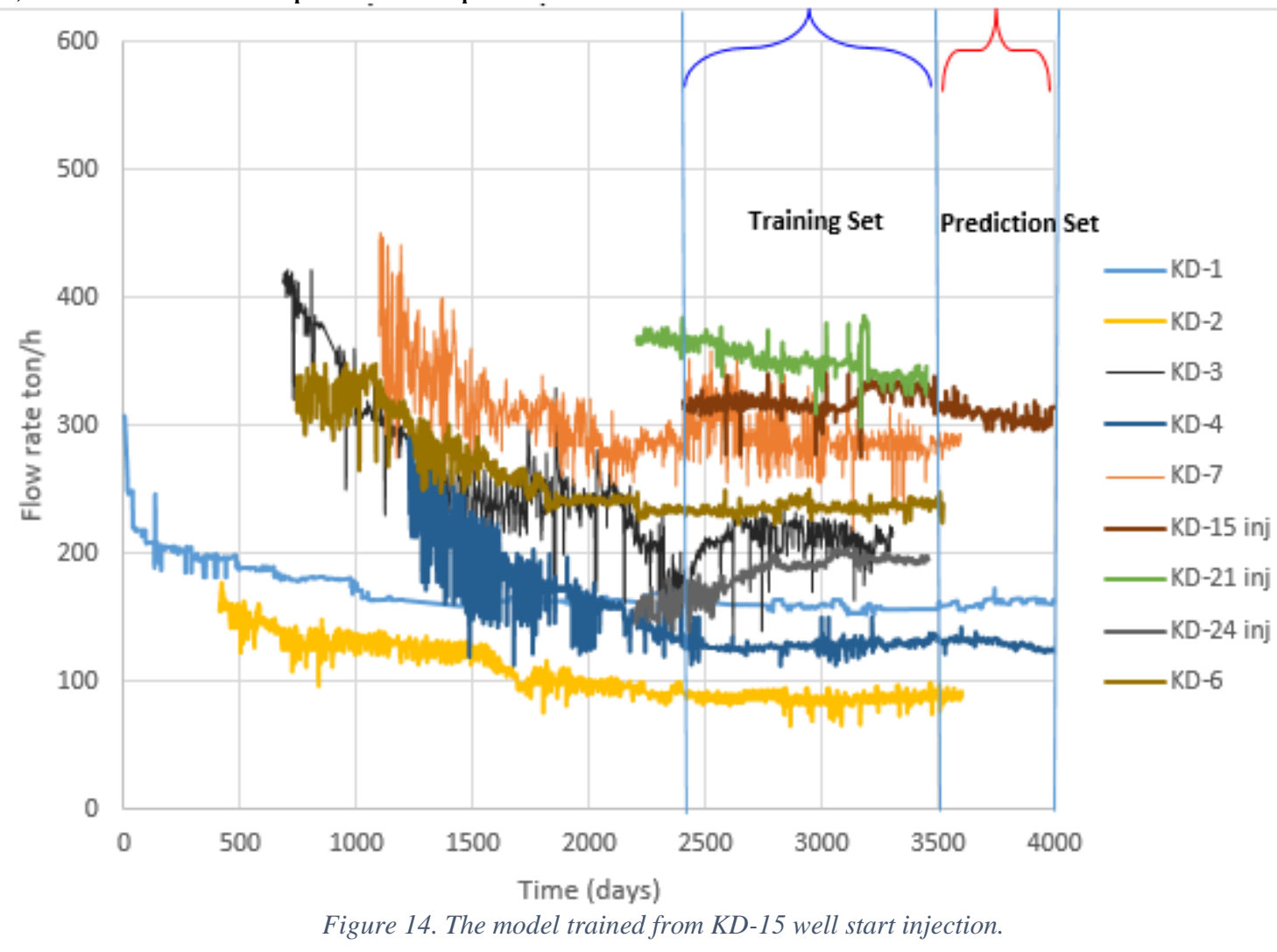

The model is ready to train using flow rates, and to predict future flow rates in the prediction set. The future forecasting will be performed for prediction set (KD-2, KD-3, KD-6, KD-7, KD-21 and KD-24) Figure 14. There is one more thing that must be known, the injectors can operate manually, and the total maximum injection rate can be a total maximum production flow rate. Total amount of the production (average) is (1109 ton/hr.) and injection is 840 (ton/hr.) Table 3.

\begin{tabular}{|l|r|l|r|}
\hline Producers & ton/hr. & Injectors & ton/hr. \\
\hline KD-1 & 162 & KD-15 & 305 \\
\hline KD-2 & 87 & KD-21 & 340 \\
\hline KD-3 & 210 & KD-24 & 195 \\
\hline KD-4 & 124 & Total & 840 \\
\cline { 1 - 2 } KD-7 & 290 & \multicolumn{2}{|c}{} \\
\cline { 1 - 2 } KD-6 & 236 & \multicolumn{2}{|l}{} \\
\cline { 1 - 2 } Total & 1109 & \multicolumn{2}{|l}{} \\
\cline { 1 - 2 } & &
\end{tabular}

Table 3. Total Production and Injection Flow Rates, (these rates were taken as an average last 50 days of flow rates for each wells) 
Therefore, the total fluid amount for injectors can be increased only 269 (ton/hr.) to provide the total production to total the injection rate Equation-1. This amount can be allocated between injectors.

Total Amount of Production - Total Amount of Injection $=1109-840=269\left(\frac{\text { ton }}{h r}\right.$. $)$

Equation 1. Estimated Total Flow Rates Difference between Injectors and Producers

Another challenging for injectors that limits injection is the pump capacity. Mostly, it might not possible to inject all disposal brine to the system via pumps. The pumps maximum allowable pressure is a restrain mechanism. In this field, pump capacities provided as pressure versus flow rates. These data are following as Table 4 .

\begin{tabular}{|l|c|c|}
\hline Injectors & ton/hr. & $\begin{array}{c}\text { Maximum Allowable } \\
\text { Pump Pressure (bar) }\end{array}$ \\
\hline KD-15 & 340 & 36 \\
\hline KD-21 & 380 & 40 \\
\hline KD-24 & 220 & 30 \\
\hline \multicolumn{2}{|c|}{ Table 4. The Injector Pumps Catalogue Capacity }
\end{tabular}

Since the injector pumps' capacities have been known, the future prediction will be built on different scenarios; changing the injection flow rates based on a maximum pump capacity or using current injected flow rates (average of last 50 days). These assumptions have been made and presented as scenarios. The future production forecasting will be compared to the different scenarios. The scenarios design will build on two injectors (KD-21 and 24) since KD-15 wells' injection rate is constant (340 ton/hr.). First scenario is to maintain injected flow rates same as current injection flow rates for each producer. Second scenario is to raise injection rates to maximum that pumps can able to inject. Third scenario is to maintain one of the injectors constant and raise the other one to the maximum injection volume. The purpose of the all scenarios is to manage reservoir efficiently, and to obtain the maximum production. Each model will be interpreted comprehensively, and the most efficient production and injection scenario will be anticipated. Table5.

\begin{tabular}{|c|c|c|}
\hline Scenario 1 & Injectors & ton/hr. \\
\hline & KD-15 & 310 \\
\cline { 2 - 3 } & KD-21 & 340 \\
\cline { 2 - 3 } & KD-24 & 195 \\
\hline Scenario 2 & Injectors & ton/hr. \\
\hline \multirow{5}{*}{} & KD-15 & 310 \\
\cline { 2 - 3 } & KD-21 & 380 \\
\cline { 2 - 3 } & KD-24 & 230 \\
\hline Scenario 3 & Injectors & ton/hr. \\
\hline & KD-15 & 310 \\
\cline { 2 - 3 } & KD-21 & 340 \\
\cline { 2 - 3 } & KD-24 & 230 \\
\hline
\end{tabular}

Table 5. Future Injection Scenarios 
Scenario 1

Flow rates till 2400 days were cut off. The training will be conducted between 2400-4000days. The prediction will perform step by step. Before starting the process, KD-21 and KD-24 injection rates will assume constant. Step one, we will assume these two injectors the injection rates constant that it is same injection rate for last 50 days Figure 15, 16.

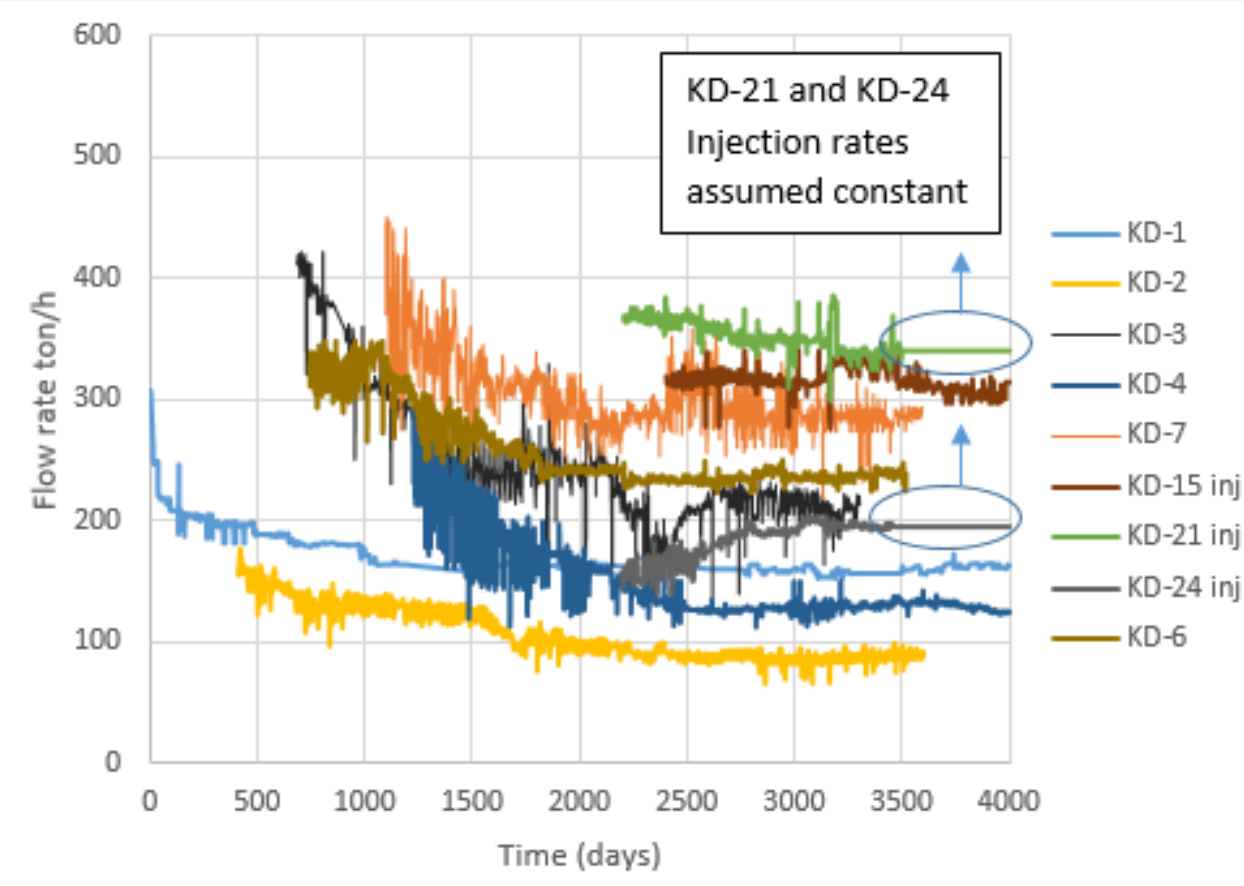

Figure $15 \mathrm{Kd}-21$ Well injection rates subjected to $340 \mathrm{ton} / \mathrm{hr}$.

Step two will be forecasting of Kd-3 well Figure 17. For step two, all wells were trained between 2403- 3520 (days), and KD-3 well future production forecasted Figure 17, 18.

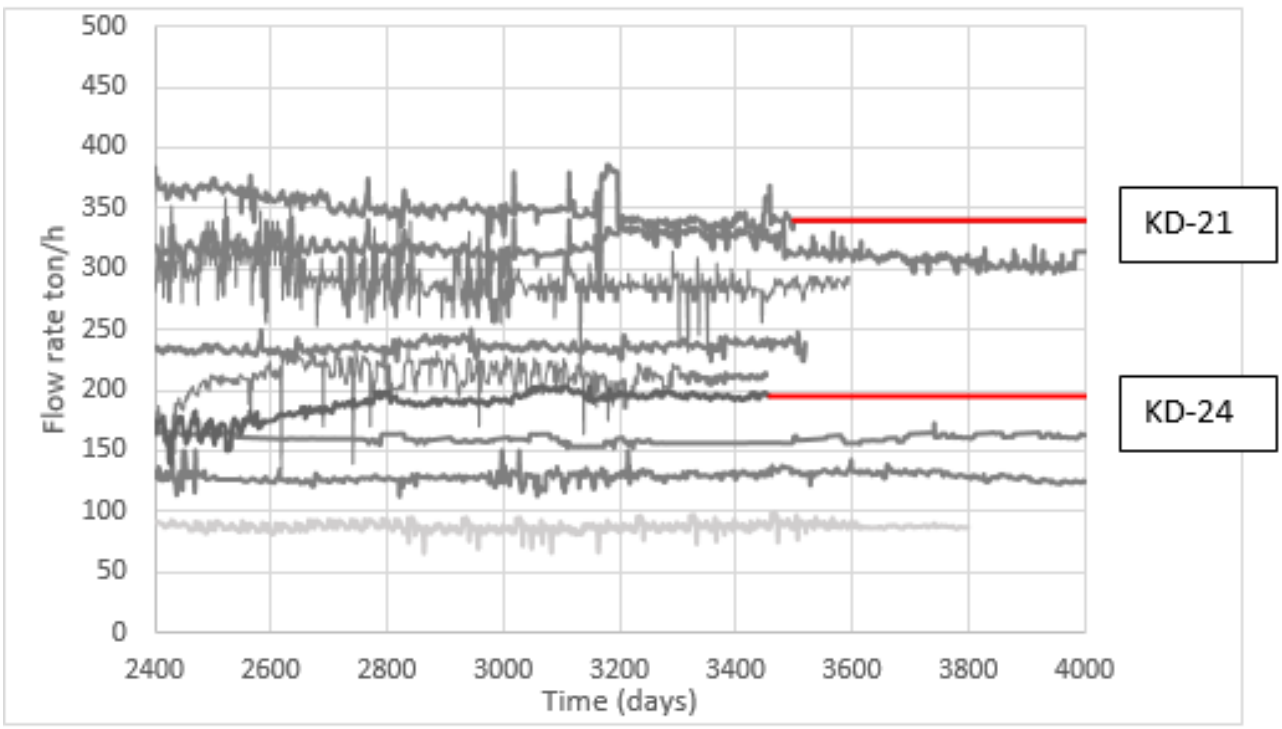

Figure 16. Flow Rates of All Wells KD-21 and Kd-24 Injection Wells Assumed Constant Flow Rate 


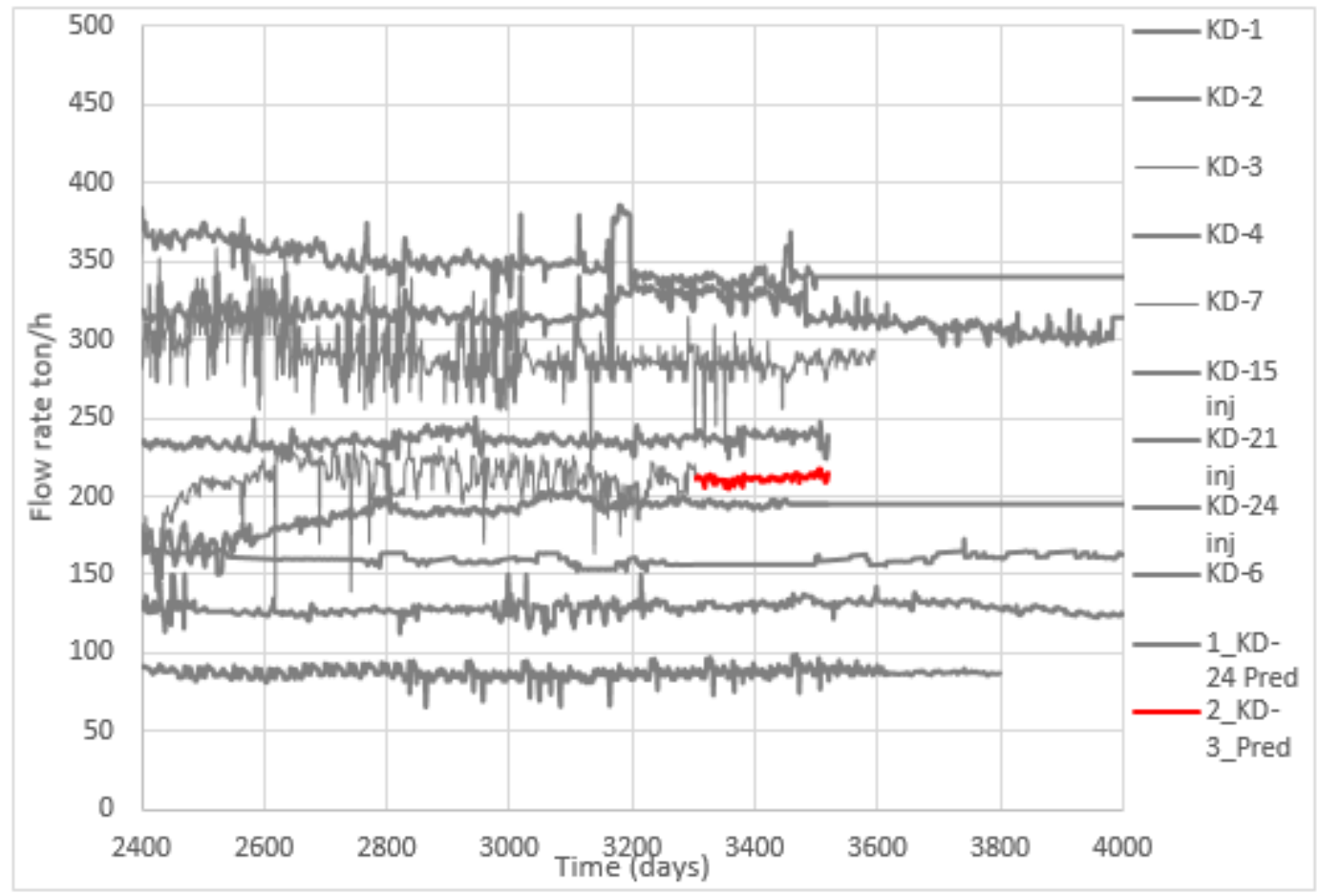

Figure 17. Kd-3 Well Prediction

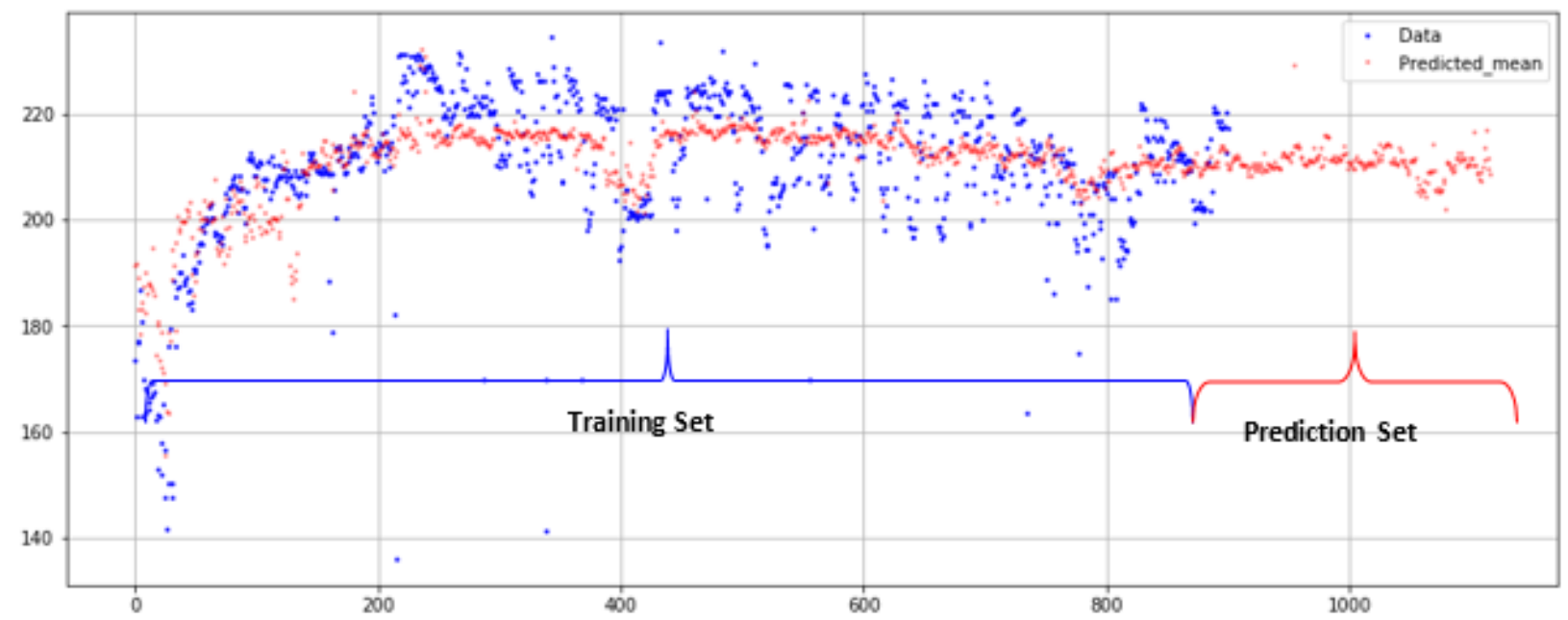

Figure 18. Step one Kd-3 Well Future Prediction (Flow Rates ton/hr. vs. Time days)

For step three, wells 1, 2, 4, 15, 21, 24 are trained between 2403-4001 (days), and KD-2 well is predicted. Figure 19, 20. 


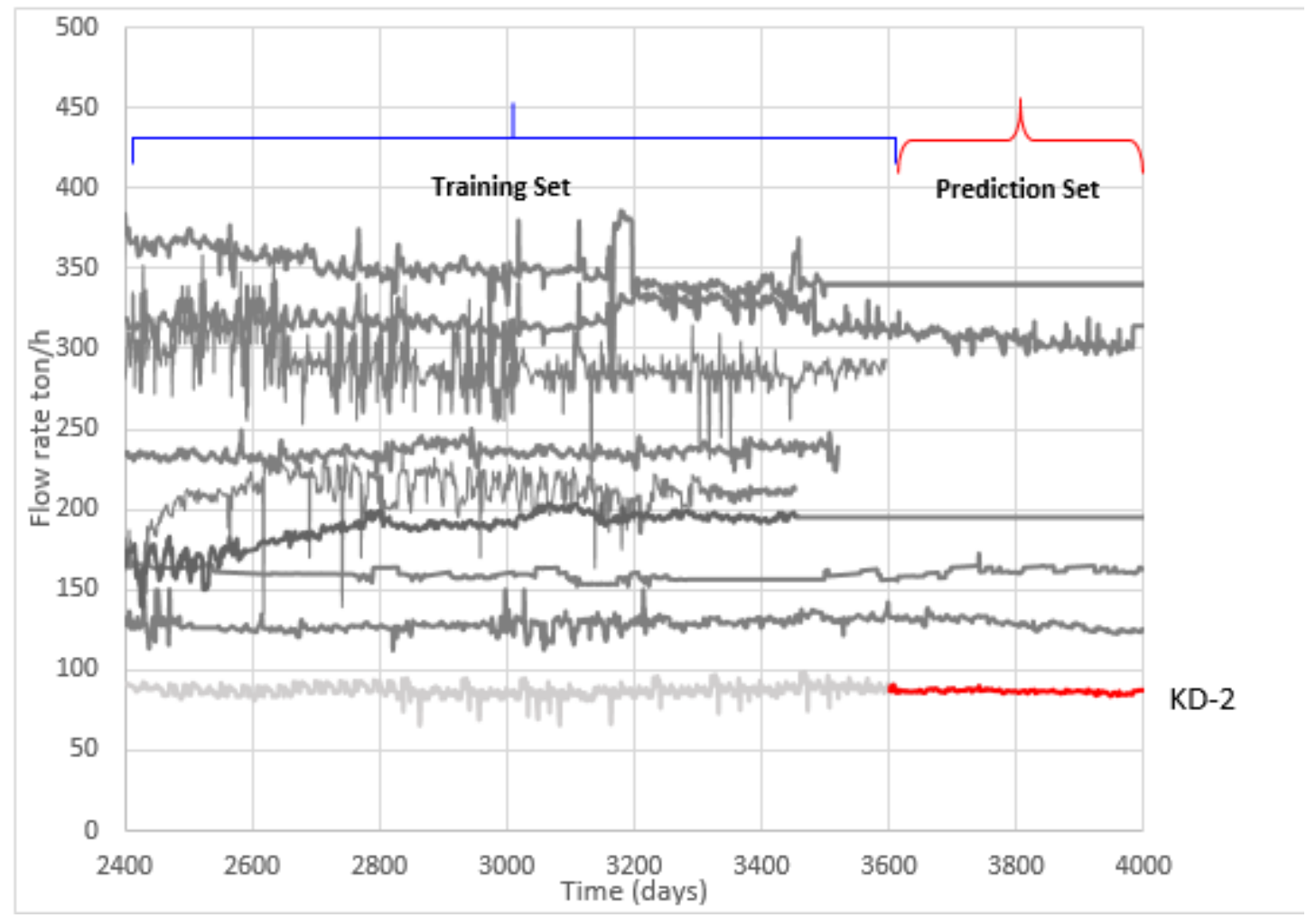

Figure 19. KD-2 Well Future Production (Flow Rates ton/hr. vs. Time days)

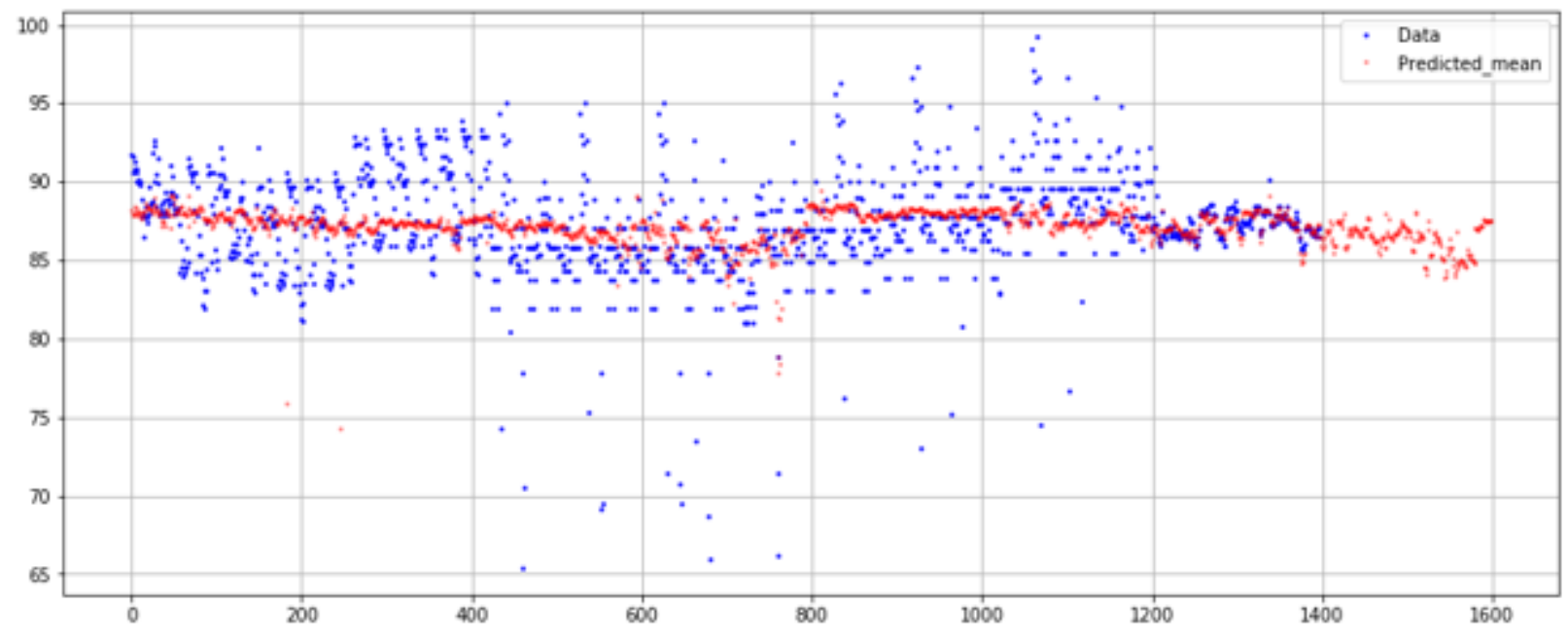

Figure 20. KD-2 Well Training and Future Prediction (Flow Rates ton/hr. vs. Time days)

Step four, to predict KD-7 well future forecasting, wells 1, 2, 4, 7, 15, 21, 24 are trained between 2403-4001 (days), and KD-7 well future flow rates are predicted. Figure 21, 22. 


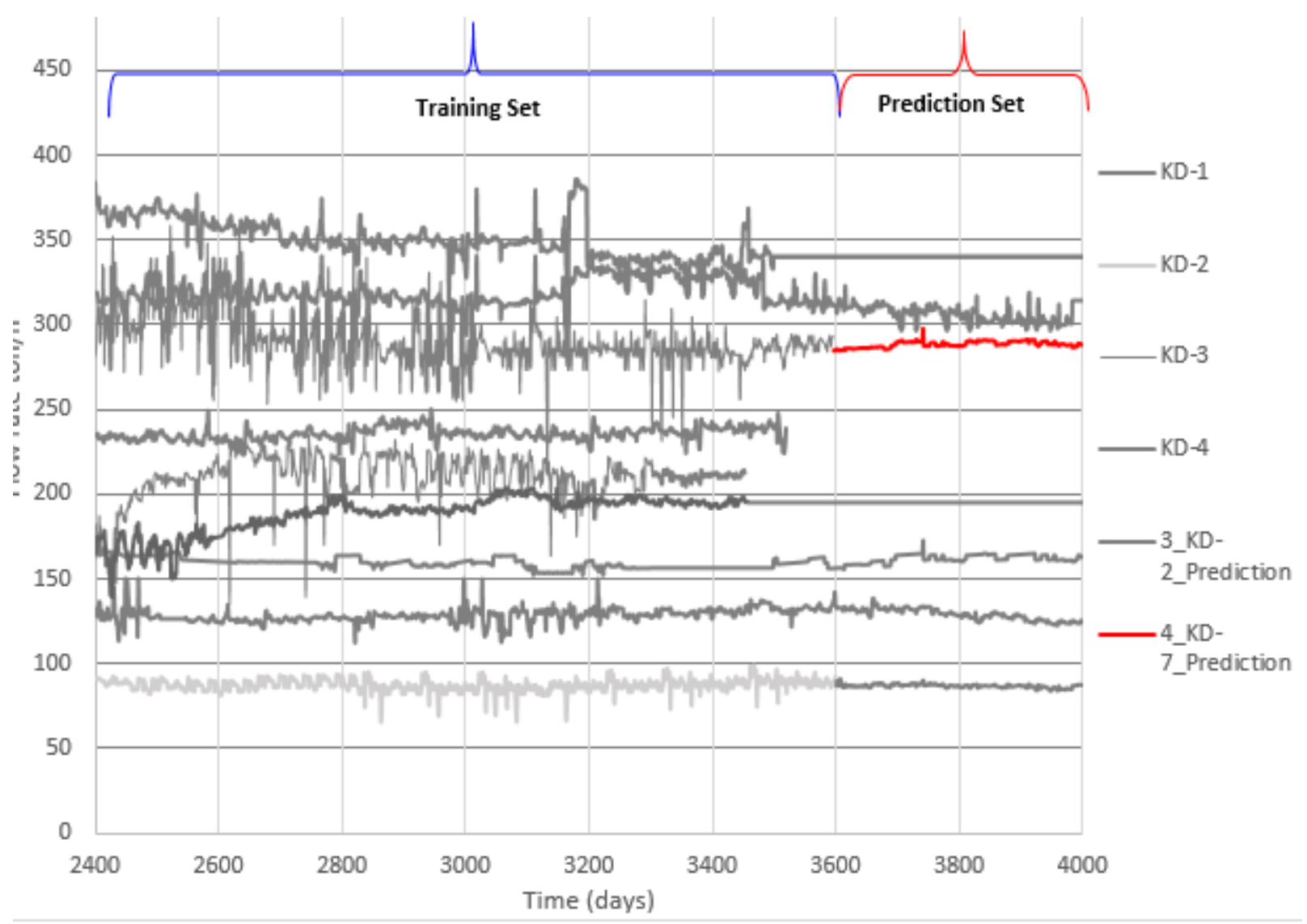

Figure 21. KD-7 Well Future Prediction (Flow Rates ton/hr. vs. Time days)

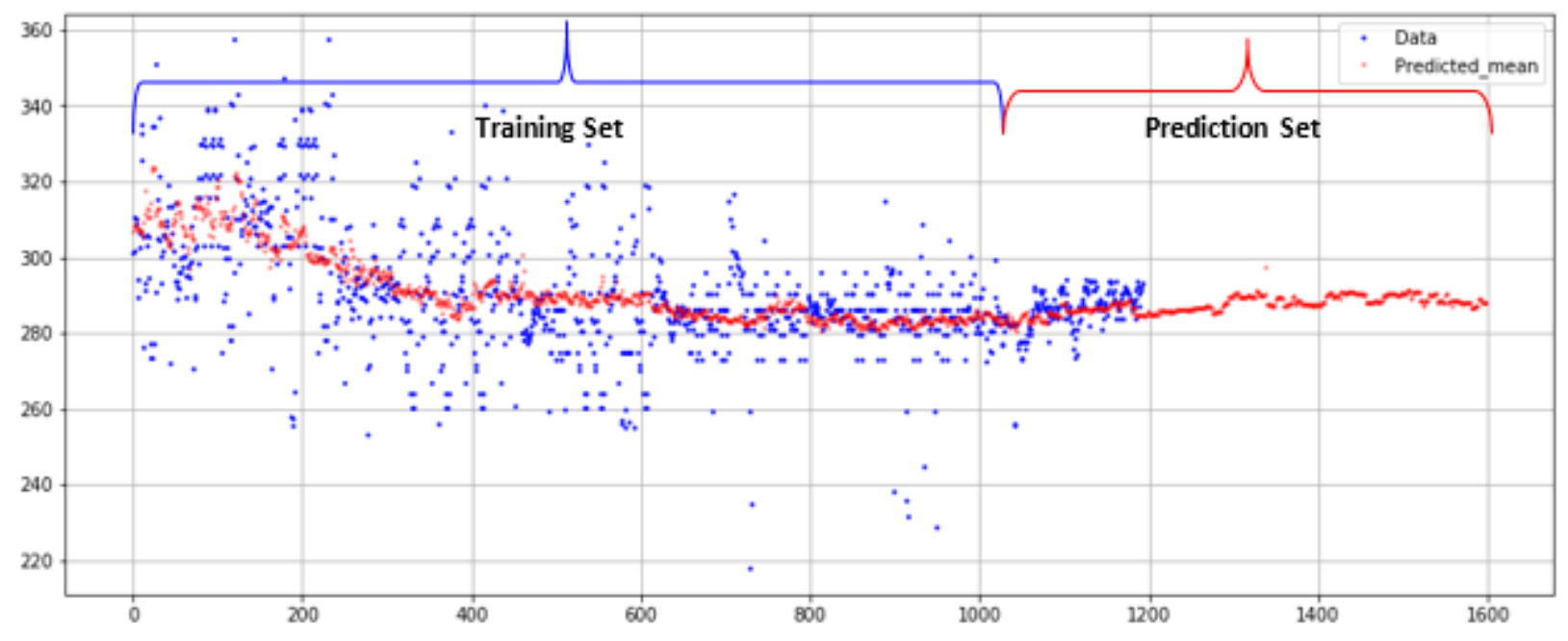

Figure 22. Kd-7 Well Training and Future Prediction (Flow Rates ton/hr. vs. Time days)

Step Five, wells 1, 2, 4, 7, 15, 21, 24, 6 are trained between 2403-4001 (days), and KD-6 future production predicted. Figure 23, 24. 


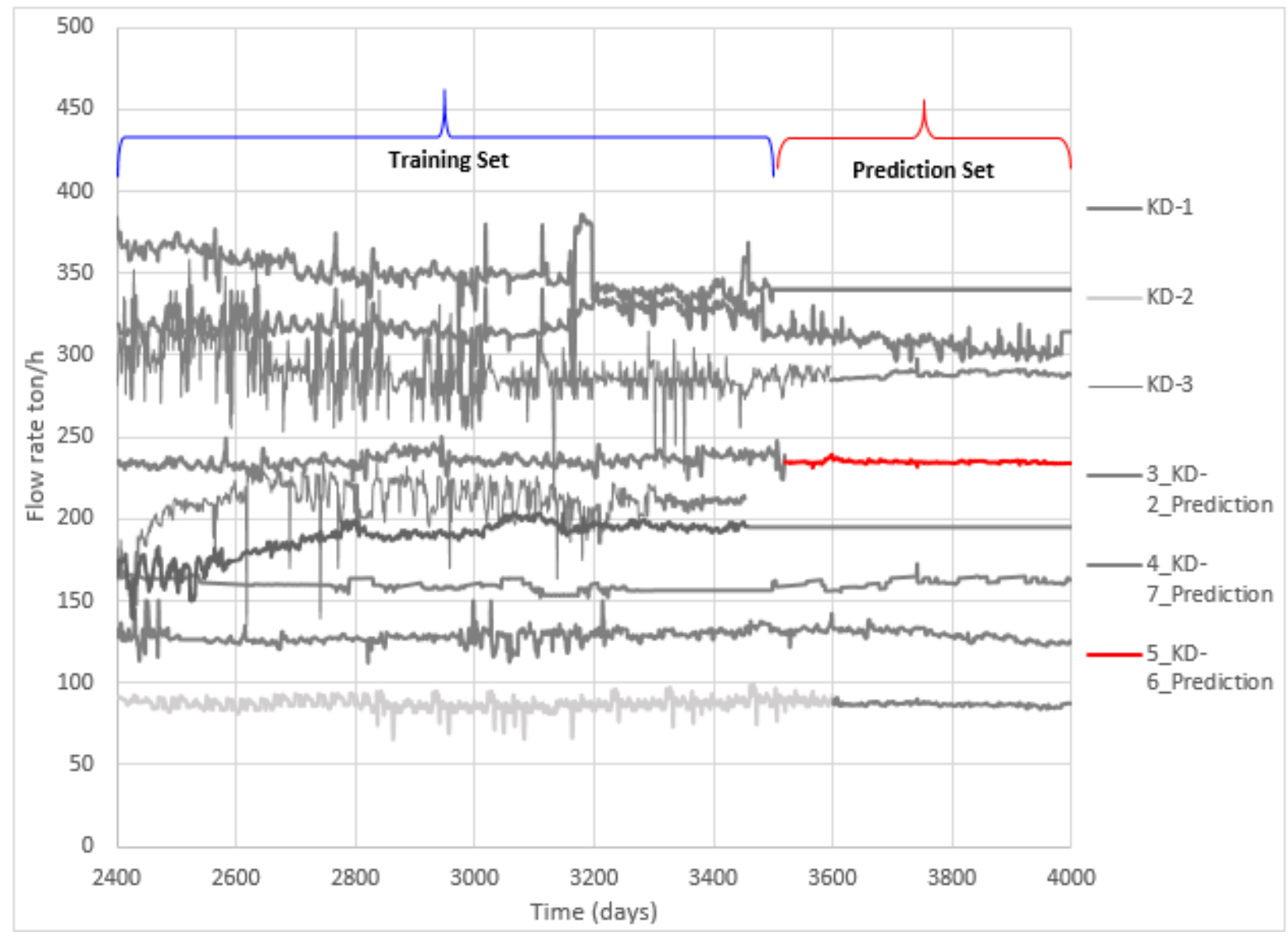

Figure 23. Kd-6 Future Prediction

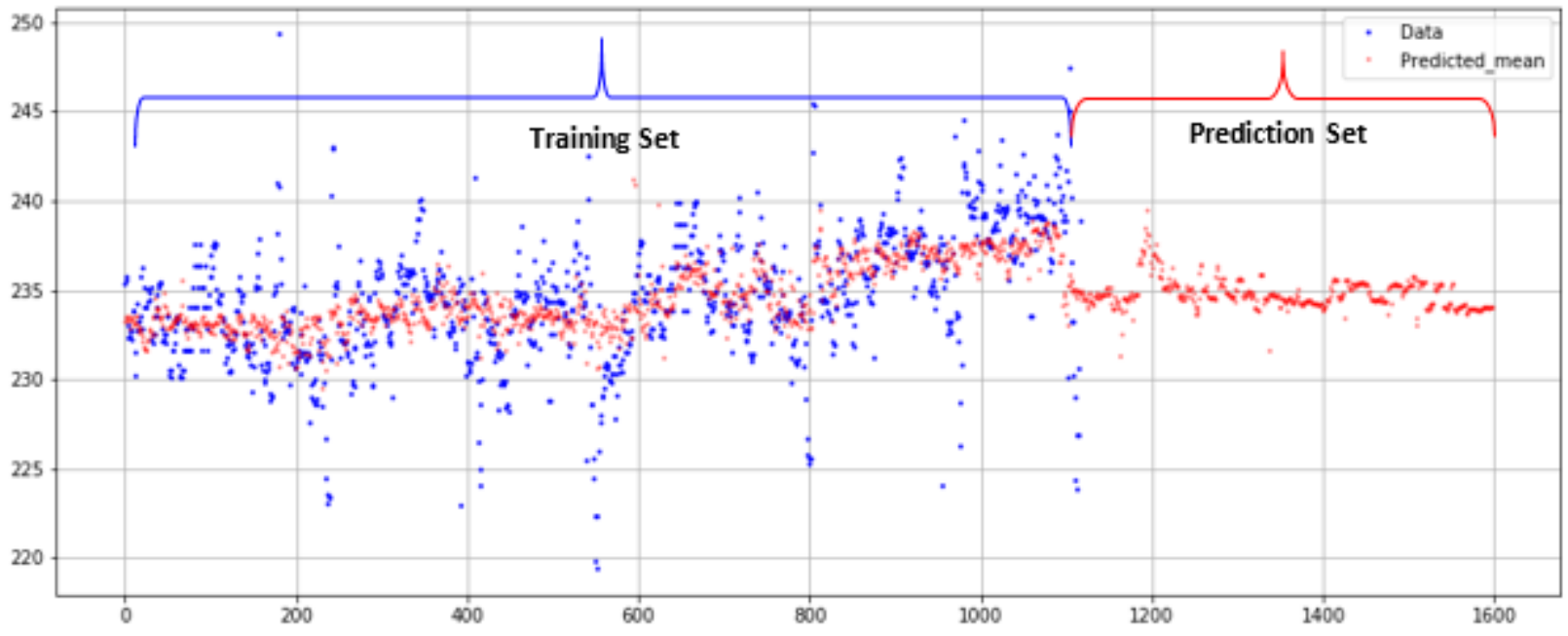

Figure 24. KD-6 Well Training and Future Prediction (Flow Rates ton/hr. vs. Time days) 
For six step, last step, all wells are trained between 2403-4001 (days), KD-3 well' future production is predicted. Figure 25, 26.

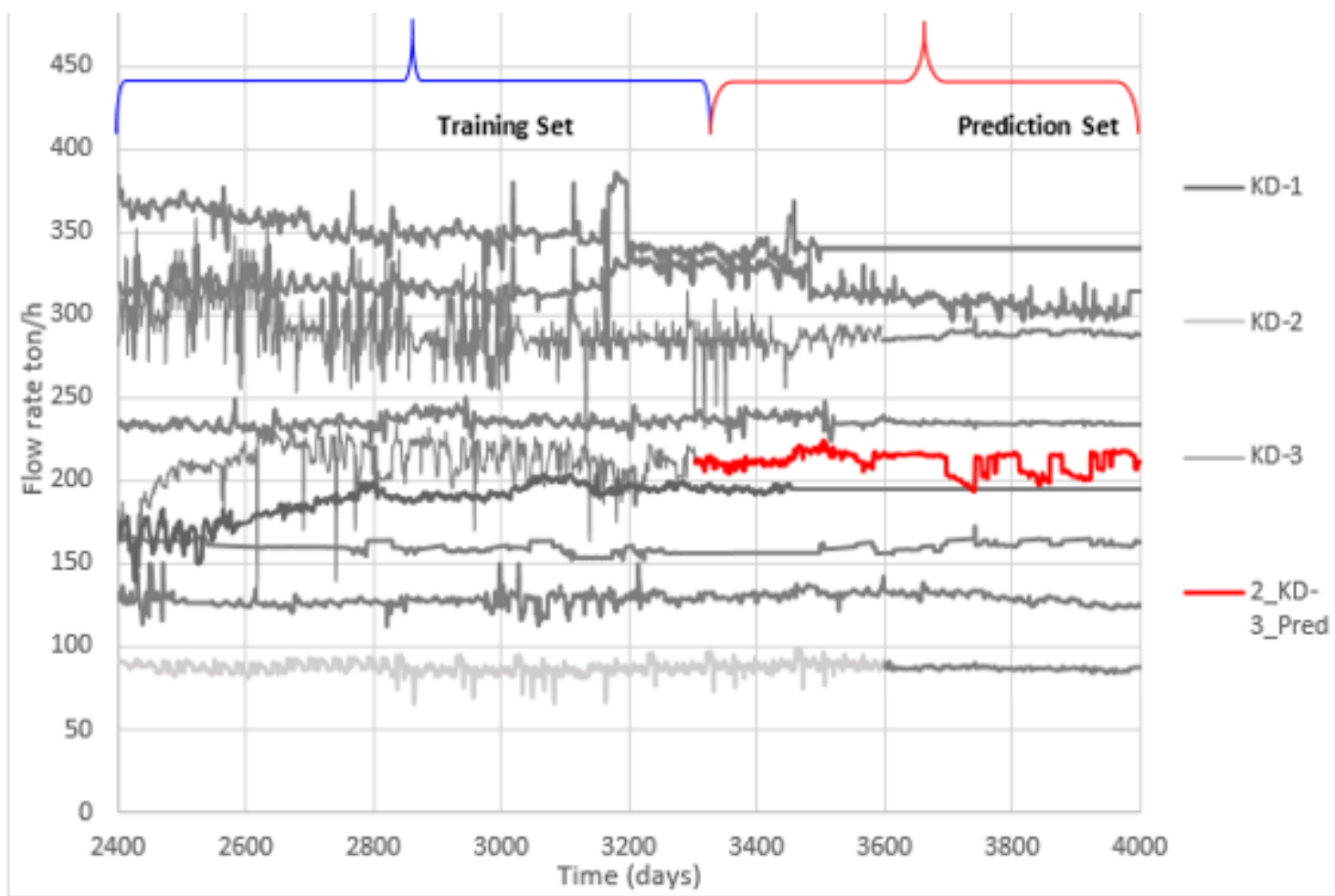

Figure 25. KD-3 Well Prediction

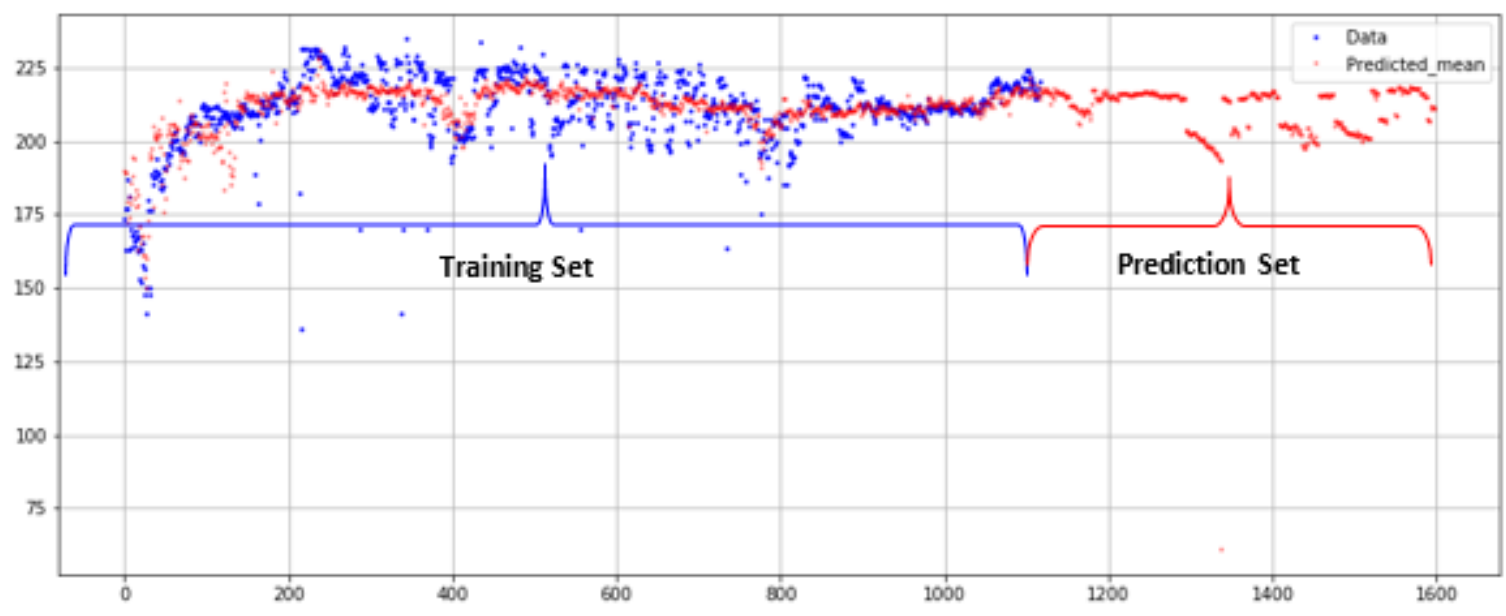

Figure 26. KD-3 Training and Future Prediction (Flow Rates ton/hr. vs. Time days)

Scenario 2

Flow rates till 2400 days were cut off. Training will be conducted between 2400-4000days. The prediction will perform step by step. Before starting the process, KD-21 and KD-24 injection rates will increase to $380 \mathrm{ton} / \mathrm{hr}$. and $230 \mathrm{ton} / \mathrm{hr}$. respectively. The same following process will be 
conducted to see future forecasting. Figure 27. Scenario-2 future forecasting for well is displayed on Figure 28. All chart for each step are displayed in the Appendix section.

As it was performed at scenario one, same procedure will be followed. The training part will start from day 2400 when the last injector started fluid injection till day 4000. Firstly, the model will train between 3520 and 4000 to predict KD-3 well Figure 31, 32. For step two, all wells were trained between 2403- 3520 (days), and KD-3 well future production forecasted. Figure 32, 33.

For step three, wells 1, 2, 4, 15, 21, 24 are trained between 2403-4001 (days), and KD-2 well is predicted. Figure 34, 35.

Step four, to predict KD-7 well future forecasting, wells 1, 2, 4, 7, 15, 21, 24 are trained between 2403-4001 (days), and KD-7 well future flow rates are predicted Figure 36, 37.

Step Five, wells 1, 2, 4, 7, 15, 21, 24, 6 are trained between 2403-4001 (days), and KD-6 future production predicted. Figure 37, 38.

For six step, last step, all wells are trained between 2403-4001 (days), KD-3 well future production is predicted Figure 39, 40.

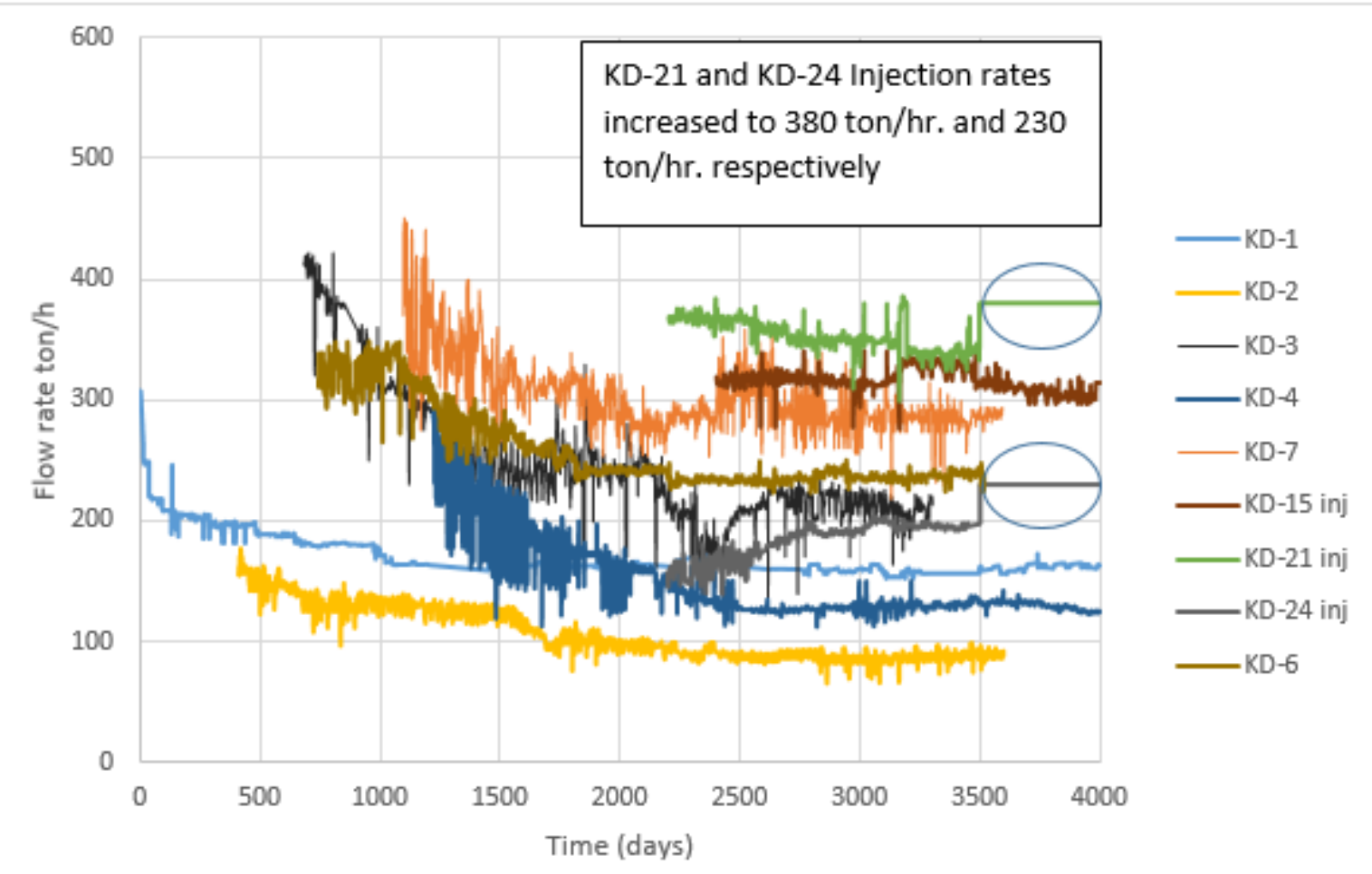

Figure 27. Flow rates vs. Time including All Wells. KD-21 and KD-24 Adjusted Flow Rates 


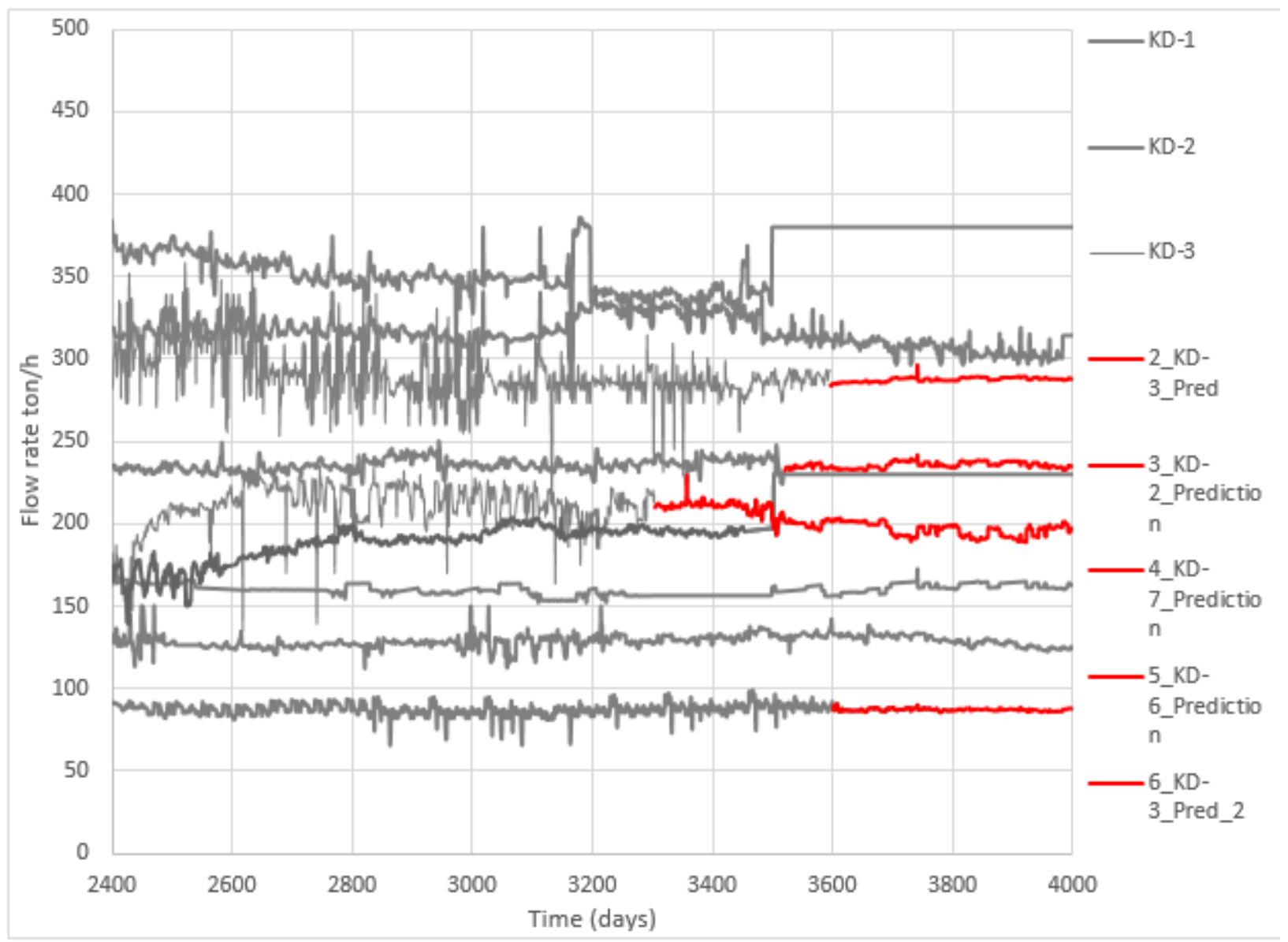

Figure 28. Scenario 2 Prediction

\section{Scenario 3}

As it was performed at scenario one and two, same steps will be followed. The training part will start from day 2400 when the last injector started fluid injection till day 4000. Firstly, the model will train between 3520 and 4000 to predict KD-3 well. Step one, we will assume these two injectors the injection rates constant that it is same injection rate for last 500 days Figure 29. Step two will be forecasting of KD-3 well Figure 30. For step two, all wells were trained between 2403- 3520 (days), and KD-3 well future production forecasted Figure 39, 40. For step three, wells 1, 2, 4, 15, 21, 24 are trained between 2403-4001 (days), and KD-2 well is predicted. Figure 41, 42. Step four, to predict KD-7 well future forecasting, wells 1, 2, 4, 7, 15, 21, 24 are trained between 2403-4001 (days), and KD7 well future flow rates are predicted. Figure 43, 44. Step Five, wells 1, 2, 4, 7, 15, 21, 24,6 are trained between 2403-4001 (days), and KD-6 future production predicted. Figure 45, 46. For six step, last step, all wells are trained between 2403-4001 (days), KD-3 well future production is predicted. Figure 47, 48.

\section{All charts for each step are displayed in the Appendix section.}




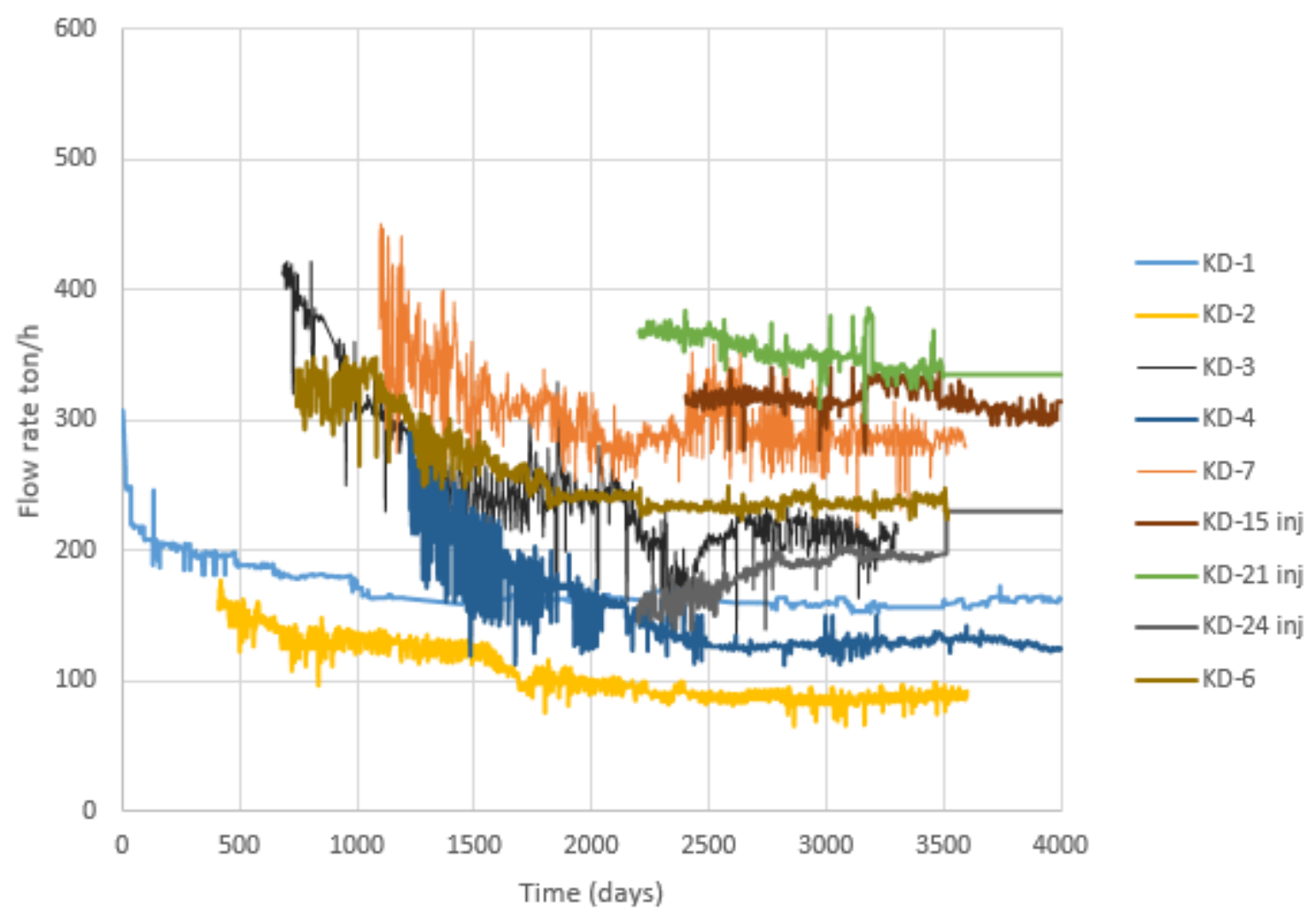

Figure 29. Scenario 3 Injectors Assumed Flow Rates

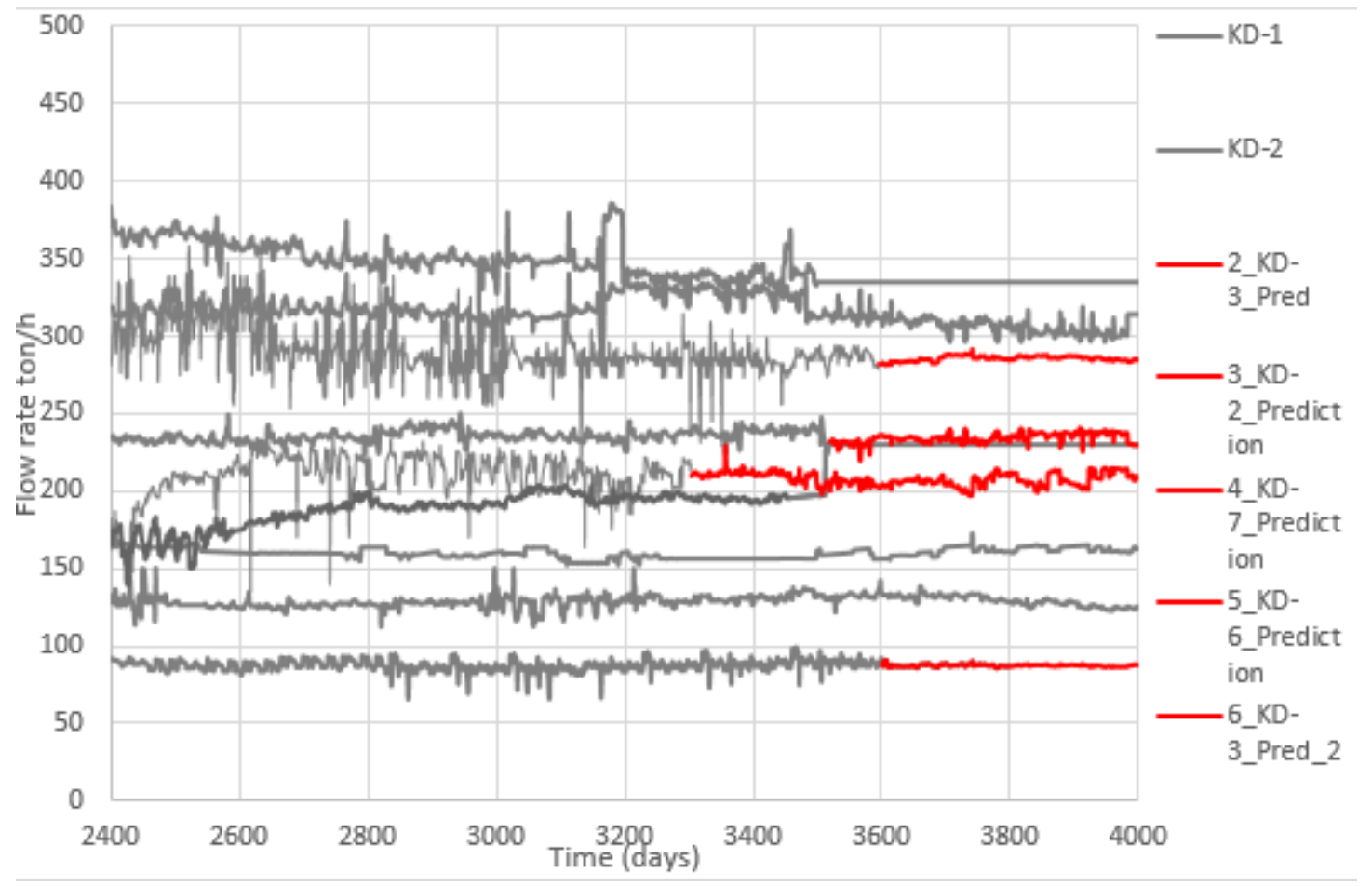

Figure 30. Predicted Future Flow Rates 
Future production forecasting has been completed based on different scenarios. Future production flow rates are as following table. According to the all scenarios have almost same production rates, However Scenario 1 has the lowest injection rates versus maximum flow rates. Future flow rates have been taken as last 50 days of production for each well Table 6.

\begin{tabular}{|c|c|c|c|c|c|c|c|c|}
\hline \multicolumn{3}{|c|}{ Scenario 1} & \multicolumn{3}{|c|}{ Scenario 2} & \multicolumn{3}{|c|}{ Scenario 3} \\
\hline $\begin{array}{l}\text { Well } \\
\text { Type }\end{array}$ & $\begin{array}{c}\text { Well } \\
\text { No }\end{array}$ & ton $/ \mathrm{hr}$. & $\begin{array}{l}\text { Well } \\
\text { Type }\end{array}$ & $\begin{array}{c}\text { Well } \\
\text { No }\end{array}$ & ton $/ \mathrm{hr}$. & $\begin{array}{l}\text { Well } \\
\text { Type }\end{array}$ & $\begin{array}{c}\text { Well } \\
\text { No }\end{array}$ & ton $/ \mathrm{hr}$. \\
\hline Injector & KD-15 & 310 & Injector & KD-15 & 310 & Injector & KD-15 & 310 \\
\hline Injector & KD-21 & 340 & Injector & KD-21 & 380 & Injector & KD-21 & 340 \\
\hline Injector & KD-24 & 195 & Injector & KD-24 & 230 & Injector & KD-24 & 230 \\
\hline Producer & KD-1 & 162 & Producer & KD-1 & 161 & Producer & KD-1 & 161 \\
\hline Producer & KD-2 & 87 & Producer & KD-2 & 87 & Producer & KD-2 & 87 \\
\hline Producer & KD-3 & 216 & Producer & KD-3 & 198 & Producer & KD-3 & 211 \\
\hline Producer & KD-4 & 124 & Producer & KD-4 & 124 & Producer & KD-4 & 123 \\
\hline Producer & KD-6 & 234 & Producer & KD-6 & 234 & Producer & KD-6 & 233 \\
\hline Producer & KD-7 & 293 & Producer & KD-7 & 287 & Producer & KD-7 & 285 \\
\hline \multicolumn{2}{|c|}{ Total Injection } & 845 & \multicolumn{2}{|c|}{ Total Injection } & 920 & \multicolumn{2}{|c|}{ Total Injection } & 880 \\
\hline \multicolumn{2}{|c|}{ Total Production } & 1116 & \multicolumn{2}{|c|}{ Total Production } & 1091 & \multicolumn{2}{|c|}{ Total Production } & 1100 \\
\hline
\end{tabular}

\section{Summary/Discussions}

Conventional reservoir models to predict future prediction might be challenge due to various reasons. Existence of condensable and non-condensable gases in the field, sometimes unknown reservoir boundary, non-isothermal fluid flow makes the problem very complicated. There are many uncertainties that can affect the results directly. To solve these problems would cost of money, time or both. Nevertheless, there might be many uncertainness, the fact that only certain data would be from field measurements. The field measurement is the outcome with all certain and uncertain parameters. Instead of using conventional methods for prediction, Artificial Intelligence is a good solution using based on field measurements of the geothermal wells with huge dataset in a very short time.

Machine Learning ML integrates all available field measurements, such as production and injection history to have comprehensive full-field reservoir modeling using machine learning and pattern recognition. For this study, we conducted the supervised learning. To aim of this study has two concepts. First, missing data prediction: the data provided from geothermal field has missing flow rates for some wells, however well-head pressure, well-head temperature, flow rates, valve positions, bottom-hole pressures are provided. By using these parameters, missing flow rates forecasted by ML supervised learning method. Second, the field has both production and injection wells, upon completing missing flow rates, future prediction of the flow rates of the production wells were forecasted.

As it can be seen from Figure 13, for some wells' first 500-600 days the flow rates are fluctuated. There might some reasons; upon completing wells, short- and long-term production and injection tests are performed which it may take up to 120 days. During the test, wells are subject to shut-in, open and changing flow rates. This test might conduct one or more than one times. Secondly, 
during the power installation or after completing power plant instalment, some tests are applied, therefore, the wells might subject to shut-in, open or changing valve position. Furthermore, there might have some problems during the electric generation for instance, power failure on electricity pylon, transmission tower etc. in such cases, power plant might stop working, or power plants work under capacity, thus the well might subject to shut-in which can take days or weeks, or limited production and injection scenarios. Moreover, the injection pump failures might affect the production and injection or selecting inaccurate capacity of injector pumps will occur inefficiency production.

The first aim of this project was completing missing flow rates. Mostly, missing flow rates predicted based on the available field data such as flow rates, well-head pressure, and temperature etc. For future prediction since such data are not available, only production and injection flow rates were used. The injection wells flow rates can be changed manually. During the operating the power plants, injected amount of fluid can be operated. For future flow production forecasting, some scenarios have been created, and different injection rates effect for predicted flow rates are evaluated. The maximum injection amount of fluid can be only produced amount of fluid. Sometimes it is possible to inject all effluent brine into the injection's wells, but sometimes it might be challenge due to low capability of injectivity of the wells or, low capacity of pumps. These two parameters should be known such the maximum volume of fluid versus maximum pressure that the pump can inject to the well. The maximum injection pressure values for the pumps is also a limitation for injection wells. If the maximum pressure capacity of the pumps knows, it also possible to predict the maximum flow rate that the pumps can operate for the injectors. AI might be a good solution to estimate maximum flow rates that can be inject to the wells using field measurements. Injection wells mostly have well-head pressure, injection pump pressures, and flow rates. These parameters can be trained, and maximum injection flow rates can be predicted with the maximum pressure values that the pump can inject. For the second part of the project, while anticipating KD-21 and KD-24 injection flow rates for future prediction, the maximum flow rates that the pumps can inject (KD-21 well 380 ton/hr., KD24 Well 230 ton/hr.) have been taken into consideration. According to the different scenarios models; while KD-21 and KD-24 injection wells support production wells (K-plot depicts correlation between the injectors and producers) KD-15 Injector well supports mostly KD-21 and KD-24 wells. The amount of injected effluence brine of KD-15 well can allocate between KD-21 and KD-24 if these two wells have enough injectivity capability, and the pumps have enough capacity to inject, or a new injection well can be opened. Accurately predicted production and injection rates will provide operating the power plants efficiently, and it will prevent from intermittent energy generating.

In the result section, future production and injection scenarios have been performed. All scenarios indicate that total production amounts are almost equal, whereas scenario 1 has the lowest injection rate. Unfortunately, entire amount of disposal brine cannot pump into the injectors due to insufficient capacity of the injectors. A new injector can drill into reservoir layers or current injector pumps can replace with the higher capacity pumps.

\section{References}

[1]. I.B Fridleifsson. Geothermal; energy for the benefit of the people

Renewable and Sustainable Energy Reviews

Volume 5, Issue 3, September 2001, Pages 299-312 
[2] Sonja L. Philipp, Agust Gudmundsson, Asdis R.I. Oelrich. How structural geology can contribute to make geothermal projects successful.

Geoscience Centre, University of Göttingen, Goldschmidtstr. 3, 37077 Göttingen, Germany [3] Stauffer, D. and Aharony, A.: Introduction to Percolation Theory. Taylor and Francis, London (1994)

[4]. Mohaghegh, S.: Data-Driven Reservoir Modeling

2017, Textbook, ISBN: 978-1-61399-560-0, Society of Petroleum Engineers

[5]. D.E. Rumelhart, G.E. Hinton, R.J. Williams

Learning representations by back-propagating errors

Nature, 323 (1986), pp. 533-536

[6]. Haykin, S.S., 1994. Neural Networks- A Comprehensive Foundation. Prentice-Hall

International, London, $842 \mathrm{pp}$

[7]. Lashari, Shan-e-Z., Application of Artificial Intelligence (AI) in Petroleum Engineering Problems, West Virginia University, Master' Thesis, 2018 
Appendix

Scenario 2

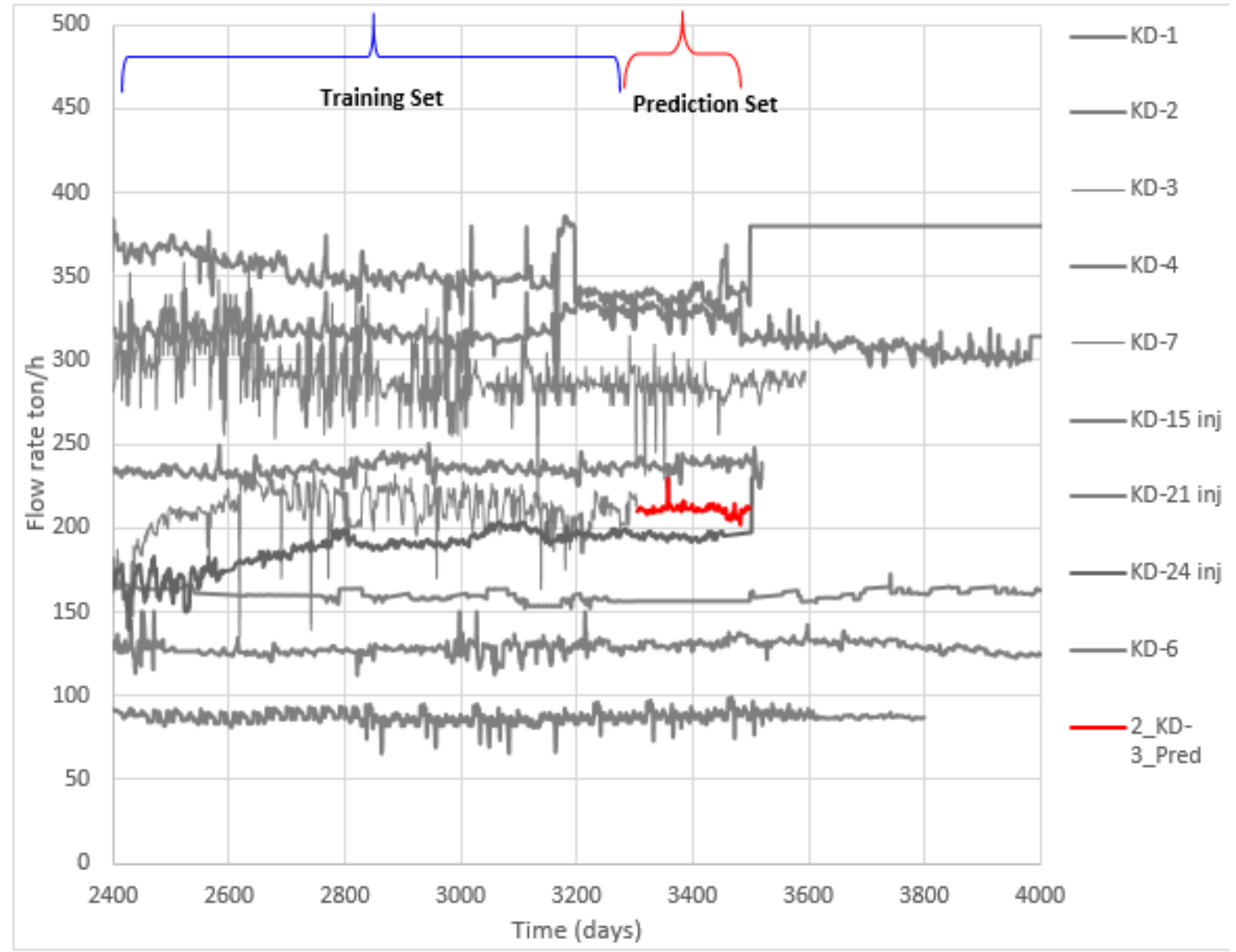

Figure 31. KD-3 Well Future Prediction

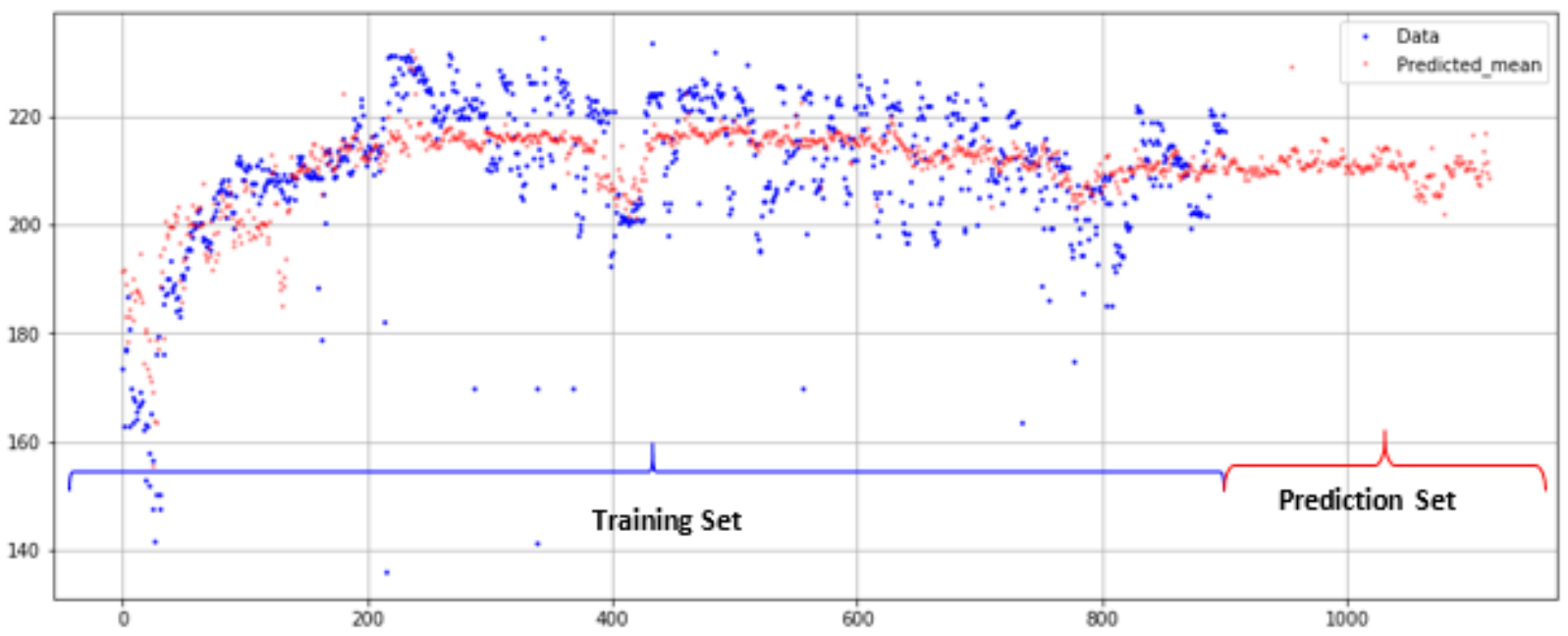

Figure 32. KD-3 Well Training and Future Prediction 


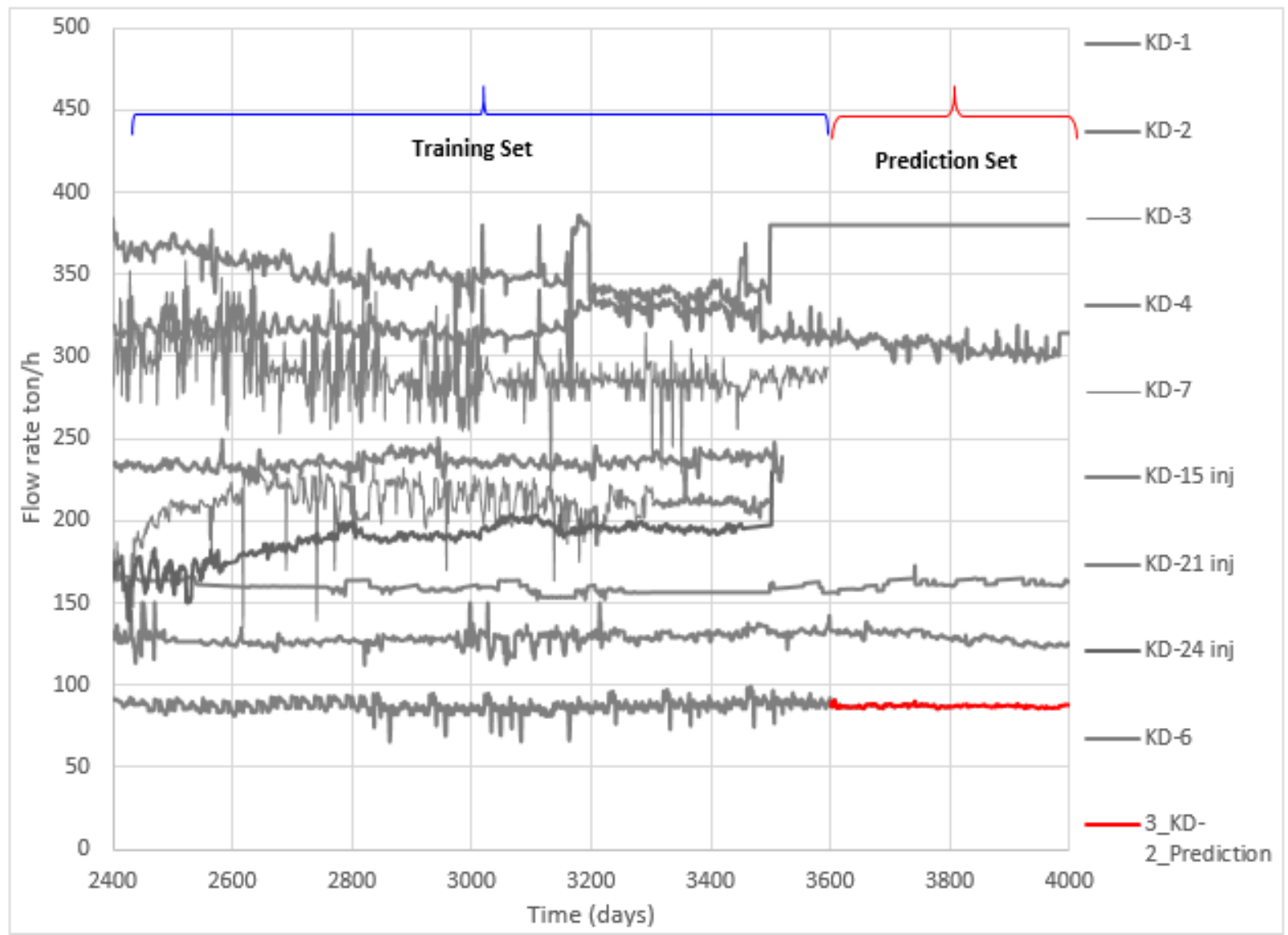

Figure 33. KD-2 Well Future Prediction

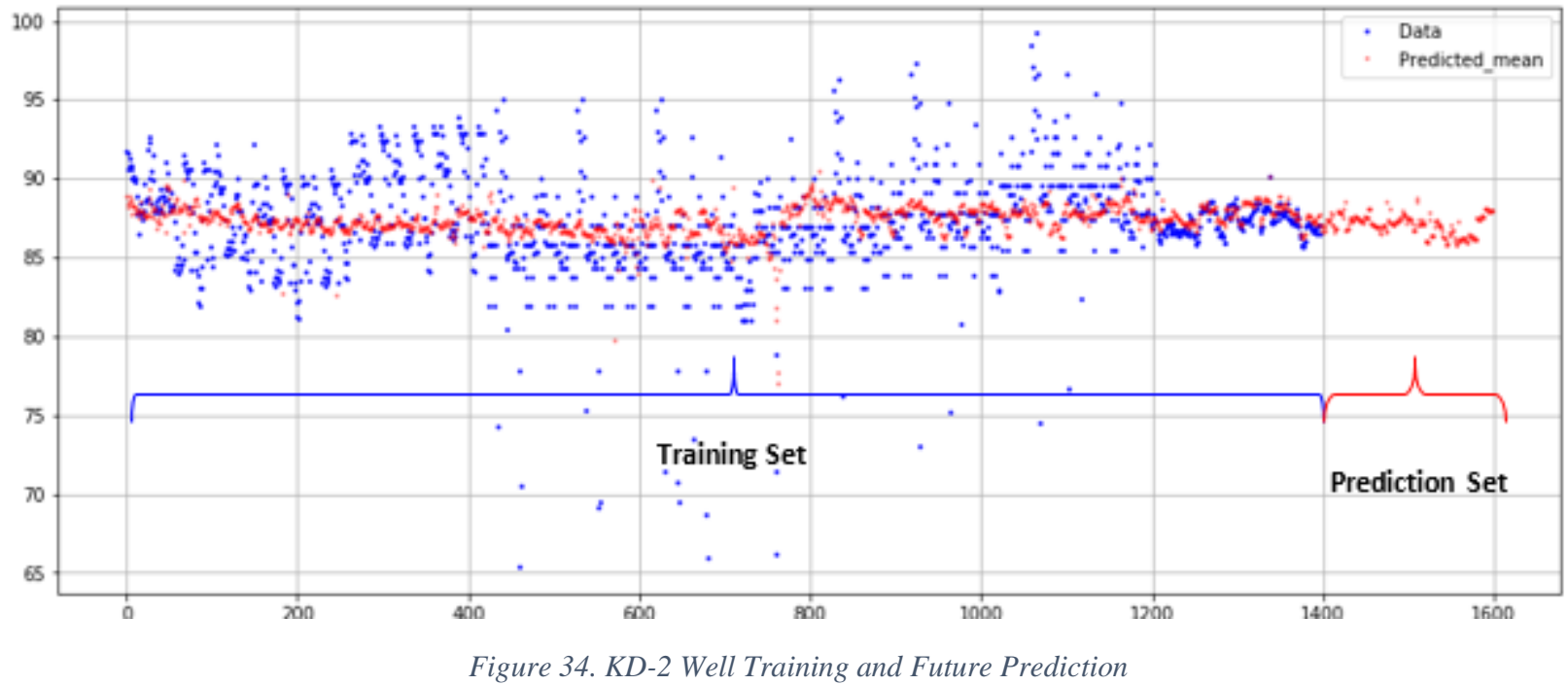




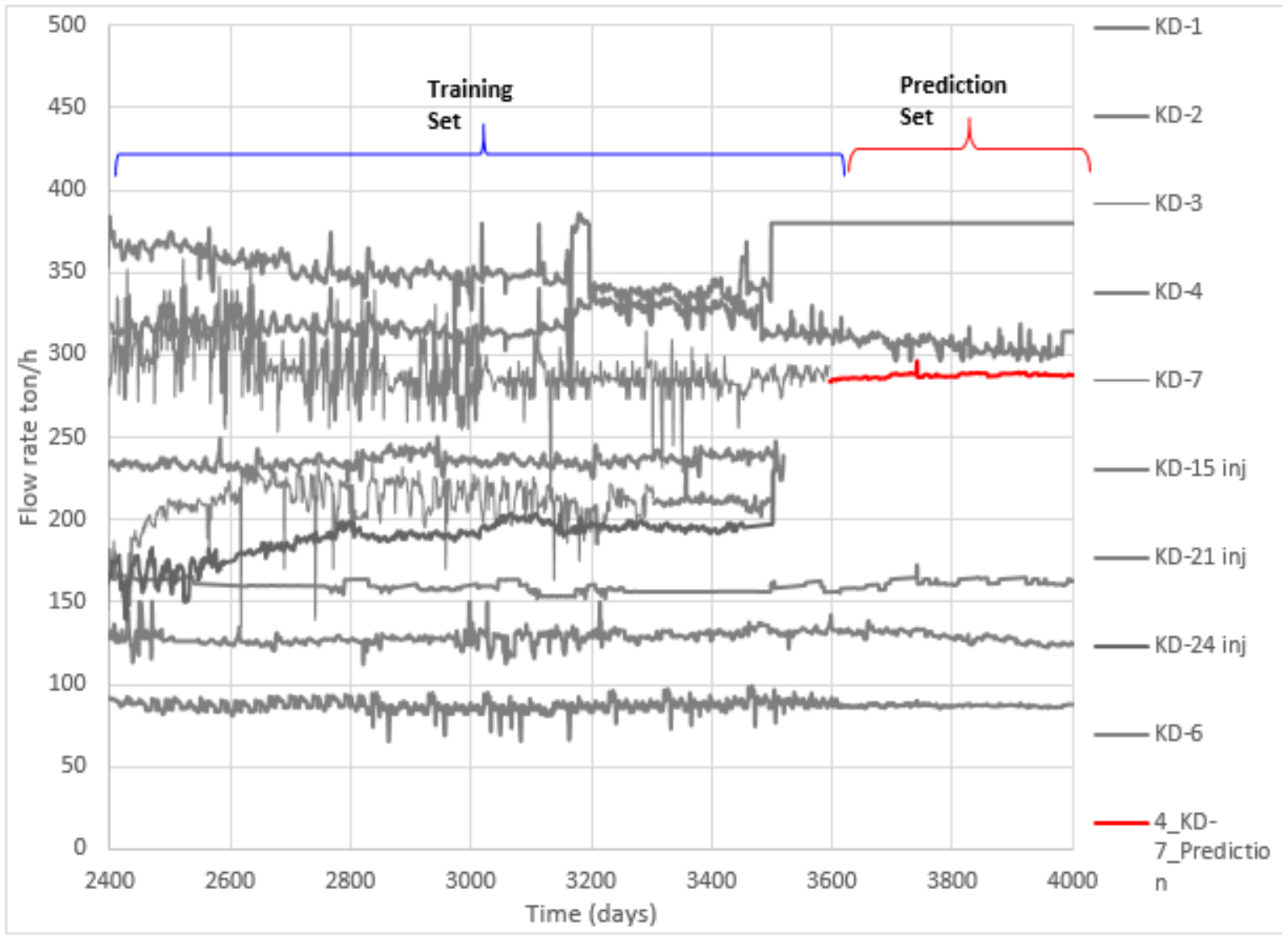

Figure 35. KD-7 Well Future Prediction

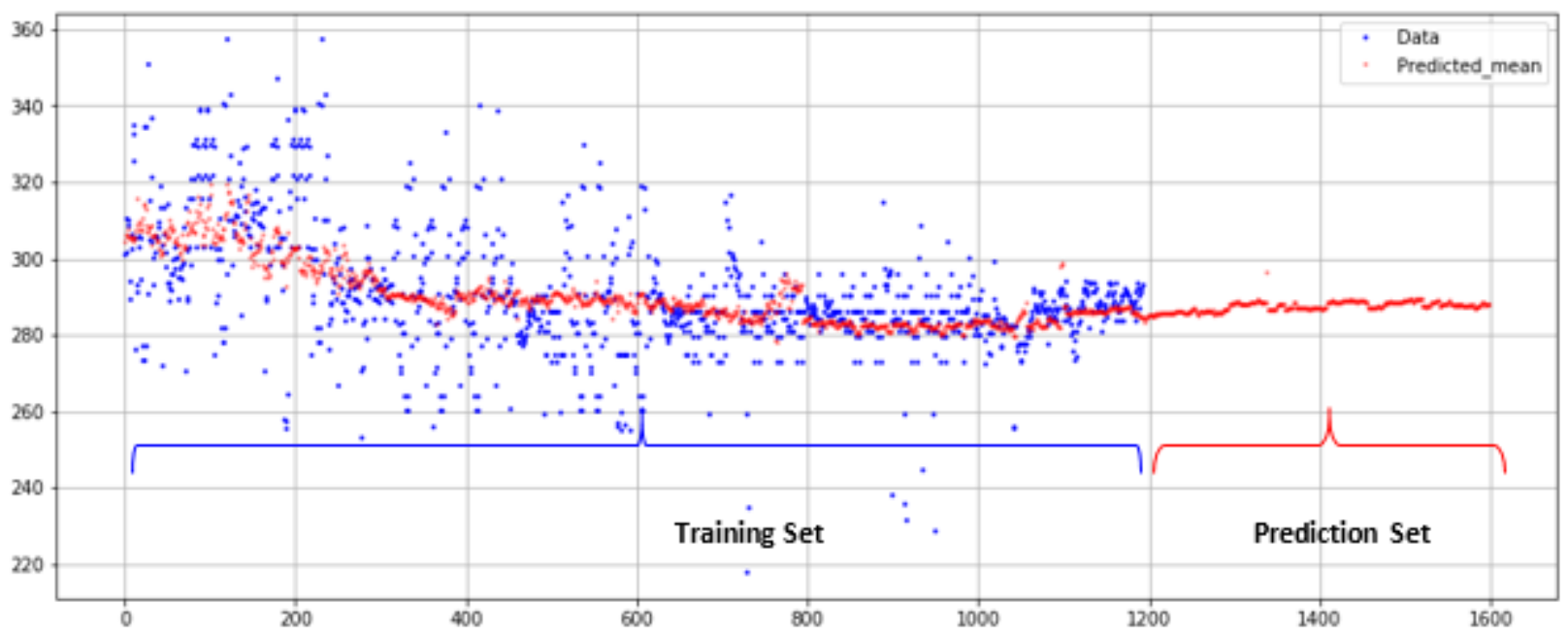

Figure 36. KD-7 Well Training and Future Prediction 


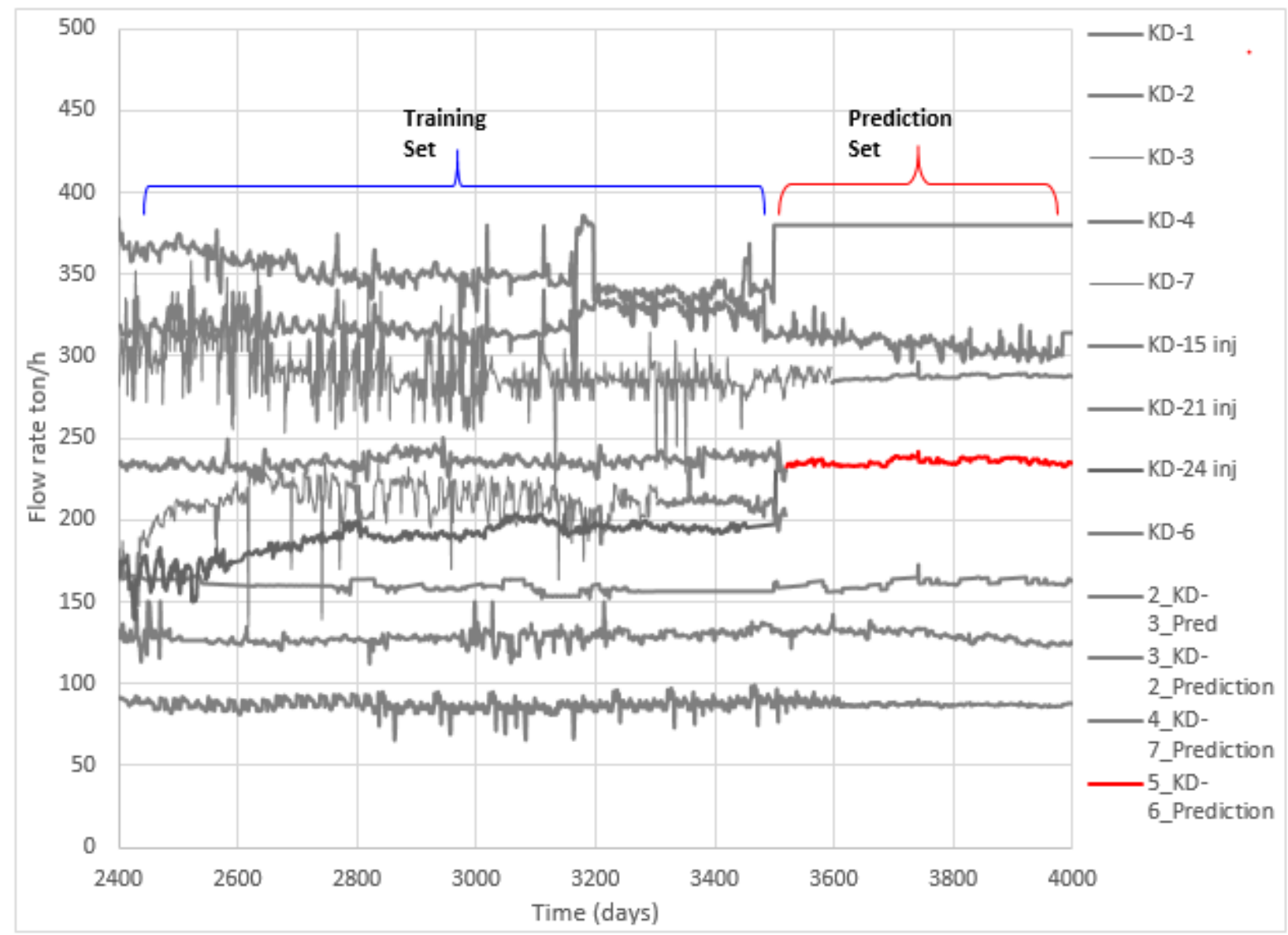

Figure 37. KD-6 Well Future Prediction

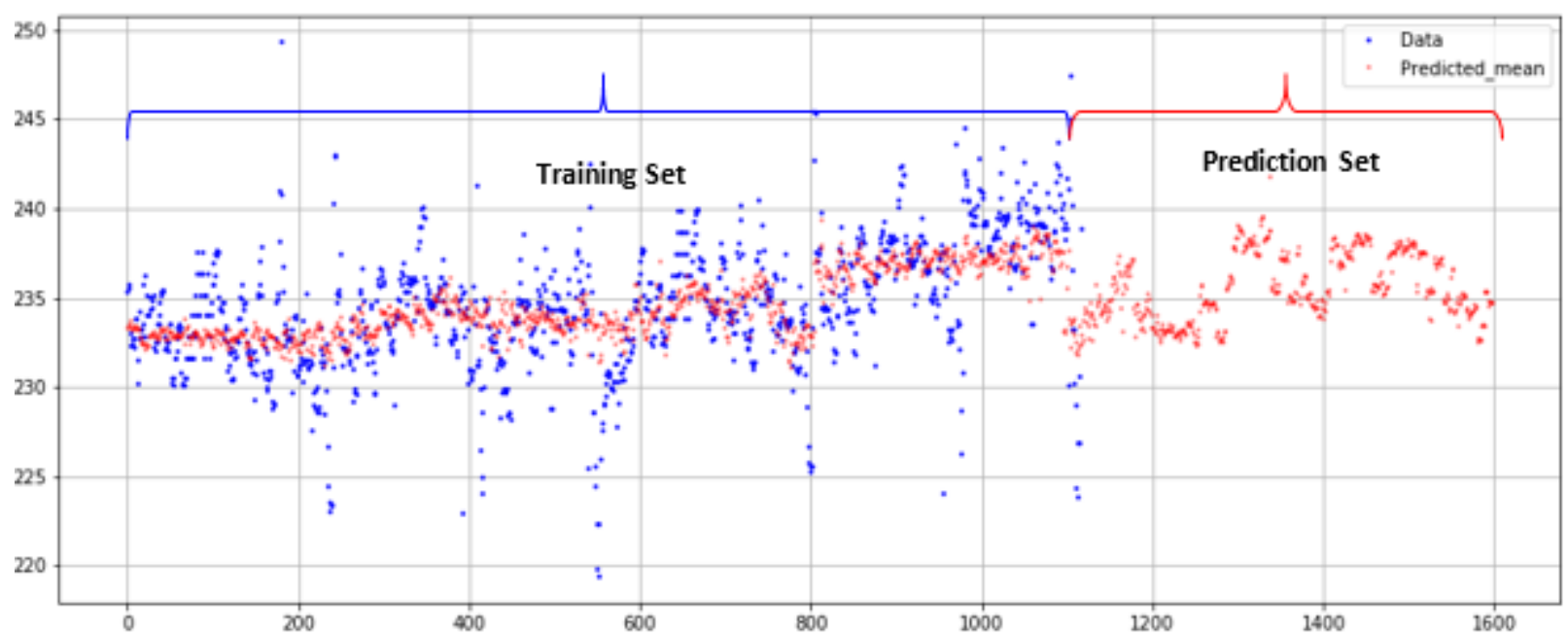

Figure 38. KD-6 Well Training and Future Prediction 


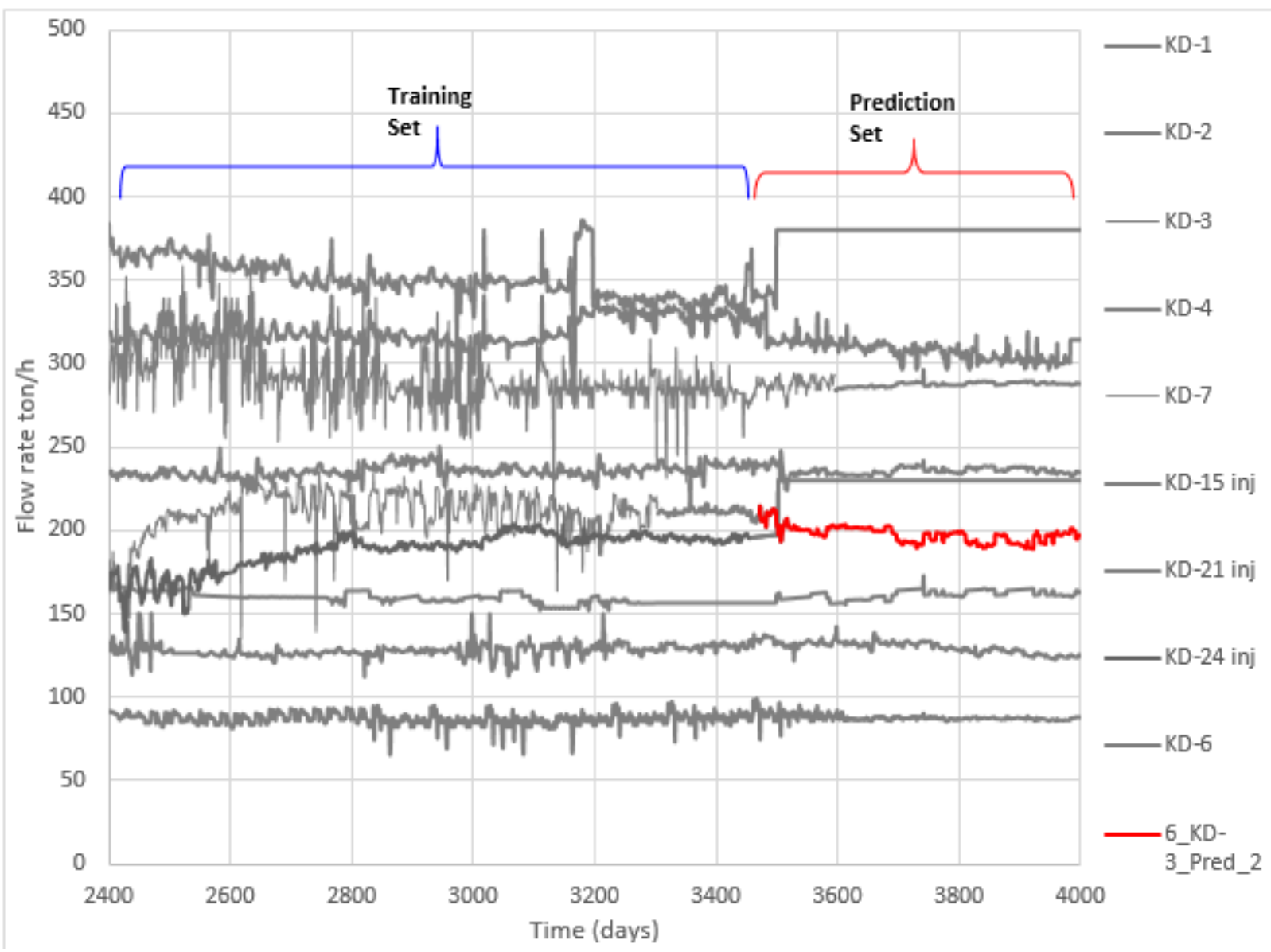

Figure 39. KD-3 Future Prediction

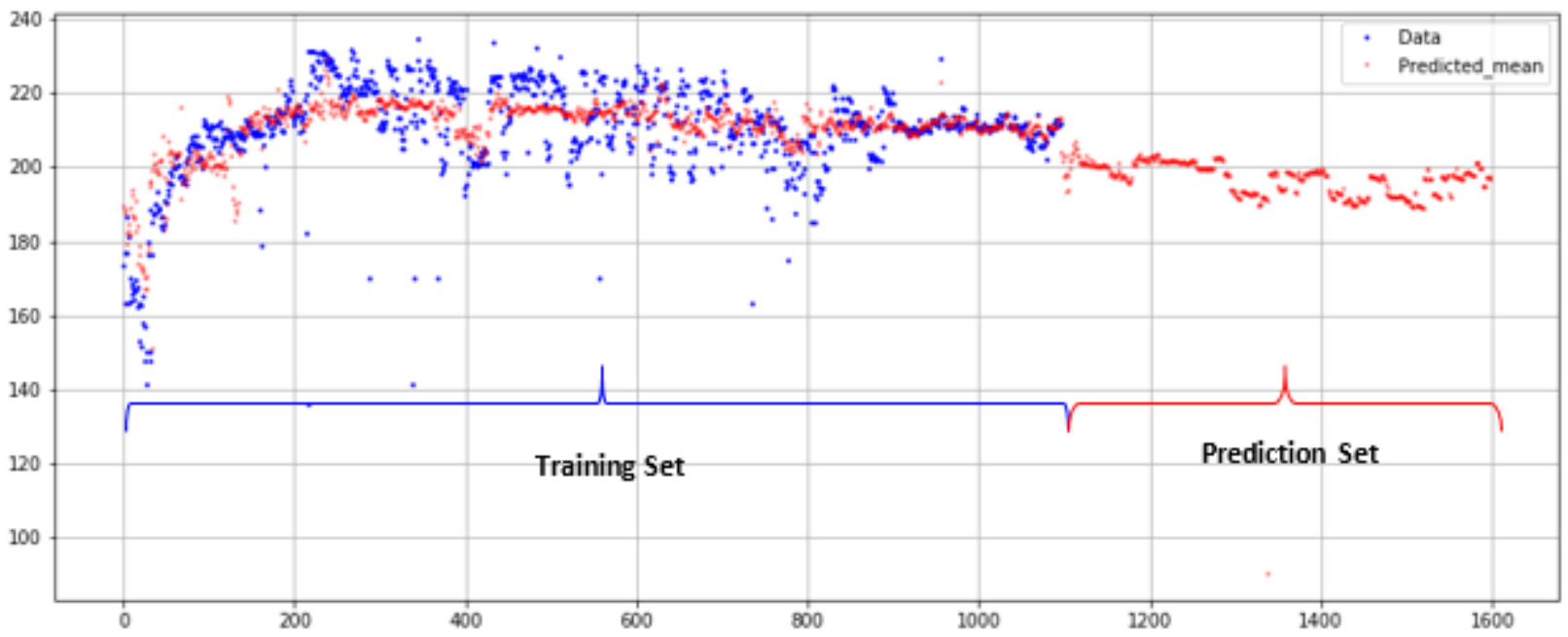

Figure 40. KD-3 Training and Future Prediction 
Scenario 3

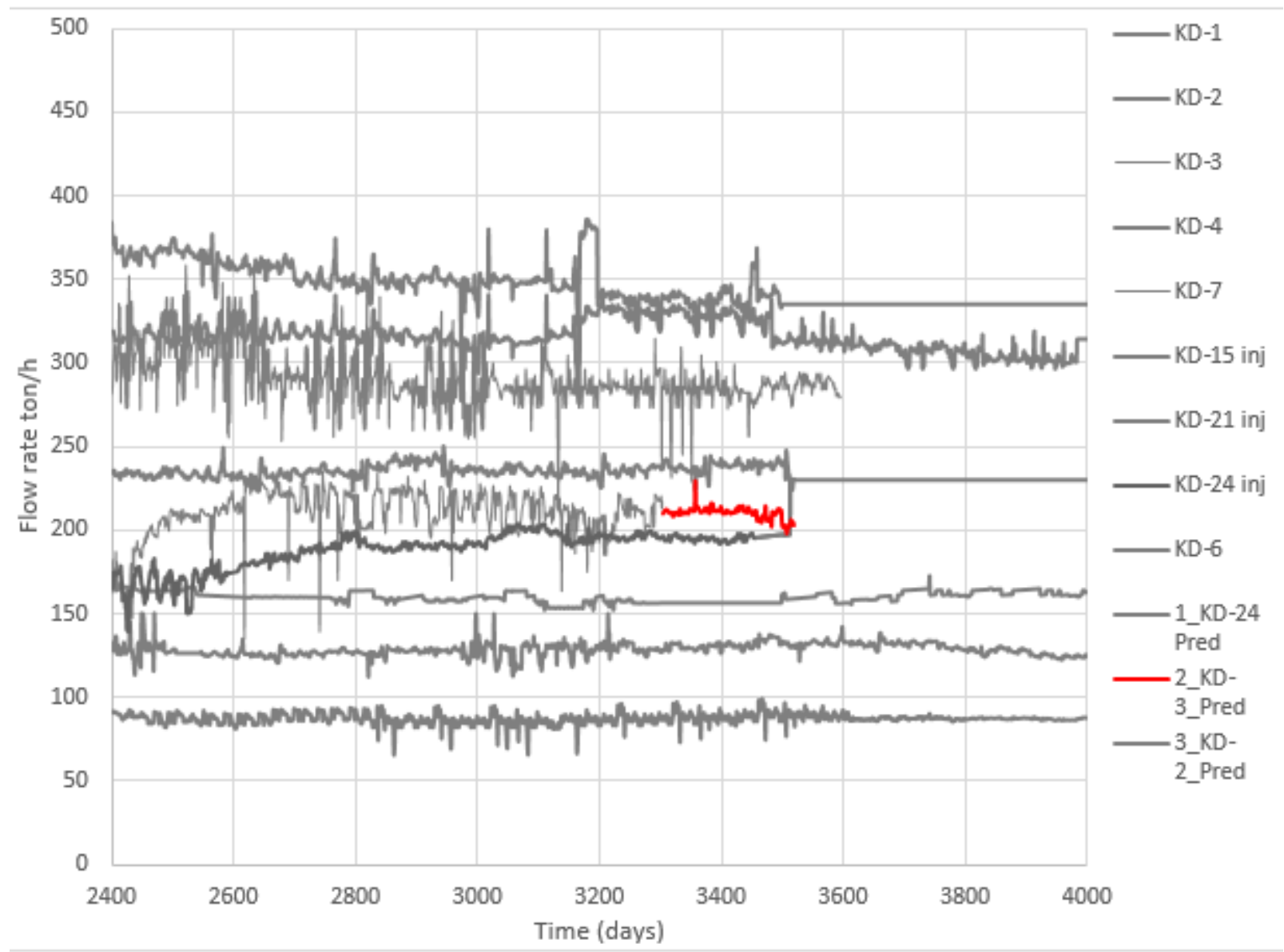

Figure 41. KD-3 Future Prediction

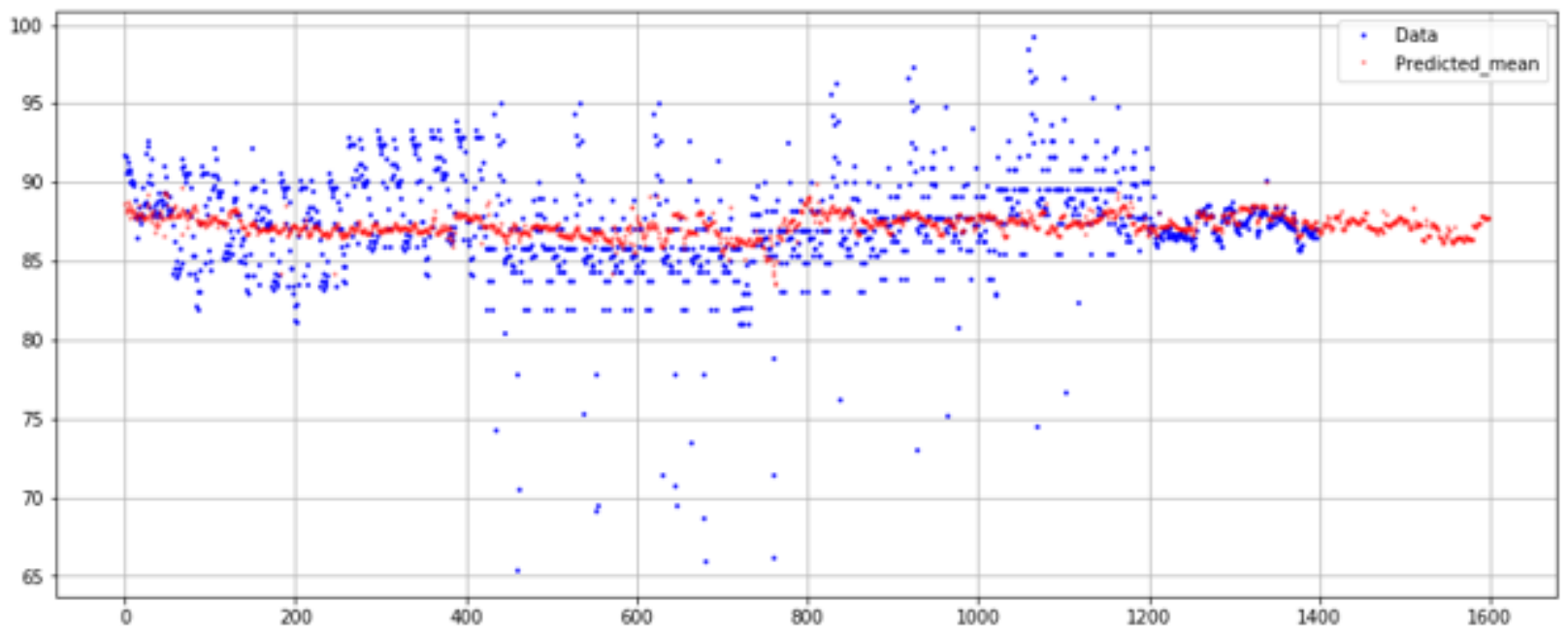

Figure 42. KD-2 Training Future Prediction 


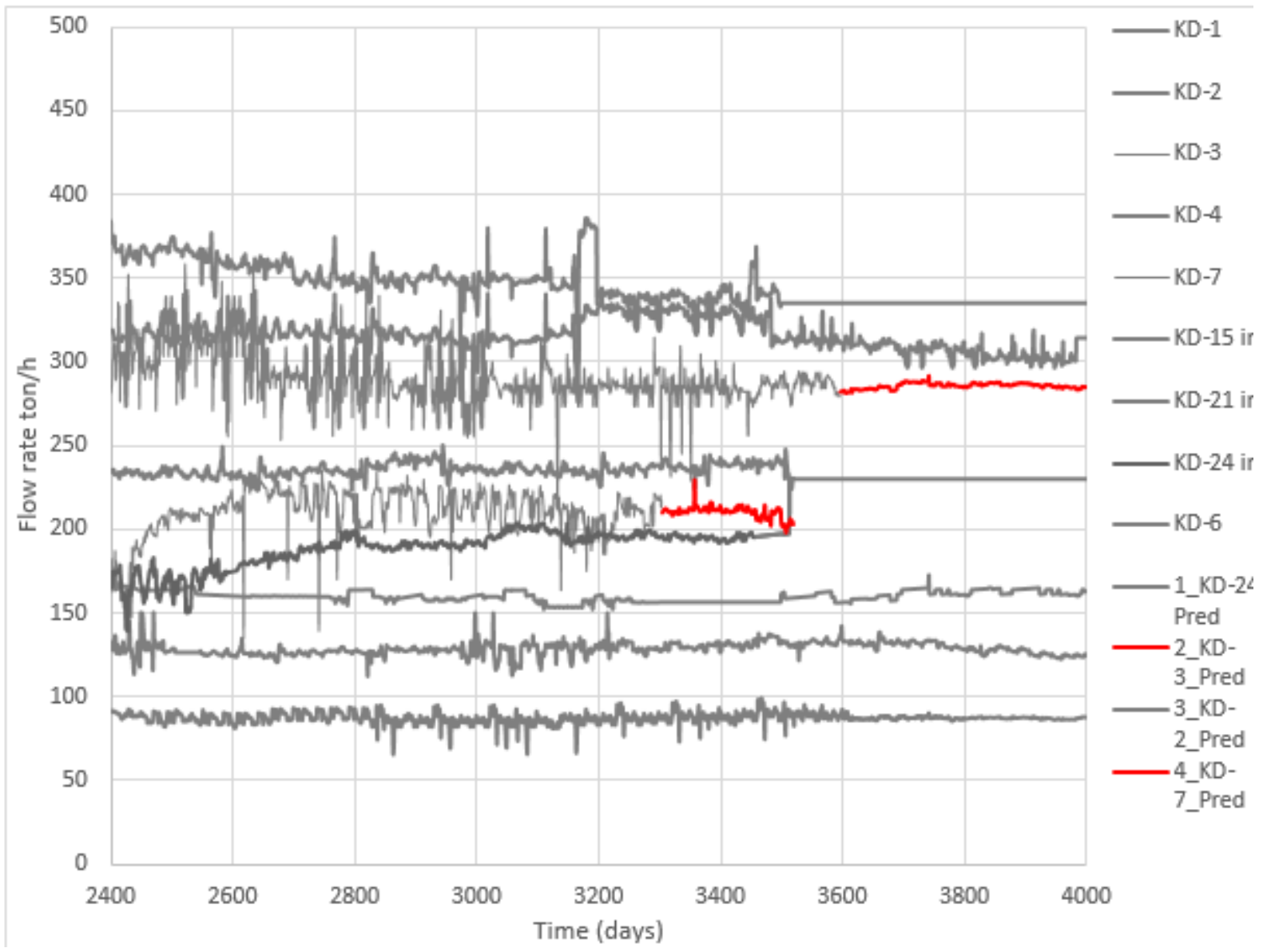

Figure 43. KD-7 Future Prediction

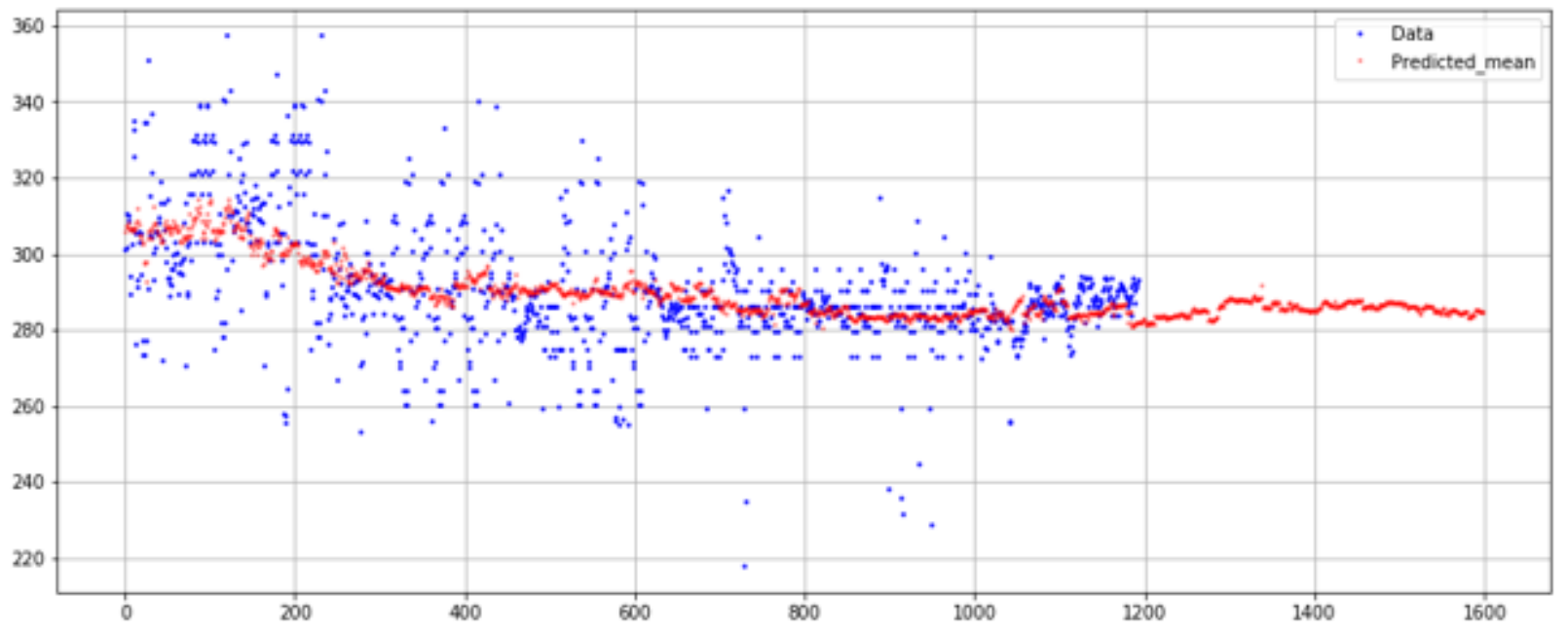

Figure 44. KD-7 Training and Future Prediction 


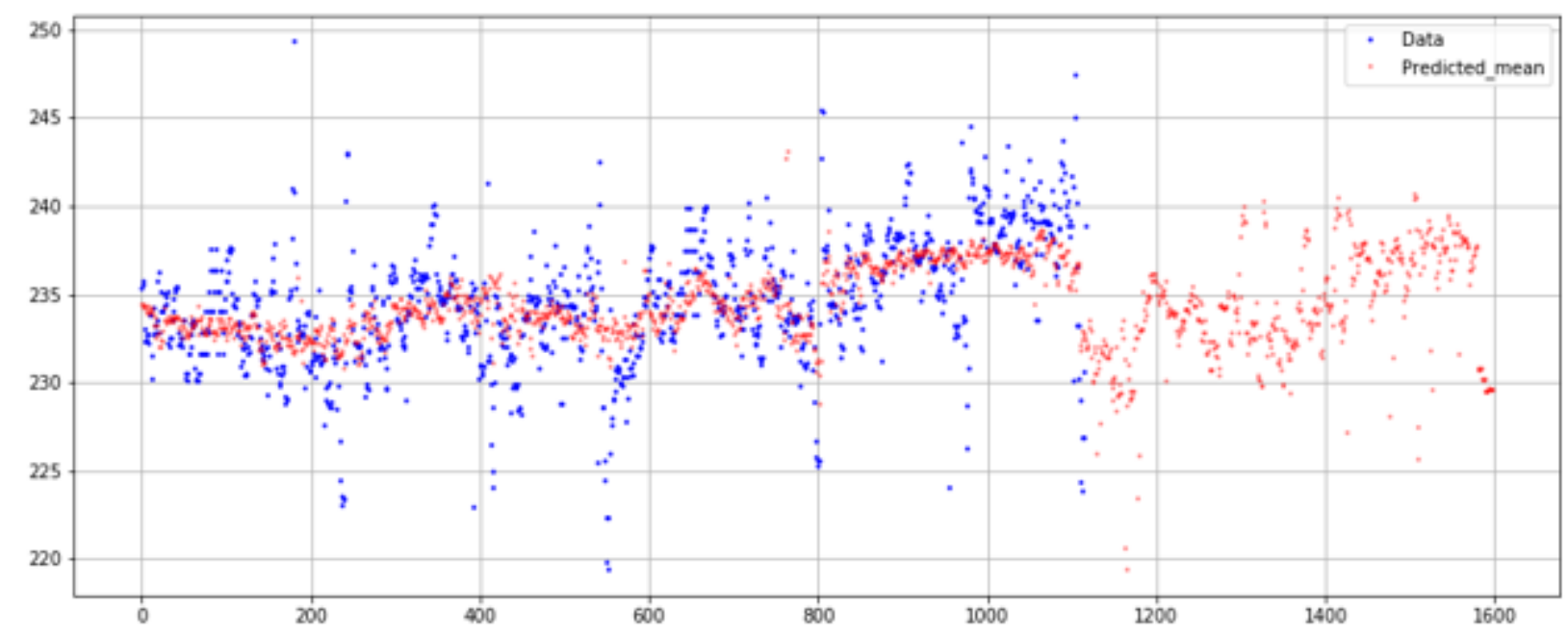

Figure 45. KD-6 Training and Future Prediction

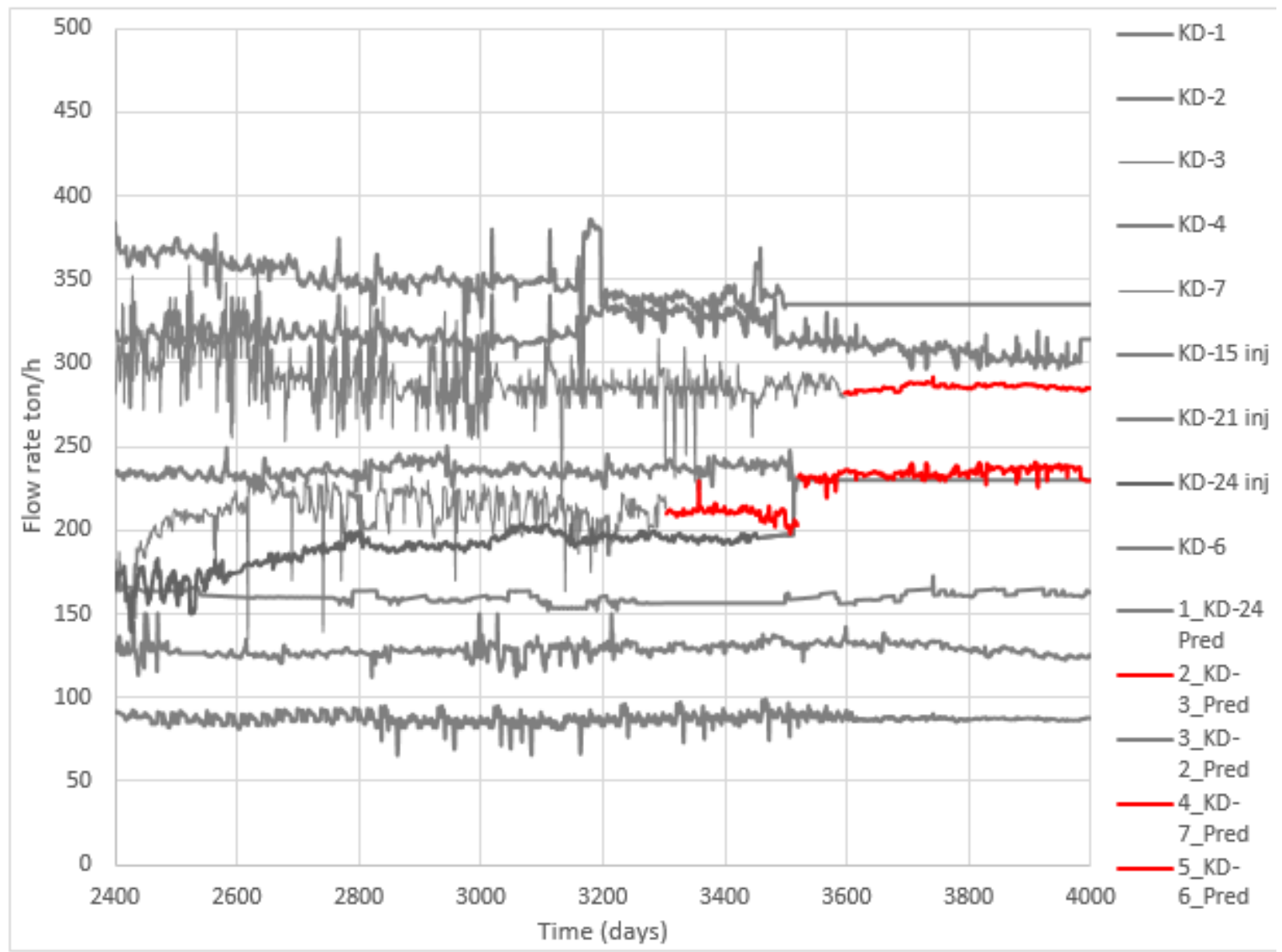

Figure 46. KD-6 Future Prediction 


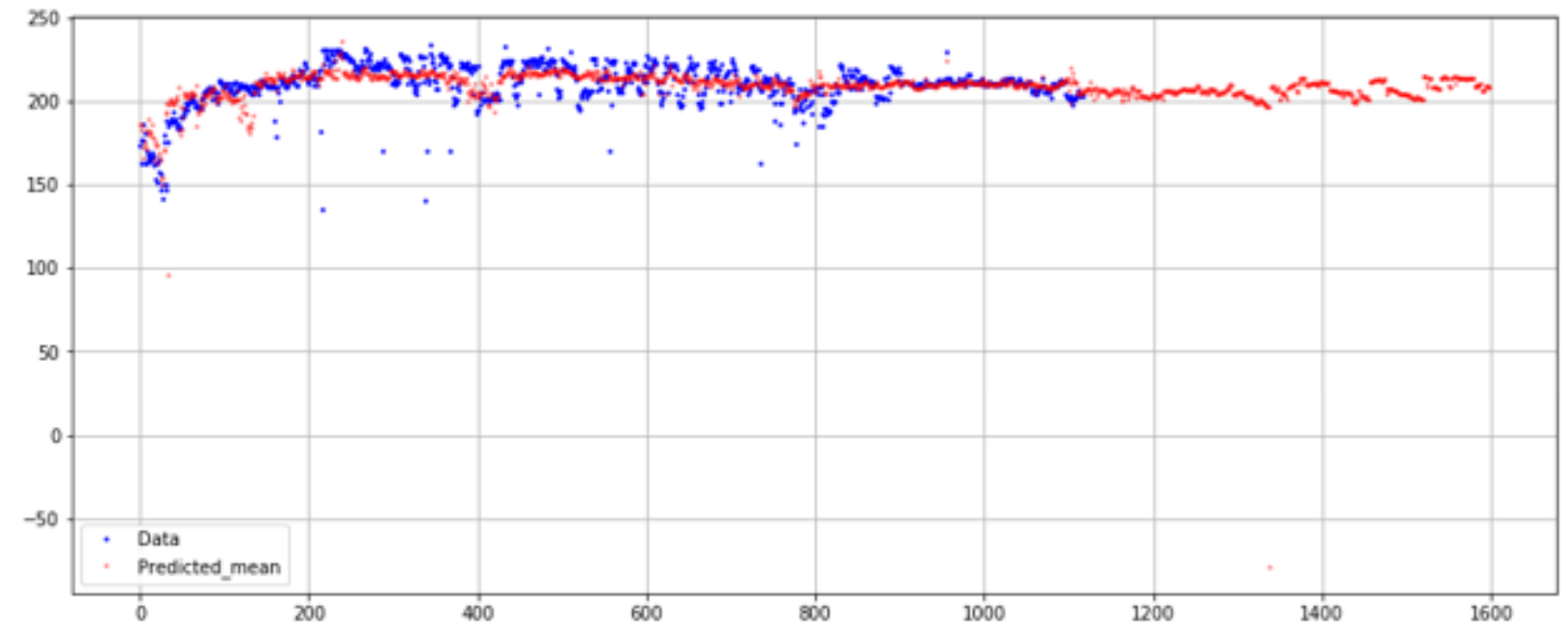

Figure 47. KD-3 Training and Future Prediction

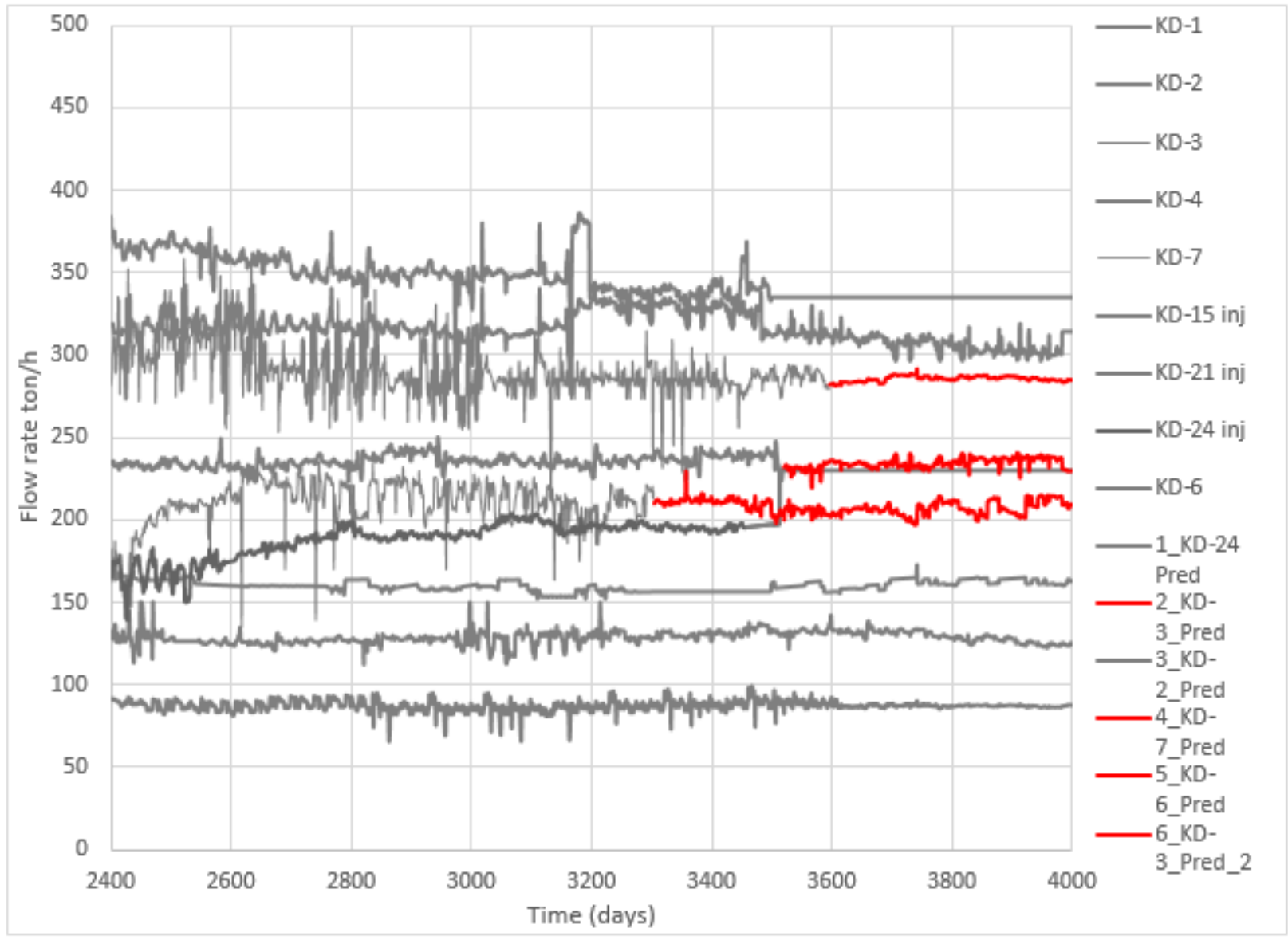

Figure 48. KD-3 Future Prediction with All Wells 
Flow Rates Visualization for Wells

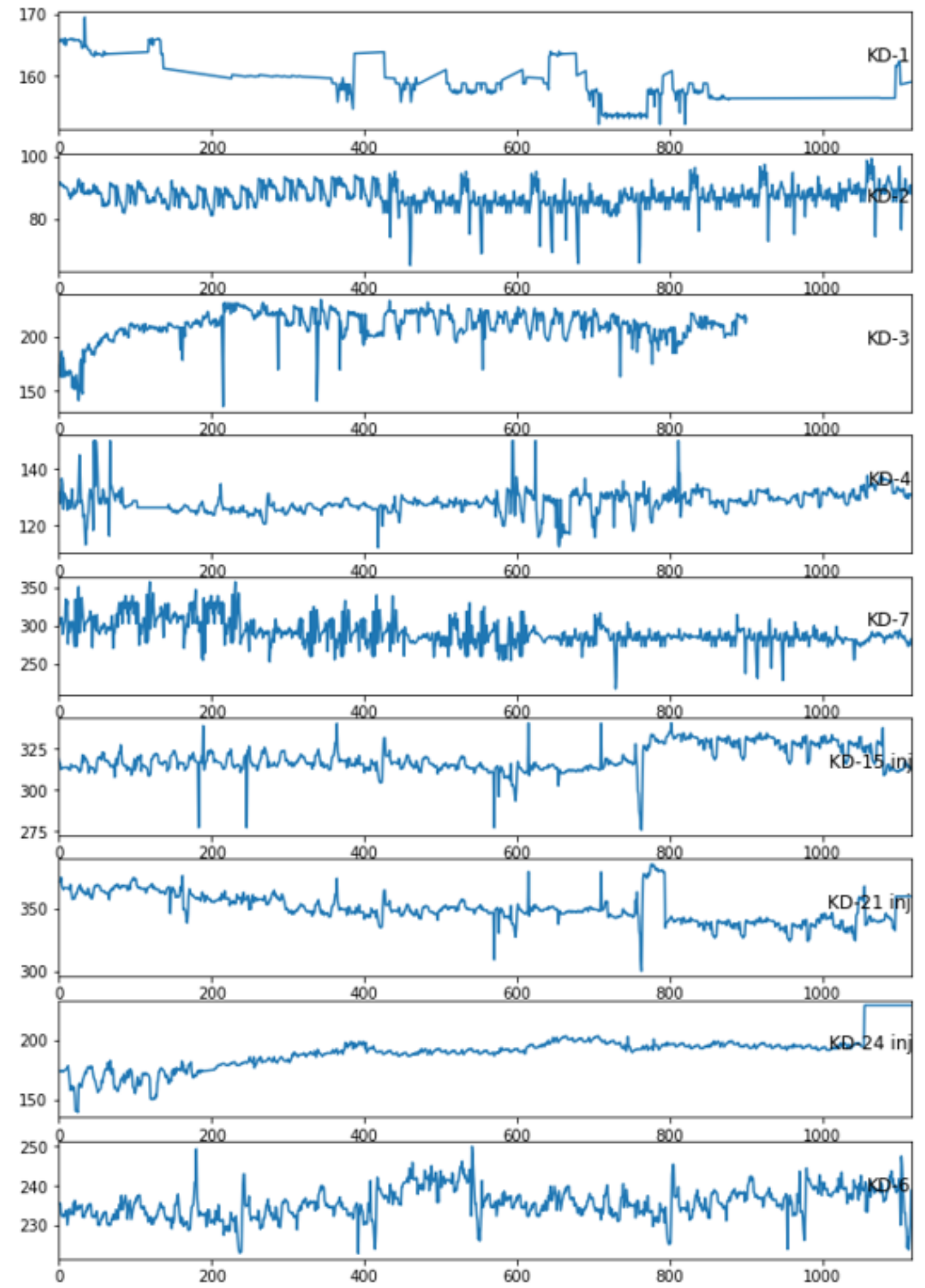


Figure 49. Wells Flow Rates vs Time (Unpredicted KD-3 Well)
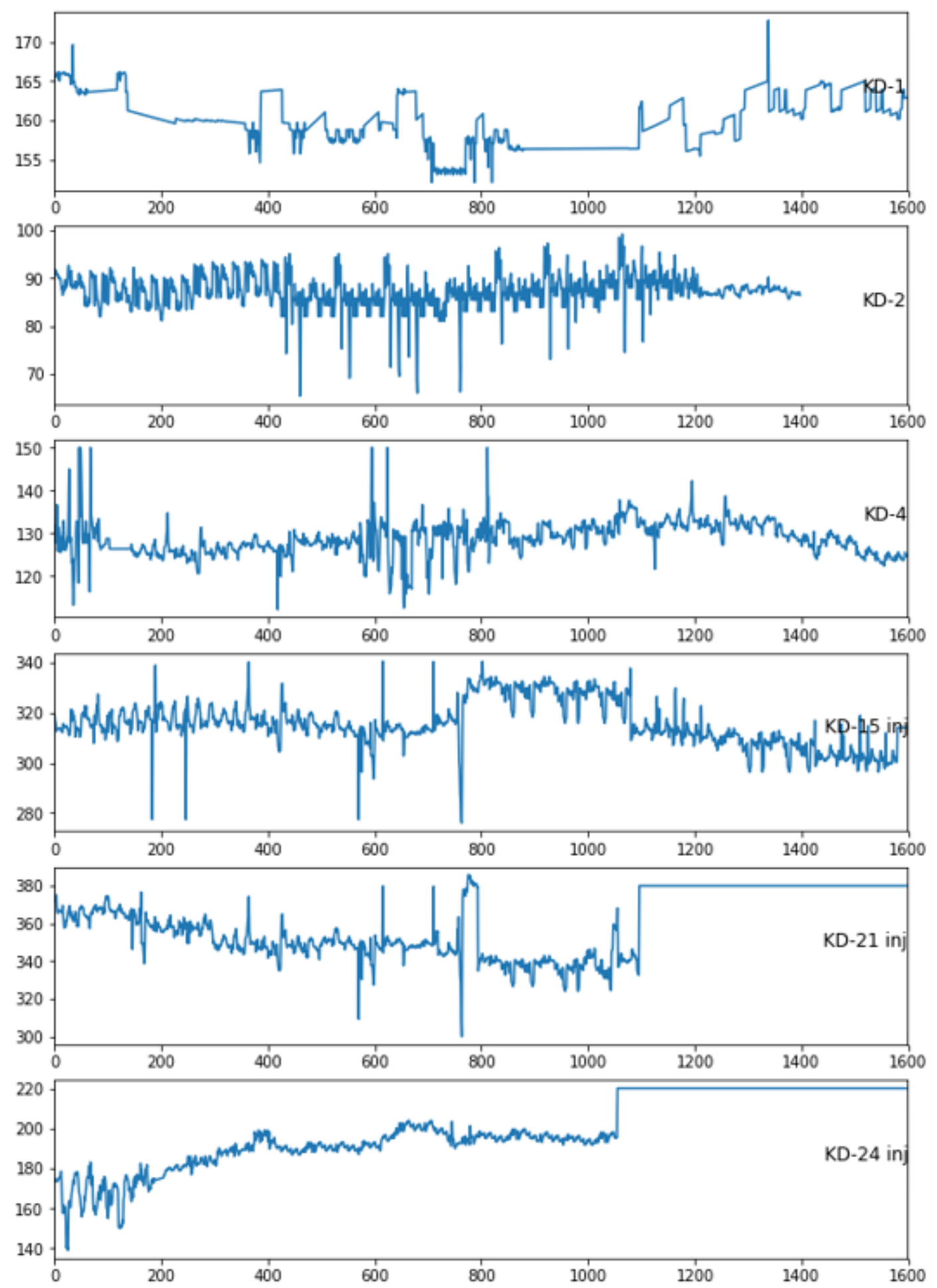

Figure 50.Wells Flow Rates vs Time (Unpredicted KD-2 Well) 

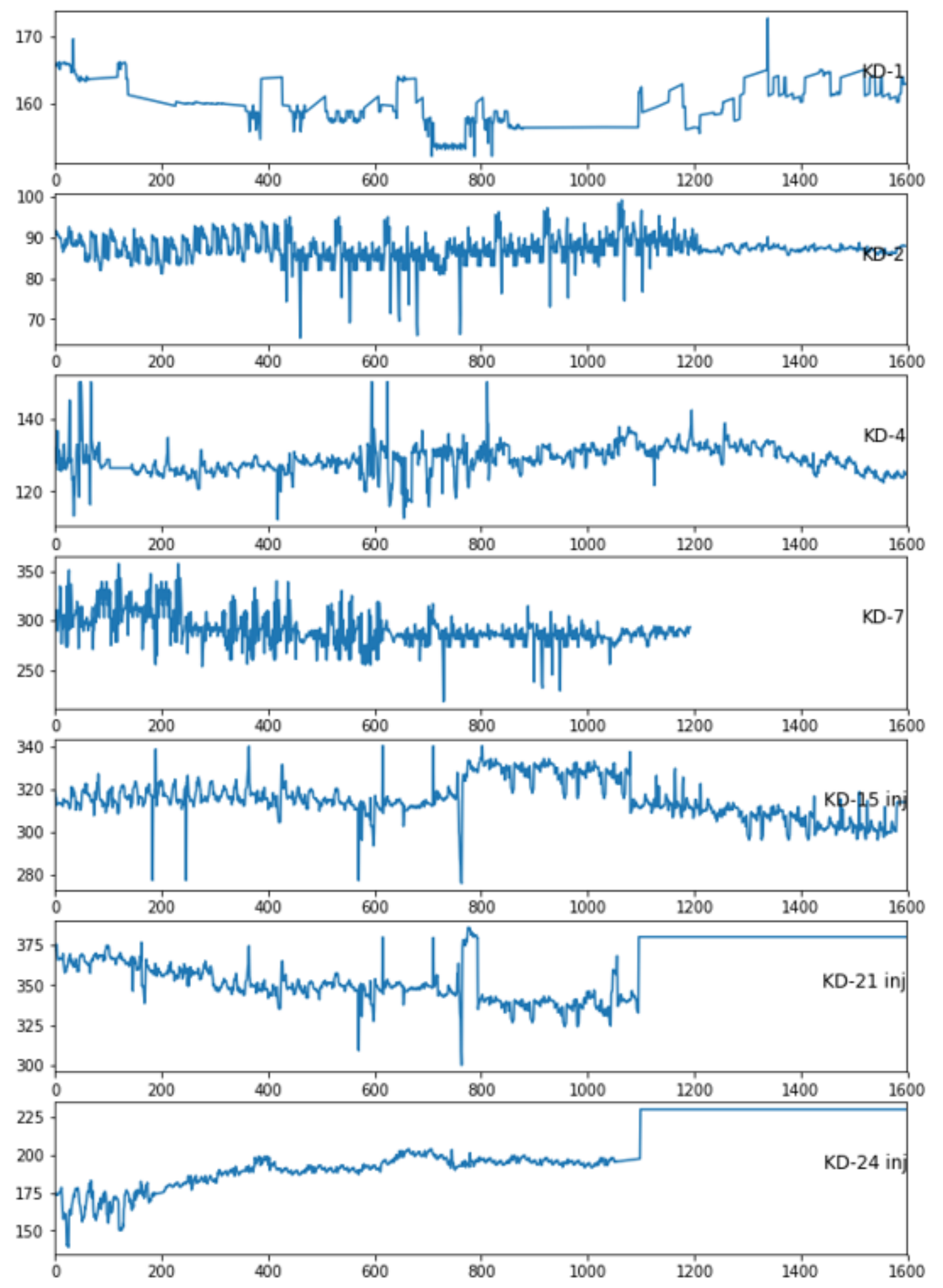

Figure 51. Wells Flow Rates vs Time (Unpredicted KD-7 Well) 

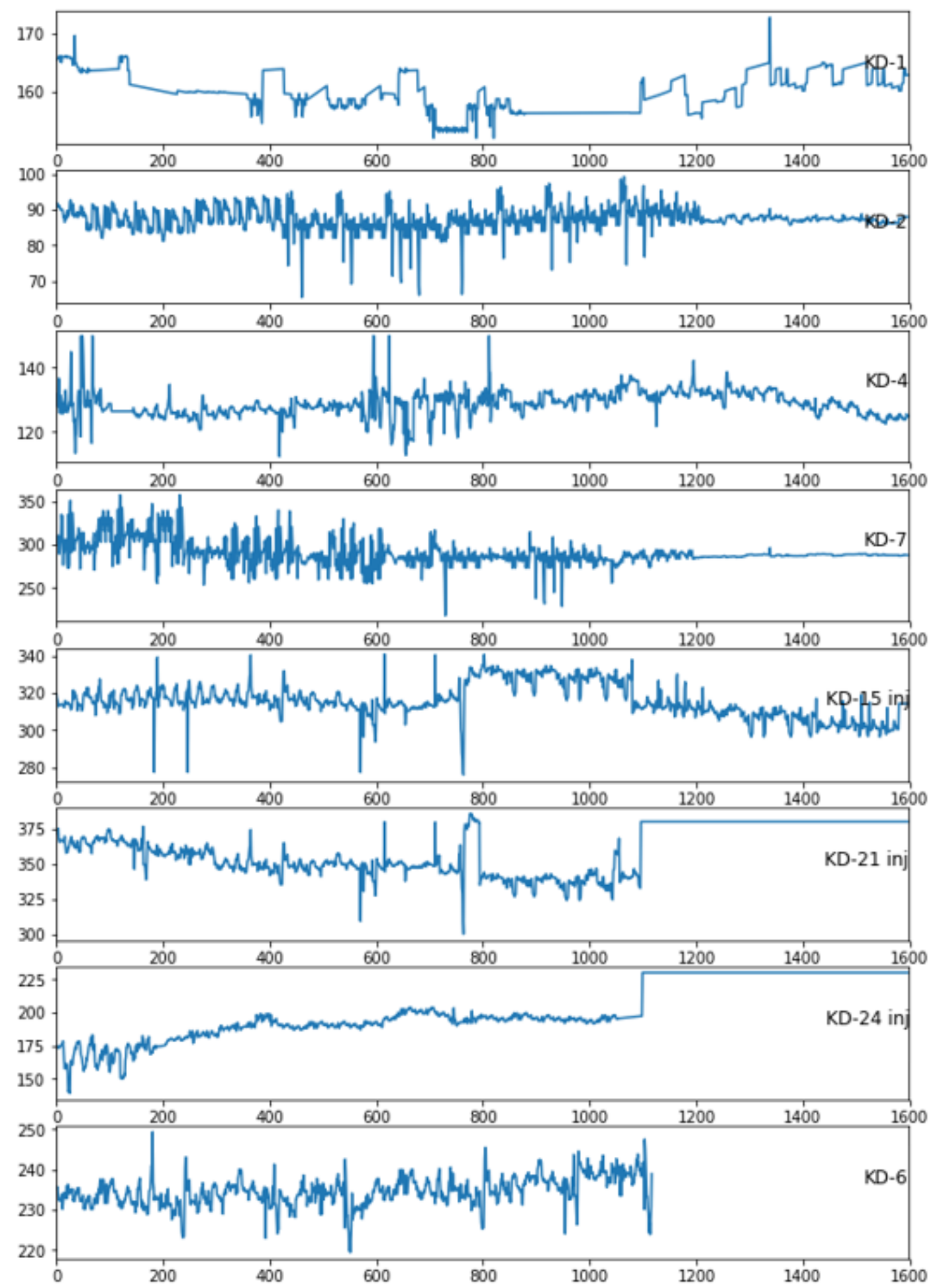

Figure 52. Wells Flow Rates vs Time (Unpredicted KD-6 Well) 


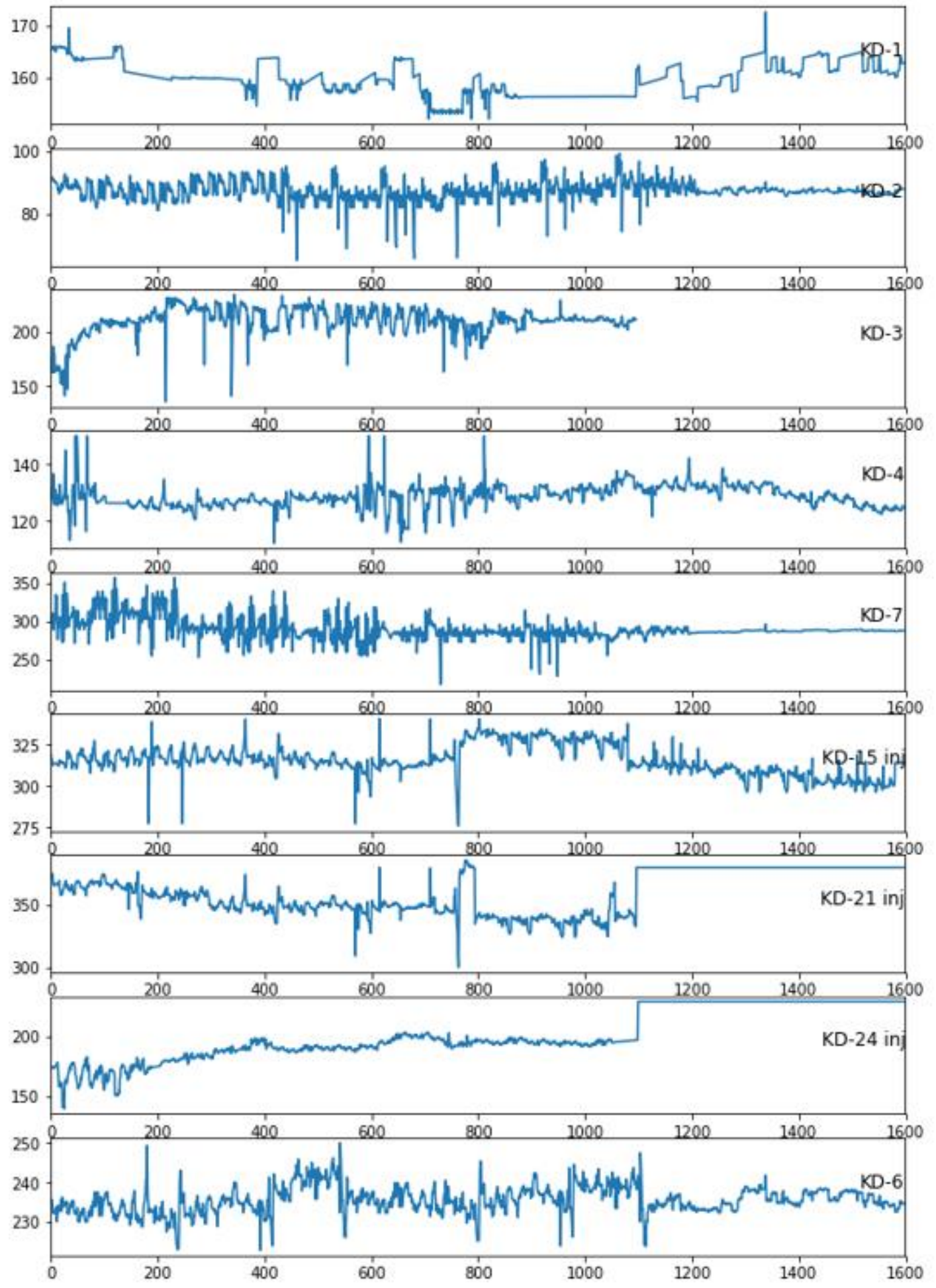

Figure 53. Wells Flow Rates vs Time (Unpredicted KD-3 Well) 
Heat Maps for Each Step of Scenarios

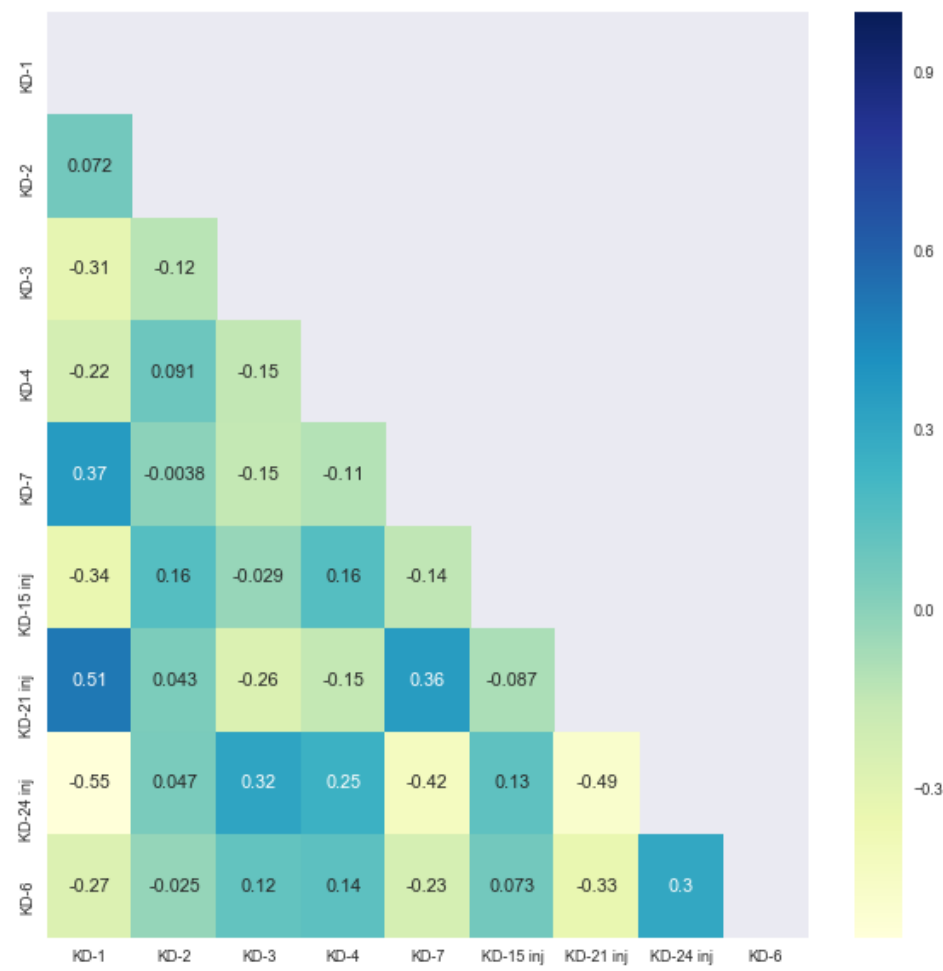

Figure 54. Step Two Predicting KD-3 Well

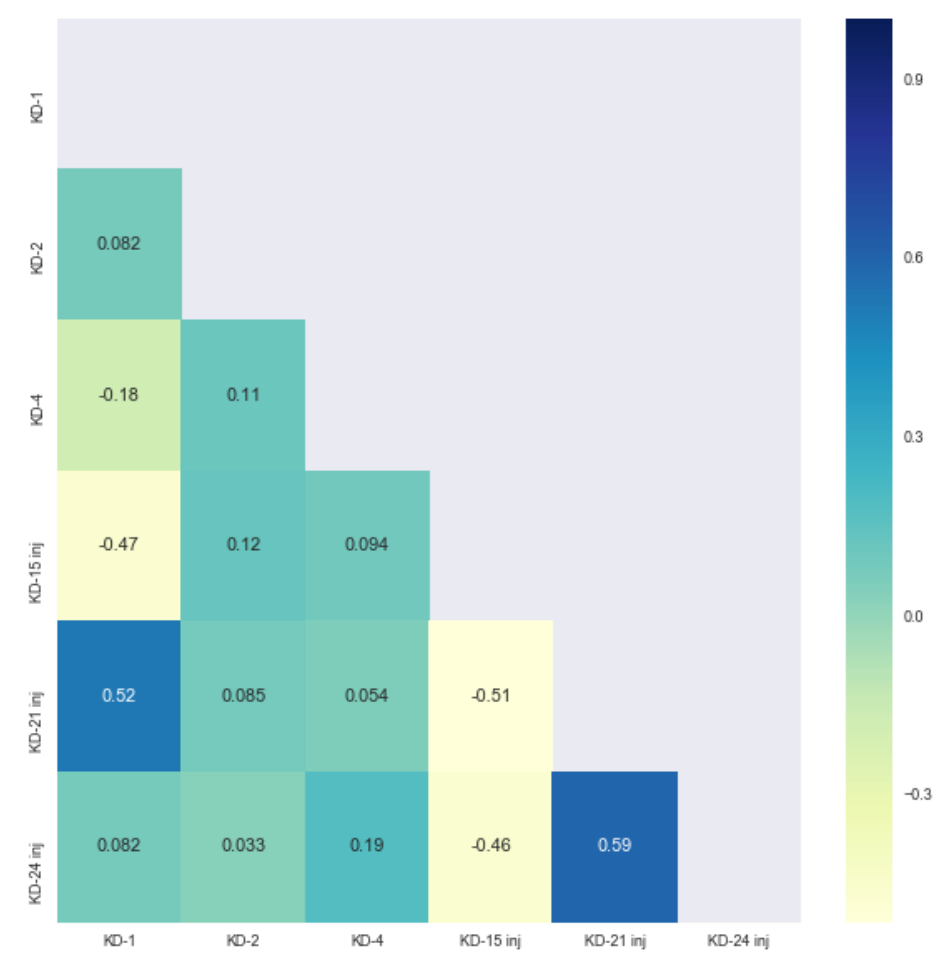

Figure 55. Step Three Predicting KD-2 Well 


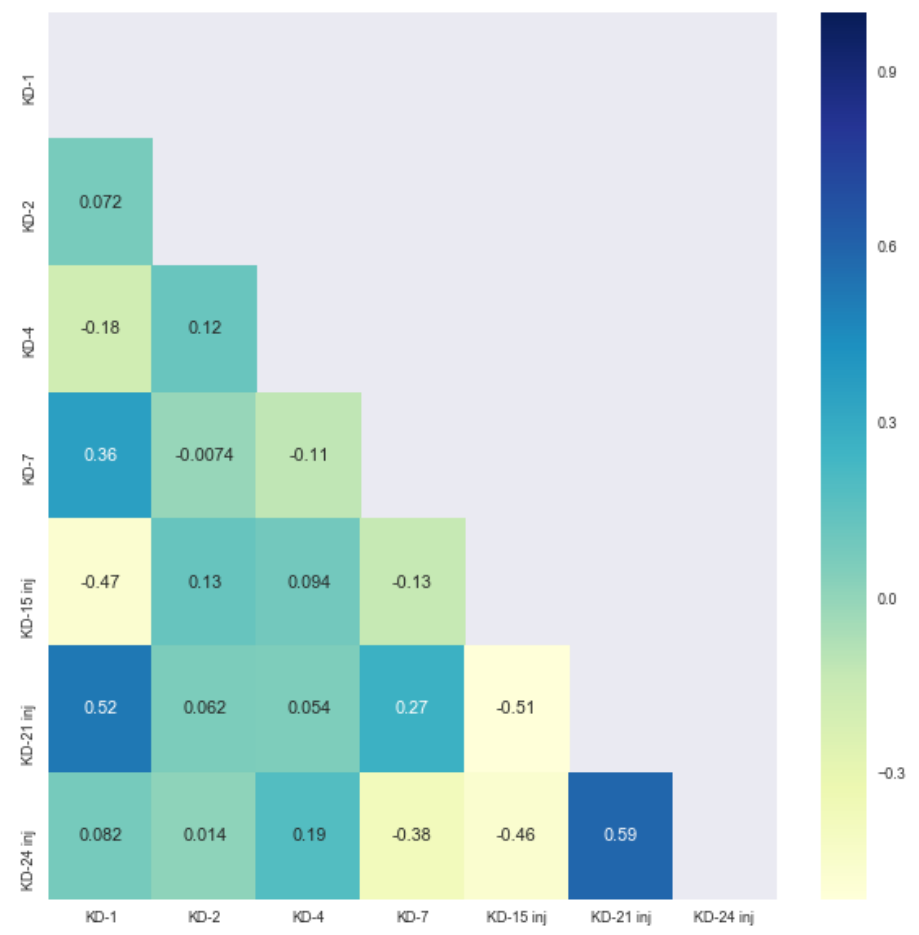

Figure 56. Step Four Predicting KD-7 Well

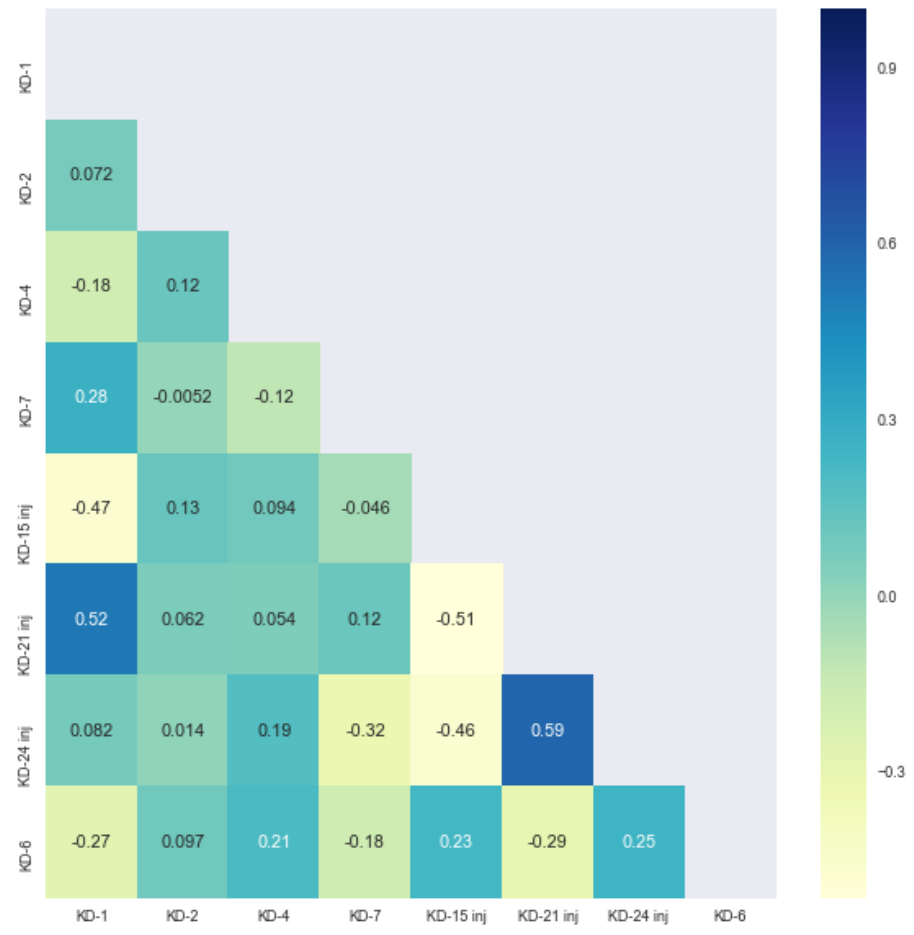

Figure 57. Step Five Predicting KD-6 Well 


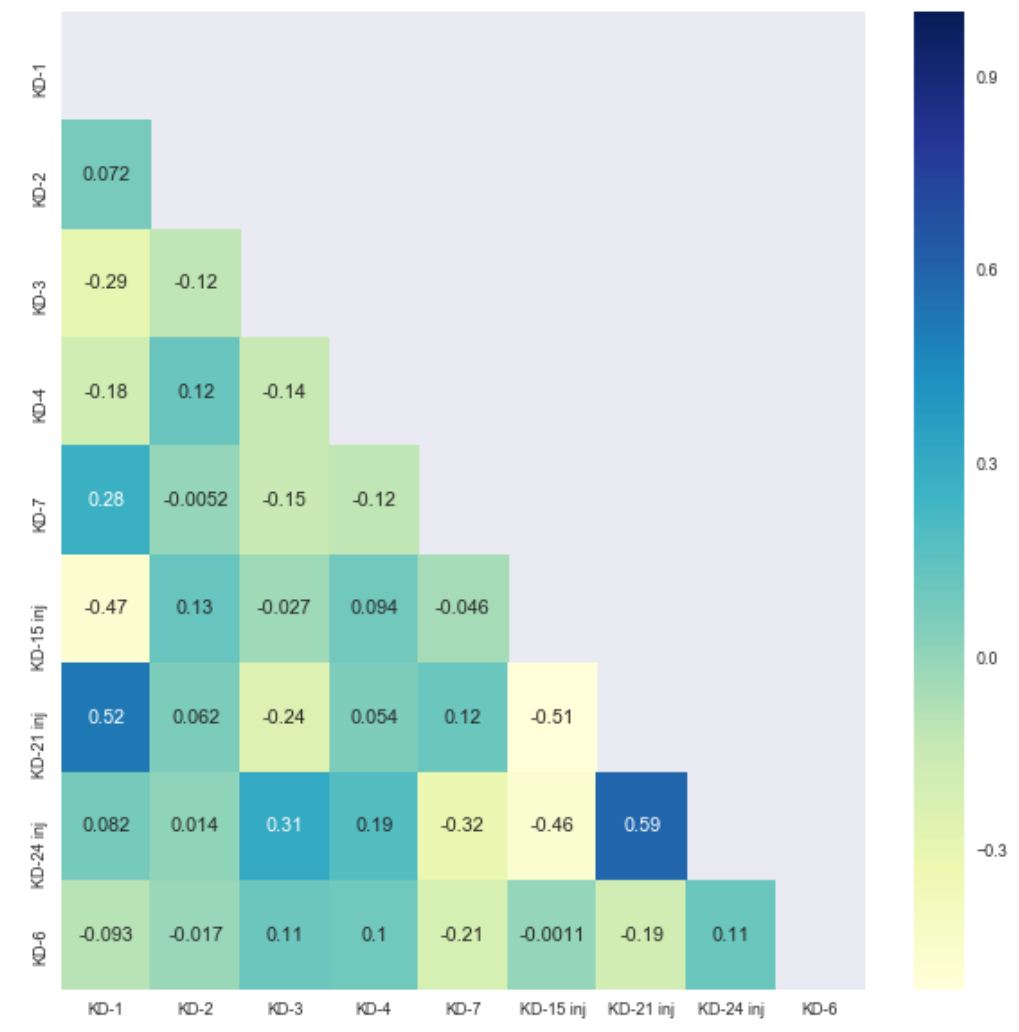

Figure 58. Step Six Predicting KD-3 Well 